\title{
Innovation in the United States Air Force Evidence from Six Cases
}

Adam R. Grissom, Caitlin Lee, Karl P. Mueller 
For more information on this publication, visit www.rand.org/t/RR1207

Library of Congress Cataloging-in-Publication Data is available for this publication.

ISBN: 978-0-8330-9184-0

Published by the RAND Corporation, Santa Monica, Calif.

(C) Copyright 2016 RAND Corporation

RAND $^{\circledR}$ is a registered trademark.

\section{Limited Print and Electronic Distribution Rights}

This document and trademark(s) contained herein are protected by law. This representation of RAND intellectual property is provided for noncommercial use only. Unauthorized posting of this publication online is prohibited. Permission is given to duplicate this document for personal use only, as long as it is unaltered and complete. Permission is required from RAND to reproduce, or reuse in another form, any of its research documents for commercial use. For information on reprint and linking permissions, please visit www.rand.org/pubs/permissions.html.

The RAND Corporation is a research organization that develops solutions to public policy challenges to help make communities throughout the world safer and more secure, healthier and more prosperous. RAND is nonprofit, nonpartisan, and committed to the public interest.

RAND's publications do not necessarily reflect the opinions of its research clients and sponsors.

\section{Support RAND}

Make a tax-deductible charitable contribution at

www.rand.org/giving/contribute

www.rand.org 
Innovation is central to the USAF's identity and purpose. With its origins in the airpower revolution of the early modern era, the service has long embraced the role of developing innovative means of going "over, not through" strategic challenges confronting the United States. Recently, however, the Air Force senior leadership has initiated a wide-ranging conversation about whether the service is sufficiently innovative today and what can be done to make it more innovative for the future.

This report contributes to that conversation by assessing six historical cases of potential Air Force innovation, some successful and others unsuccessful, in the context of the scholarly literature on military innovation. The insights we develop across these cases will, we hope, help senior Air Force leaders sharpen the emerging conversation and develop a common understanding of the distinctly Air Force approach to innovation. This report should therefore be of interest to all airmen engaged in the emerging conversation, but particularly Air Force senior leaders and strategic planners in Headquarters, U.S. Air Force, and in the major commands.

The research reported here was sponsored by Maj Gen Steven Kwast, Air Force Quadrennial Defense Review Office, and Maj Gen David Allvin, Director of Strategic Planning, Deputy Chief of Staff for Strategic Plans and Programs, Headquarters, United States Air Force. It was conducted within the Strategy and Doctrine Program of RAND Project AIR FORCE.

\section{RAND Project AIR FORCE}

RAND Project AIR FORCE (PAF), a division of the RAND Corporation, is the U.S. Air Force's federally funded research and development center for studies and analyses. PAF provides the Air Force with independent analyses of policy alternatives affecting the development, employment, combat readiness, and support of current and future air, space, and cyber forces. Research is conducted in four programs: Force Modernization and Employment; Manpower, Personnel, and Training; Resource Management; and Strategy and Doctrine. The research reported here was prepared under contract FA7014-06-C-0001.

Additional information about PAF is available on our website: http://www.rand.org/paf/ 


\section{Contents}

Preface

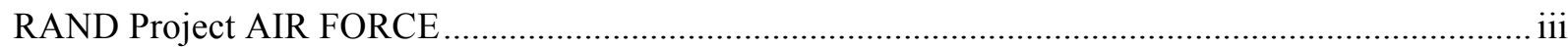

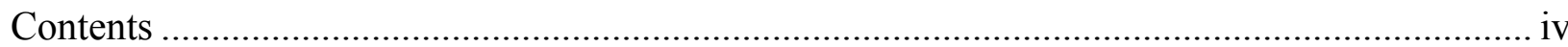

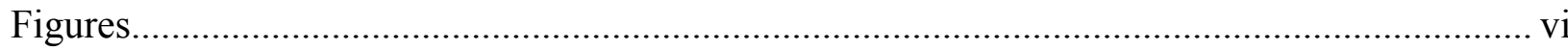

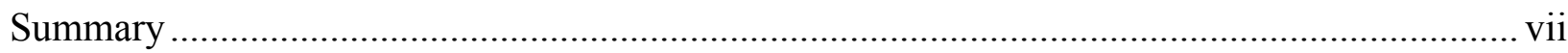

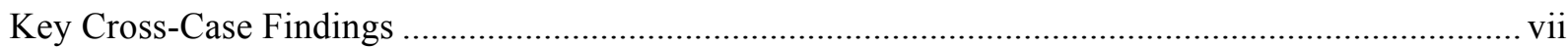

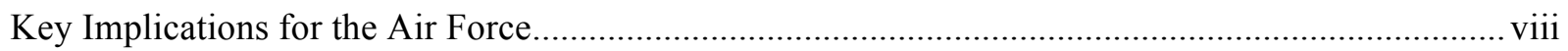

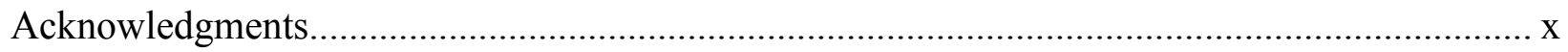

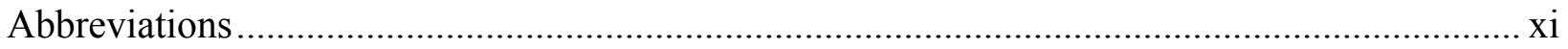

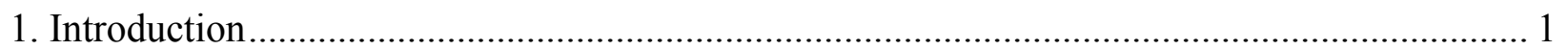

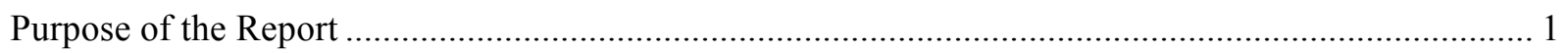

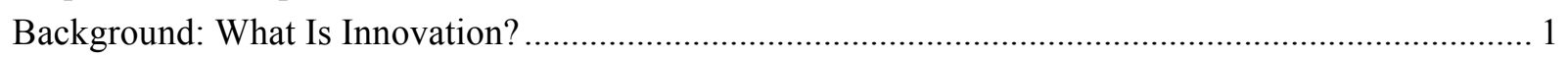

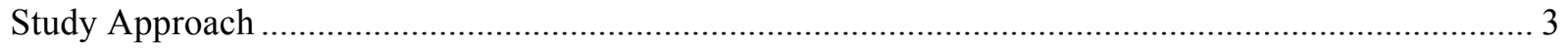

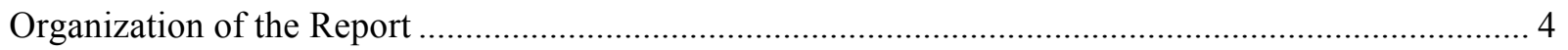

2. Peacetime Strategic Reconnaissance (1946-1972) ...................................................... 6

1945-1946: Framing the Strategic Problem and Establishing the Institutional Framework................... 6

1946-1971: Developing Operational Solutions for Peacetime Strategic Reconnaissance..................... 11

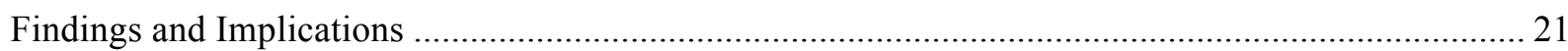

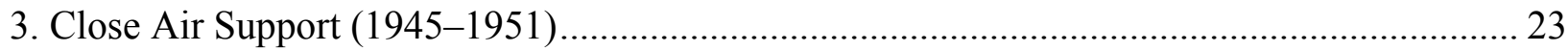

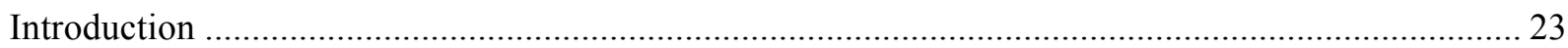

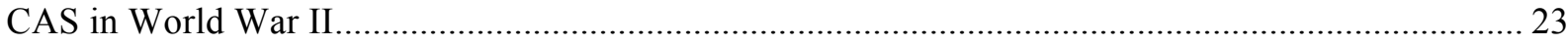

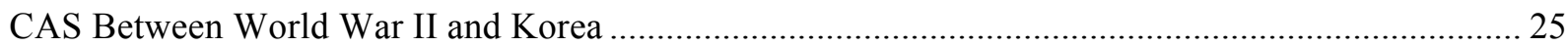

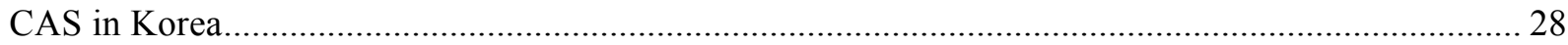

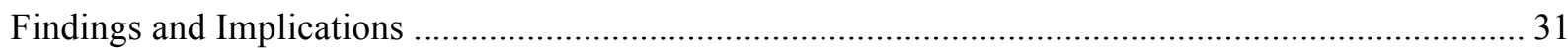

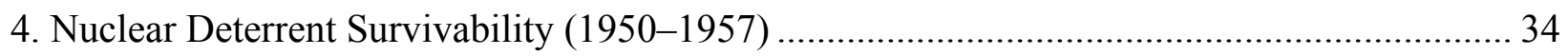

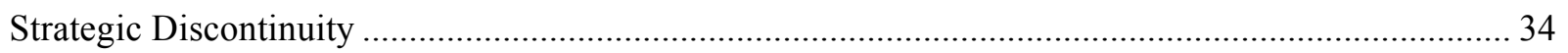

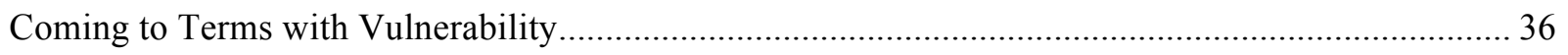

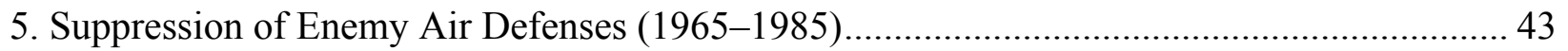

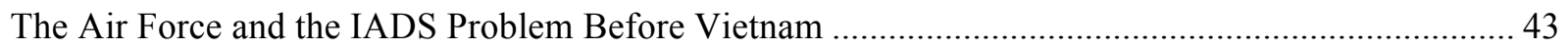

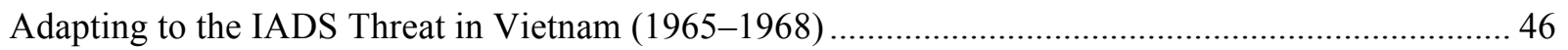

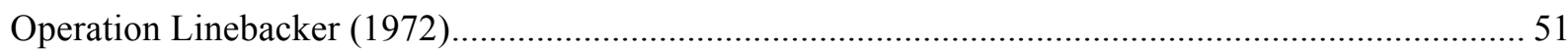

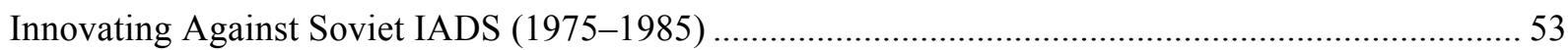

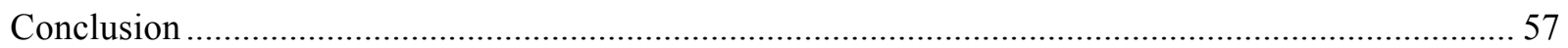

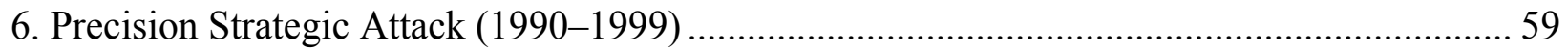

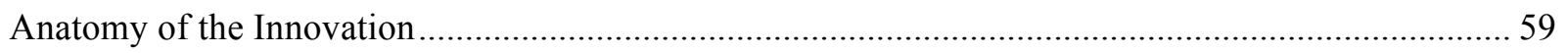

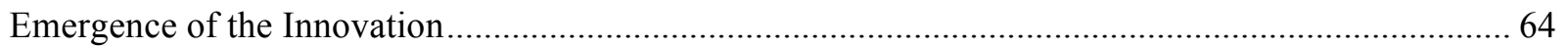

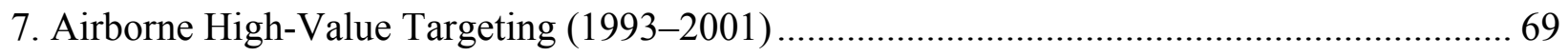




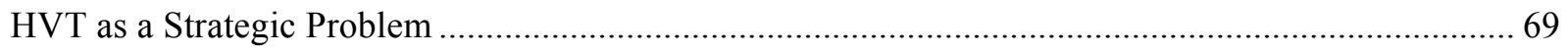

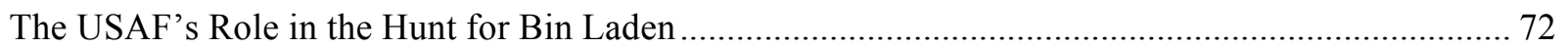

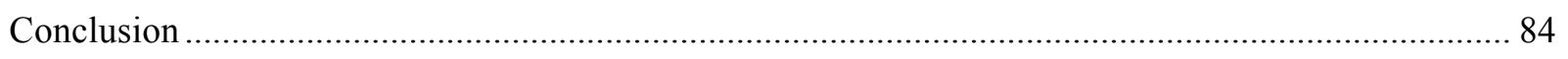

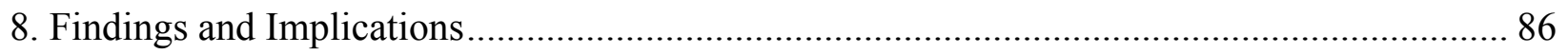

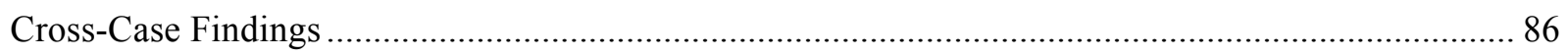

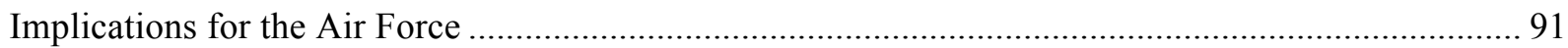

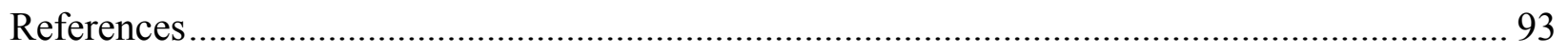




\section{Figures}

1.1. Case Studies Developed in This Project ........................................................................ 4

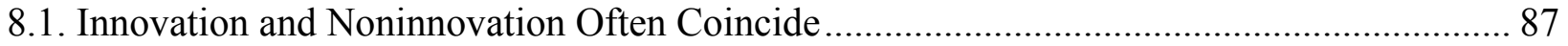

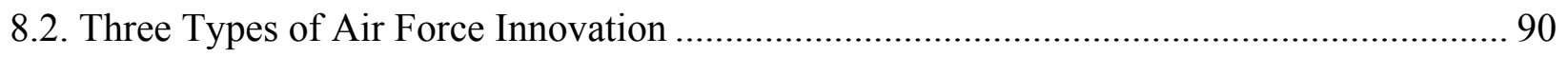




\section{Summary}

Developing innovative means to go "over not through" national strategic challenges has long been central to the Air Force's contribution to American security. ${ }^{1}$ Recently, however, U.S. Air Force (USAF) senior leaders have raised the questions of whether the service is sufficiently innovative today and what can be done to make it more innovative for the future. This report assesses six historical cases of Air Force innovation or apparent failure to innovate. These case studies include innovations in strategic reconnaissance (1946-1972), nuclear survivability (1950-1960), suppression of enemy air defenses (1975-1985), and precision strategic attack (1990-1999). Cases of apparent failure to innovate include close air support after World War II (1946-1951), early efforts to defeat Soviet integrated air defenses (1960-1970), and airborne high-value targeting in the post-Cold War era (1990-2001).

\section{Key Cross-Case Findings}

- Air Force innovation begins with strategy. While many believe technological change is the root cause of military innovation, our research indicates that major Air Force innovations usually start with the identification and framing of a strategically important operational problem. When the Air Force leadership has identified, framed, and prioritized concrete operational problems to be solved, the service has proven to be remarkably innovative. Strategic reconnaissance, nuclear survivability, precision strategic attack, and post-Vietnam suppression of enemy air defenses are all examples. When the Air Force has failed to identify and frame concrete strategic problems, however, it generally has not innovated. Key examples include the stagnation of close air support capabilities between 1946 and 1951 and the missed opportunities for airborne high-value targeting innovation during the decade leading up to the terrorist attacks of September 11, 2001. Fostering innovation in the Air Force is therefore, first and foremost, about strategy - identifying, framing, and prioritizing strategically important operational problems to be solved by airmen.

- The Air Force innovates differently than other military organizations. The strategic studies literature on military innovation points to centralized changes in formal doctrine and organizational structures as the reliable indicators of innovation. By contrast, our research suggests that Air Force innovation is more likely to be driven by decentralized efforts of individuals and operational units and that the most reliable indicator of an Air Force innovation is the de facto emergence of a new type of air campaign. Major USAF innovations in defense suppression and precision strategic attack, for example, were not accompanied by obvious changes to formal doctrine or organizational structures. On the

\footnotetext{
${ }^{1}$ Global Vigilance, Global Reach, Global Power for America, Washington, D.C.: Headquarters, U.S. Air Force, 2014. This idea is developed in Paula G. Thornhill, “Over Not Through”: The Search for a Strong, Unified Culture for America's Airmen, Santa Monica, Calif.: RAND Corporation, OP-386-AF, 2012.
} 
other hand, neither was the decline of close air support capabilities during the late 1940s signaled by any changes to doctrine or the composition of fighter wings. Innovation and stagnation became evident only in the changing patterns in how Air Force units actually trained and operated. For the USAF, therefore, changes to formal doctrine and organizations are not the reliable indicators of innovation that they are, according to the expert literature, in other military services. Outside observers not intimately familiar with current operations are therefore likely to underestimate the scope and importance of Air Force innovation.

- Air Force innovation is a decentralized, diffuse, and diverse phenomenon. The case studies indicate that different parts of the Air Force innovate in different ways. Headquarters Air Force and major commands often seek "long-cycle innovation" by developing new technologies and platforms over many years. Operational units engage in "immediate adaptation" as they adjust tactics and techniques on a sortie-by-sortie basis. Between these extremes is "short-cycle innovation" that brings together operators, developers, and aggressors for sustained field exercises and experiments to solve a strategically important operational problem on an accelerated basis in peacetime.

\section{Key Implications for the Air Force}

1. To drive innovation, the Air Force senior leadership requires a mechanism for deliberately identifying and framing strategically important operational problems. Our analysis indicates that concretely framed problems are essential ingredients for Air Force innovation. Yet there is no mechanism today, inside or outside the Air Force strategic planning system, that will allow the senior leadership to identify and frame strategically important operational problems in a deliberate fashion. Our conversations with senior leaders indicate that, in the absence of such a mechanism, the demands of running the service make it difficult to focus attention "outward" on national strategic challenges and their constituent operational problems. Senior Air Force leaders should consider devising a mechanism through which they can identify and frame strategically important operational problems, assign them to Air Force organizations and units to be solved, and concentrate resources to enable those efforts. ${ }^{2}$

2. The Air Force should carefully preserve its capacity to foster short-cycle innovation. The recent Air Force 30-year strategy emphasizes the need for rapid peacetime innovation in response to evolving strategic problems and threats. This fits our definition of short-cycle innovation, and the case of post-Vietnam suppression of enemy air defenses (SEAD) innovation provides a canonical example. The capacity required for that innovation was provided by the Nellis "Flag" exercises and schoolhouses, where operators, materiel and concept developers, and aggressors worked a problem together on a recurring basis. However, as noted in the recent Air Force 30-year strategy, the service's capacity for short-cycle innovation is extremely limited and may become much more so with budget reductions. The Air Force leadership should examine whether its

\footnotetext{
${ }^{2}$ After this document was complete, the USAF began experimenting with Enterprise Capability Collaboration Teams (ECCTs) as part of the formal servicewide strategic planning process. While only time will tell what becomes of the ECCT initiative, it does represent the type of mechanism our analysis suggests would be very helpful in fostering innovation.
} 
current field experimentation capacity is sufficient and, more important, whether it is well suited to innovating in response to contemporary national strategic problems.

3. Airpower innovation, as a distinct phenomenon, is poorly understood outside the Air Force. The military innovation literature, extraordinarily influential in the U.S. Department of Defense (DoD) and on Capitol Hill, is primarily built on historical case studies of ground forces. Our analysis suggests that the USAF (and perhaps air arms in general) innovate differently than ground and maritime services. Yet very little scholarship has been published on USAF innovation, apart from early Cold War nuclear developments, and virtually nothing has been published in strategic studies on airpower innovation since 9/11. This compares with hundreds of books and articles published on ground force innovation in the last 15 years. This monograph makes a start toward rectifying that imbalance, but much more remains to be done to foster an informed conversation about airpower innovation in the broader defense community. 


\section{Acknowledgments}

This monograph began as a series of discussions with then-Maj Gen Steven Kwast in his Pentagon office during the summer and fall of 2013. The authors are particularly grateful for the intellectual engagement and support of General Kwast and Dr. Paula Thornhill, Director of the Strategy and Doctrine Program in RAND Project AIR FORCE. Our work was influenced in important ways by a number of Air Force officers and civilians, including James Brooks, Col Gregory Butler, Maj Mary Carnes, Patrick Cotter, Lee DeRemer, Eric Fanning, Col Kevin Kennedy, Maj Jeffrey Krulik, Jamie M. Morin, Lt Gen Larry O. Spencer, Col Michael Bob Starr, Thomas Svetecz, Col Michael Trumpfheller, and Scott Wheeler. At RAND, our work benefitted enormously from conversations with Christopher A. Mouton, David A. Ochmanek, and David T. Orletsky. Sarah Harting and Jerry Sollinger made important contributions to the team's research and writing, respectively. John Gordon and Benjamin Lambeth, of RAND, and James Russell, from the Naval Postgraduate School, provided thorough and constructive reviews that significantly improved the document. 


\section{Abbreviations}

\begin{tabular}{|c|c|}
\hline AAA & anti-aircraft artillery \\
\hline AMC & Air Materiel Command \\
\hline $\mathrm{AOC}$ & Air Operations Center \\
\hline ARDC & Air Research and Development Command \\
\hline BUORL & Boston University Optical Research Laboratory \\
\hline CONOPS & concept of operation(s) \\
\hline CSAF & Chief of Staff, Air Force \\
\hline DoD & Department of Defense \\
\hline HAF & Headquarters Air Force \\
\hline HVT & high-value target \\
\hline IADS & Integrated Air Defense System \\
\hline IGY & international geophysical year \\
\hline ISR & intelligence, surveillance, and reconnaissance \\
\hline $\mathrm{JCS}$ & Joint Chiefs of Staff \\
\hline JDAM & joint direct attack munition \\
\hline LGB & laser-guided bombs \\
\hline MAJCOM & Major Command \\
\hline NRO & National Reconnaissance Organization \\
\hline PACAF & Pacific Air Force \\
\hline PAVN & People's Army of Vietnam \\
\hline PGM & precision guided munitions \\
\hline RPA & remotely piloted aircraft \\
\hline RWR & radar warning receivers \\
\hline SAAS & School of Advanced Airpower Studies \\
\hline SAB & Scientific Advisory Board \\
\hline SAC & Strategic Air Command \\
\hline
\end{tabular}


SAM

SEAD

SSB

TAC

TACC

TLAM

USAAF

USAF

USAFE

USSBS

WADC

WDD surface-to-air missile

suppression of enemy air defenses

small smart bomb

Tactical Air Command

Tactical Air Control Center

Tomahawk land attack missile

U.S. Army Air Forces

United States Air Force

U.S. Air Forces in Europe

United States Strategic Bombing Survey

Wright Air Development Center

Western Development Division 


\section{Introduction}

Innovation is intrinsic to the identity of the United States Air Force (USAF). The service's very existence is rooted in the proposition that airpower can provide novel solutions to national strategic problems. It is therefore not surprising that innovation occupies a central place in Air Force thinking and that the service periodically returns to the question of whether it can become more innovative.

\section{Purpose of the Report}

Air Force senior leaders have initiated a conversation about what can and should be done to make the service more innovative. The purpose of this report is to contribute to that conversation by assessing a series of historical cases of Air Force innovation, or apparent failure to innovate, in the context of the scholarly literature on military innovation. Our primary aim is to inform Air Force efforts to make the service more innovative.

\section{Background: What Is Innovation?}

In everyday use the term "innovation" can refer to any new idea, device, or method. Among security-studies academics and DoD practitioners, however, "military innovation" has a much more specific and concrete meaning: "a change in operational praxis that produces a significant increase in military effectiveness.",

Military Innovation Studies is the subfield of strategic studies devoted to examining this phenomenon. Over the last 30 years the subfield has developed a range of theories of why and how military organizations innovate. For analysts these theories serve as conceptual lenses for examining historical and contemporary cases. ${ }^{4}$ For practitioners they provide practical rules of thumb for understanding the motivations and mechanisms of military innovation. In this study, we draw on the theories for two purposes: to structure the research and to frame the recommendations.

\footnotetext{
${ }^{3}$ Adam Grissom, "The Future of Military Innovation Studies," Journal of Strategic Studies, Vol. 29, No. 5, October 2006, pp. 905-934. See, for example, Memorandum from Secretary of Defense Charles Hagel, “The Defense Innovation Initiative," Washington, D.C.: Department of Defense, November 15, 2014; and Dima Adamsky and Kjell Inge Bjerga, Contemporary Military Innovation: Between Anticipation and Adaptation, New York: Routledge, 2012.

${ }^{4}$ Henry S. Rowen, "Policy Analysis as Heuristic Aid: The Design of Means, Ends, and Institutions," in Laurence Tribe, Corinne Schelling, and John Voss, eds., When Values Conflict: Essays on Environmental Analysis, Discourse, and Decision, Cambridge, Mass.: Ballinger, 1976, pp.137-151.
} 
The military innovation literature is vast and multifaceted, but the major theories in the subfield can be distilled to five central factors:

- Threat: Military organizations innovate in response to the capabilities of current or potential adversaries. They may seek to emulate an adversary's capabilities or create an asymmetric capability to offset the threat. ${ }^{5}$

- Technology: Military organizations innovate in response to advances in technology that create new challenges or opportunities for the development of new capabilities. The USAF's internal views of innovation have often favored the technological dimension. ${ }^{6}$

- Bureaucratic Politics: Military organizations innovate in response to bureaucratic challenges posed by sister organizations, such as other services or platform communities, particularly when roles, missions, and budgets are up for grabs. Most of the theoretical work done on military innovation emphasizes this factor. ${ }^{7}$

- Culture: Military organizations each possess a unique culture that frames how the organization sees the world, defines problems, and seeks solutions.

Organizations innovate when presented with a threat to the dominant culture or, alternatively, the culture may constrain how organizations respond to the bureaucratic, technological, and threat incentives listed above. ${ }^{8}$

- Adaptation: Operational units in the field adapt on a day-by-day basis to the tactical and operational problems they encounter. This is a relatively new theme of research in the military innovation studies subfield. ${ }^{9}$

\footnotetext{
${ }^{5}$ The key works are Kenneth Waltz, Theory of International Politics, New York: McGraw Hill, 1979; and Joao Resende-Santos, Neorealism, States, and the Modern Mass Army, Cambridge, UK: Cambridge University Press, 2007.

${ }^{6}$ I. B. Holley, Ideas and Weapons: Exploitation of the Aerial Weapon by the United States in World War I, New Haven, Conn.: Yale University Press, 1953. See also Stephen B. Johnson, The United States Air Force and the Culture of Innovation, Washington, D.C.: Air Force History and Museums Program, 2002.

${ }^{7}$ The key works are Barry Posen, The Sources of Military Doctrine: France, Britain, and Germany between the World Wars, Ithaca, N.Y.: Cornell University Press, 1984; Owen R. Cote, Jr., The Politics of Innovative Military Doctrine: The U.S. Navy and Fleet Ballistic Missiles, Ph.D. dissertation, Massachusetts Institute of Technology, 1996; Stephen P. Rosen, Winning the Next War: Innovation and the Modern Military, Ithaca, N.Y.: Cornell University Press, 1991; Stephen P. Rosen, "New Ways of War: Understanding Military Innovation," International Security, Vol. 13, No.1, Summer 1988, pp. 134 168.

${ }^{8}$ The key works are Dima Adamsky, The Culture of Military Innovation, The Impact of Cultural Factors in the Revolution in Military Affairs in Russia, the US, and Israel, Stanford, Calif.: Stanford University Press, 2010, p. 10; and Thomas Mahnken, Technology and the American Way of War Since 1945, New York: Columbia University Press, 2008.

${ }^{9}$ The key works are James Russell, Innovation, Transformation, and War: Counterinsurgency Operations in Anbar and Ninewa Provinces, Iraq, 2005-2007, Stanford, Calif.: Stanford University Press, 2011; and Theo Farrell, "Improving in War: Military Adaptation and the British in Helmand Province, Afghanistan, 2006-2009," Journal of Strategic Studies, Vol. 33, No. 4, August 2010, pp. 567-594; Robert Foley, “A Case Study in Horizontal Military Innovation: The German Army, 1916-1918," Journal of Strategic Studies, Vol. 35, No. 6, December 2012, pp. 799-827.
} 
These theories are not mutually exclusive; many factors are likely to be at work in any given organization at any particular time. In this monograph we use them to focus the analysis and frame our implications and recommendations.

As will be seen, however, our research suggests that the literature has important limitations in explaining USAF innovation. In particular, Air Force innovation appears more decentralized and diffuse than suggested by literature. Major Commands play a larger role, and formal top-down doctrinal and organizational change play a smaller role, than theory would indicate. The Air Force is also diverse, including "long-cycle" technological development, immediate adaptation by operational units, and a middle ground "short-cycle" innovation involving operational units, prototype technologies, and field experimentation. The USAF therefore has a distinct heritage of, and approach to, innovation that is not widely appreciated by scholars and policymakers.

\section{Study Approach}

This study investigates how and why the USAF has innovated, and failed to innovate, in the past - with the goal of informing USAF policies for the future. To develop an understanding of USAF innovation, the team selected a sample of historical cases of potential innovation, conducted a detailed analysis of each case, and compared the findings to derive insights across cases. We used the major theories of innovation, briefly summarized above, as heuristic devices for this analysis but did not confine the case studies to the existing theories. Our method, formally known as "controlled comparison method of difference," allows us to identify the factors that tend to be associated with successful cases of innovation or, alternatively, with failures to innovate.

As will be evident, some cases occurred over a relatively short period, and the causal story is relatively straightforward. Other cases extended over decades or involved complex causal dynamics. As a result, the case study chapters do not share a universal structure and page length; some are much longer and more detailed than others. Our goal was simply to describe the key causal factors and the process of innovation as concisely as possible. The resulting chapters stand on their own as individual studies and provide the necessary inputs for Chapter 8 , which compares the results of the studies to identify commonalities and differences across cases. Where commonalities are evident, they are highlighted as potential findings of value to the evolving conversation on Air Force innovation. ${ }^{10}$

We selected the cases based on five criteria. First, we defined "innovation" in accordance with the expert literature: a change in operational praxis that produces a significant increase in military effectiveness. Our cases are therefore operational in

\footnotetext{
${ }^{10}$ S. Van Evera, Guide to Methods for Students of Political Science, Ithaca, N.Y.: Cornell University Press, 1997, pp. 67-71.
} 
nature, rather than strictly technological or doctrinal. Second, we included both successes and failures to avoid certain methodological issues with studying one or the other exclusively. Third, we selected a set of case studies that spanned the entire history of the Air Force, partly to investigate whether the service's approach to innovation has changed over time. Fourth, we selected cases across multiple mission communities to better draw conclusions that are valid across these communities. Fifth, due to limitations of time and resources, we selected straightforward cases that posed little execution risk. In practice, this pointed us toward cases in which the team already possessed some degree of expertise. It also excluded classified cases and those that might have posed significant complications in terms of access to primary and secondary sources. Figure 1.1 lists each of the case studies and the time period each covered.

Figure 1.1. Case Studies Developed in This Project

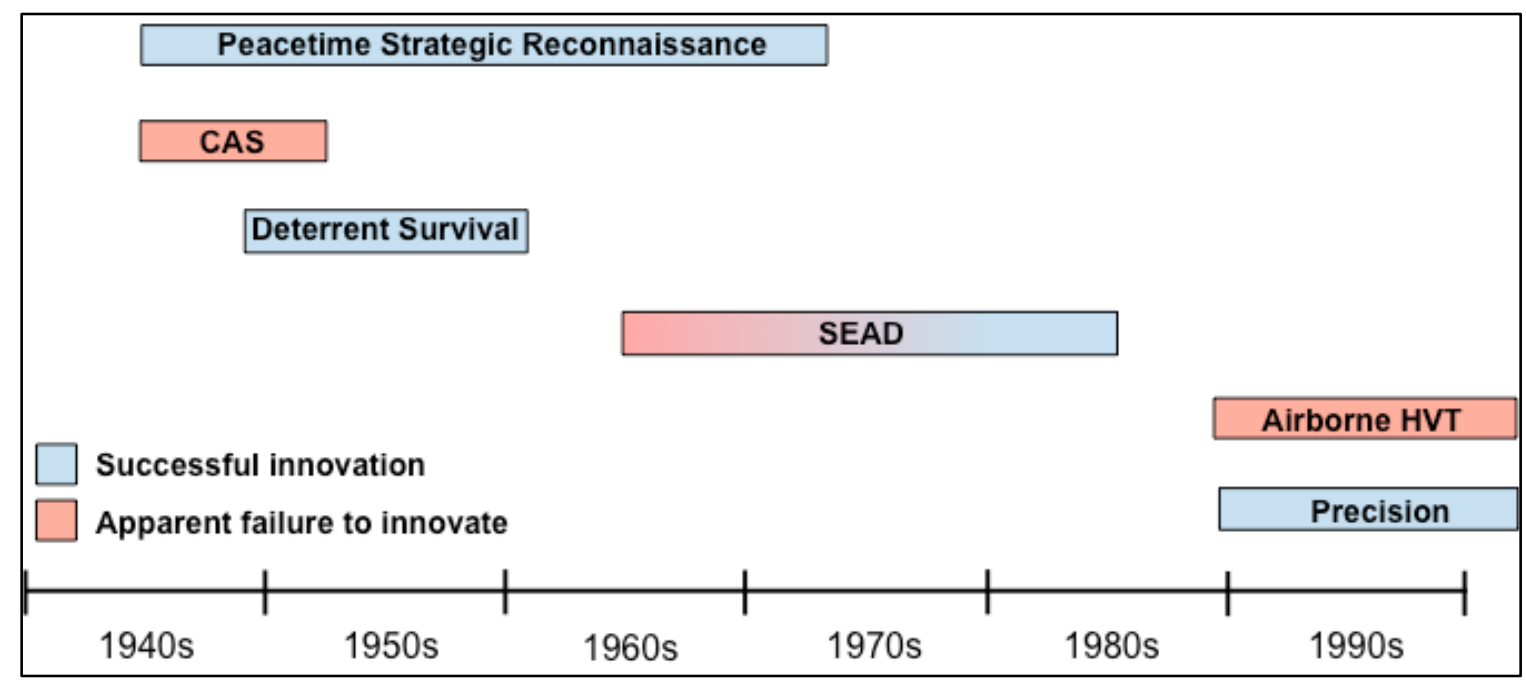

This set of case studies is sufficiently broad and varied to provide useful insights about innovation in the Air Force. However, additional cases would add important breadth and depth to this account, as discussed in Chapter 8.

\section{Organization of the Report}

Chapter 2 explores the USAF's efforts to develop a peacetime strategic reconnaissance capability in the early years of the Cold War. Chapter 3 tells the story of stagnating Air Force close air support (CAS) capabilities between World War II and Korea. Chapter 4 focuses on how the USAF adjusted to the possibility of nuclear attacks against forces and bases that had never before faced serious threats to their survival. Chapter 5 chronicles the USAF's efforts to innovate and adapt to cope with the problem of Soviet Integrated Air Defense Systems (IADS). Chapter 6 analyzes the dimensions 
and history of the precision strategic attack innovation of the 1990s. Chapter 7 explores how the USAF's approach to airborne high-value targeting (HVT) hampered efforts to capture or kill al Qaeda founder Osama bin Laden in the late 1990s through 2001. Chapter 8 looks across the case studies for common insights and what these might imply for the USAF. 


\section{Peacetime Strategic Reconnaissance (1946-1972)}

This case study describes the USAF's efforts to develop a peacetime strategic reconnaissance capability in the early years of the Cold War. In the late 1940s, Air Force leaders quickly recognized a new strategic problem of the nuclear age: the need for peacetime reconnaissance of the Soviet Union. The capability was seen as essential to guard against strategic surprise while preserving America's own strategic advantage.

In light of the challenge, the Air Force not only established a new major command (MAJCOM) focused on research and development - the Air Research and Development Command (ARDC) - but also institutionalized relationships with outside scientists, industry, and academia to pursue new reconnaissance technologies. Drawing on these resources, the USAF advanced satellite technology while pursuing a variety of interim solutions, from modified bombers to high-altitude balloons and advanced reconnaissance aircraft (such as the U-2 Dragon Lady, SR-71 Blackbird, and drones), until photoimaging satellites were ready. By the time the Strategic Arms Limitation Treaty (SALT I) was signed in May 1972, the USAF had developed the "national technical means" to successfully execute a peacetime strategic reconnaissance campaign to reduce uncertainty in the nuclear age.

This chapter is divided into three sections. The first section gives some historical context for the U.S. Army Air Forces' (USAAF's) realization after World War II that peacetime reconnaissance of the Soviet Union had become a strategic problem. It also explores the organizational structures and key figures that enabled the USAAF to frame this strategic problem in the late 1940s. The second section discusses the USAF's role in developing a series of operational solutions to deal with strategic reconnaissance of the Soviet Union, culminating with the first successful flight of the CORONA reconnaissance satellite. The final section discusses the implications of the strategic reconnaissance case for strategic-level innovation in the USAF today.

\section{5-1946: Framing the Strategic Problem and Establishing the Institutional Framework}

During World War II, the USAAF took advantage of rapidly improving aerial reconnaissance technologies - including higher-flying, faster aircraft and improved lenses, cameras, and films - to gather targeting data before bombing runs and to assess 
their impact afterward. ${ }^{11}$ Based on that experience, the USAAF started to make a conceptual distinction between strategic and tactical reconnaissance, defining the former as "the program of acquiring aerial intelligence as a basis for carrying on strategic air warfare against the enemy." 12 In contrast, tactical reconnaissance involved "the large scale daily cover of enemy forward areas, damage assessment photographs for fighter bomber attacks and enemy airfields, and other special targets up to 150 miles from the front." ${ }^{\prime 13}$ The notion that strategic reconnaissance could contribute to winning a warrather than simply scouting for a battle — began to lay the conceptual foundation for strategic aerial reconnaissance during the Cold War. ${ }^{14}$

In the wake of World War II, however, the Truman administration and the newly created Joint Chiefs of Staff (JCS) did not approach strategic reconnaissance in a systematic way. With no immediate threats on the horizon, President Harry Truman planned to simply use the atomic bomb as a blunt deterrent to keep the U.S.S.R. in line and was preoccupied with demobilization and reducing budgets. ${ }^{15}$ The JCS drew up an anti-Soviet war plan, known as PINCHER, but it generically focused on strategic aerial bombardment of Russian cities because the JCS did not have good intelligence on specific targets in Russia's closed society. ${ }^{16}$ The JCS and USAAF Air Intelligence knew they needed a peacetime reconnaissance capability to accurately assess the Soviet Union's capabilities and intentions. ${ }^{17}$ But reconnaissance efforts were piecemeal and underfunded in the years immediately following World War II, ${ }^{18}$ while the implications of war planning in the atomic age were not yet well understood.

USAAF Chief of Staff (CSAF) Gen H. H. "Hap" Arnold sought to bring a sense of urgency to the problem. Peacetime strategic reconnaissance was needed not just for war planning, he argued, but also to prevent strategic surprise. Profoundly affected by the advent of Germany's V-2 rocket, General Arnold warned Secretary of War Robert Patterson in 1945 that adversaries using new technologies would attack the United States without warning, and therefore the United States would need "continuous knowledge of

\footnotetext{
${ }^{11}$ Gregory W. Pedlow and Donald E. Welzenbach, The CIA and the U-2 Program, 1954-1974, Langley, Va.: Central Intelligence Agency, 1998, p. 1; John T. Farquhar, A Need to Know: The Role of Air Force Reconnaissance in War Planning, 1945-1953, Maxwell AFB, Ala.: Air University Press, 2004, p. 15.

${ }^{12}$ Quoted in Farquhar, 2004, p. 18.

${ }^{13}$ Farquhar, 2004, p. 18.

${ }^{14}$ Farquhar, 2004, p. 18.

${ }^{15}$ Neil Sheehan, A Fiery Peace in a Cold War: Bernard Schriever and the Ultimate Weapon, New York: Random House, 2009, p. 54.

${ }^{16}$ Farquhar, 2004, p. 35.

${ }^{17}$ Farquhar, 2004, p. 36.

${ }^{18}$ See Farquhar, 2004, pp.37-41, for a review of post-World War II reconnaissance programs.
} 
potential enemies" in order "to provide warning of impending danger." 19 The United States had to react quickly against enemies with the capability to launch Pearl Harborlike attacks on the nation's vital centers. What was needed, according to General Arnold, was a long-term strategy that exploited space to provide timely warning of strategic attack. $^{20}$

Another champion of peacetime strategic reconnaissance in the USAF was Col Richard Leghorn, who would advance the cause throughout his postwar career. After flying reconnaissance missions in World War II, Colonel Leghorn became deputy commander of Task Unit 1.52, the USAAF unit participating in the 1946 atomic tests at Bikini Atoll. While en route to the atoll, he read the United States Strategic Bombing Survey (USSBS). ${ }^{21}$ He was struck by the U.S. focus on tactical reconnaissance, which he believed had led to missed opportunities during World War II to knock out vital enemy centers. He concluded, for example, that the United States might have been able to end the war sooner had it taken a more strategic view of reconnaissance and focused on bombing the Germans' electrical grid. ${ }^{22}$ His personal experience, combined with his assessment of the USSBS and his observation of the destructive nature of atomic weapons, convinced him of the need for a new reconnaissance philosophy not built around the USAAFs' World War II-era obsession with traditional targeting and damage assessment in wartime, but instead focused on peacetime surveillance of warning indicators, force levels, and the enemy's capability to launch a surprise atomic attack. ${ }^{23}$

Also in 1946, a new USAAF-sponsored reconnaissance research organization, known as the Boston University Optical Research Laboratory (BUORL), asked Colonel Leghorn to give the lab's inaugural speech. ${ }^{24} \mathrm{He}$ described how the advent of atomic warfare fundamentally changed the U.S. strategic situation. He assumed other countries would gain access to atomic weapons and that once they launched an attack, the United States would have little opportunity to recover and launch a counterattack. Therefore, advance warning would be essential. Peacetime aerial reconnaissance could provide such warning,

\footnotetext{
${ }^{19}$ Quoted in Curtis Peebles, The Corona Project: America's First Spy Satellites, Annapolis, Md.: Naval Institute Press, 1997, p. 1.

${ }^{20}$ David Spires, Beyond Horizons: A Half Century of Air Force Space Leadership, Colorado Springs, Colo.: Air Force Space Command, 1998, p. 10; Stephen M. Rothstein, Dead on Arrival?: The Development of the Aerospace Concept: 1944-1958, Maxwell AFB, Ala.: Air University Press, November 2000, p. 12.

${ }^{21}$ United States Strategic Bombing Survey (USBSS) Summary Report (European War), September 30, 1945. See pp. 33-34 for description of missed opportunity to hit German electrical grid. Also, see USBSS Summary Report (Pacific War), July 1, 1946.

${ }^{22}$ Peebles, 1997, p. 2.

${ }^{23}$ Air Force Space Command, Biography of Colonel Richard Sully Leghorn, USAF (Ret.), undated.

${ }^{24}$ Peebles, 1997, p. 2.
} 
he argued, but it would have to be conducted at high altitudes to avoid detection, since military reconnaissance overflights would likely be viewed as acts of aggression. ${ }^{25}$

\section{Establishing the Institutional Framework to Support Strategic Innovation}

By the mid-1940s, General Arnold and Colonel Leghorn had broadly outlined the peacetime strategic reconnaissance problem, but there was no institutional framework in the USAAF to operationalize solutions. The USAAF's primary research and development (R\&D) efforts at the time took place at Air Materiel Command (AMC), but that organization was focused on the rapid acquisition of proven aviation technologies, not long-term R\&D.

To keep the World War II-era momentum for innovation alive in the USAAF, which would become the USAF as of September 18, 1947, General Arnold established institutions committed to long-term R\&D, including the Scientific Advisory Group (SAG), later known as the Air Force Scientific Advisory Board (SAB), and the RAND Corporation. These institutions were structured to promote USAAF ties to the scientific community, because General Arnold believed that the next war would be won by technical competence. $^{26}$

As early as December 1945, the SAG (which was chaired by General Arnold's friend, engineer Theodore Von Karman) issued a landmark report, Toward New Horizons. The report called for a continuation of the USAAF tradition of sponsoring external research in the scientific, academic, and industrial communities. ${ }^{27}$

In 1949, the SAB-commissioned Ridenour Report led to the establishment of the new ARDC MAJCOM. Its role would be to promote a long-term R\&D agenda rather than focus on short-term technologies, which consumed AMC's time, especially after the outbreak of the Korean War in $1950 .^{28}$ The Ridenour Report also led to the creation of a new Air Staff position, Deputy Chief of Staff for Development, which was filled by Maj Gen Gordon Saville. ${ }^{29}$ During the 1950s, the SAB would support several strategic

\footnotetext{
${ }^{25}$ Peebles, 1997, pp. 2-3.

${ }^{26}$ Bernard Schriever, "Military Space Activities: Recollections and Observations," in R. Cargill Hall and Jacob Neufeld, eds., The US Air Force in Space: 1945 to the Twenty-first Century, Washington, D.C.: USAF History and Museums Program, 1998, pp. 11-12.

${ }^{27}$ Army Air Forces Scientific Advisory Group, "Science, the Key to Air Supremacy," Toward New Horizons, Washington, D.C.: Headquarters, Army Air Forces, 1945.

${ }^{28}$ Michael H. Gorn, Harnessing the Genie: Science and Technology Forecasting for the Air Force, 19841986, Washington, D.C.: Office of Air Force History, 1988, pp. 48-50; Robert Perry, Origins of the USAF Space Program: 1945-1956, Vol. V, Wright-Patterson AFB, Ohio: Air Force Systems Command History Office, 1961, p. 33.

${ }^{29}$ Nick A. Komons, Science and the Air Force; A History of the Air Force Office of Scientific Research. Arlington, Va.: Office of Aerospace Research, 1966, p. 24.
} 
reconnaissance assets discussed in the next section, including the USAF's WS-117L satellite program and the CL-282, the prototype design for the U-2 spy plane.

General Arnold also established Project RAND in 1946 to keep the USAF focused on long-term technological innovation. ${ }^{30}$ To protect its research independence, Project RAND would report directly to a new Deputy Chief of Air Staff for Research and Development position, filled by Gen Curtis LeMay. ${ }^{31}$ In this capacity, LeMay spent much of his time shielding Project RAND from AMC, which was loath to see an external organization do anything but respond directly to their specific R\&D requests. ${ }^{32}$ LeMay's position established an important precedent of autonomy at Project RAND, and, in 1948, the organization known today as the RAND Corporation, or simply RAND, became totally independent from the USAF. RAND would become a nerve center of peacetime strategic reconnaissance research, establishing the feasibility of building satellites in its first-ever report, Preliminary Design of an Experimental World-Circling Spaceship, ${ }^{33}$ and continuing to pursue satellite studies in the early 1950s, when the notion was still considered far-fetched. ${ }^{34}$

Obstacles persisted throughout this period, however. Eager to save money after World War II, the Truman administration had sought to trim budgets by focusing on proven technologies at the expense of far-reaching concepts. Vannevar Bush, a powerful scientific advisor to Truman, had publicly derided General Arnold and Von Karman in 1945 for recommending "fantastic" space technologies. ${ }^{35}$ The lack of White House support for R\&D came at the same time that the USAAF had become embroiled in a bureaucratic battle for institutional independence, which further diverted its attention from technological innovation and peacetime reconnaissance. Later, elements of the USAF that shared AMC's preferences for focusing on proven technologies-elements such as the Strategic Air Command (SAC) and the Wright Air Development Center (WADC) - also resisted long-term technical development efforts to improve reconnaissance.

It would be left to a diverse coalition of innovators - including RAND and the SAB, uniformed officers within the Air Staff, mid-level Air Force R\&D commands, and outside organizations from academia, the scientific community, and industry - to explore

\footnotetext{
${ }^{30}$ Andrew D. May, The RAND Corporation and the Dynamics of American Strategic Thought, Ph.D. dissertation, Emory University, 1998, pp. 22-23.

${ }^{31}$ Alex Abella, Soldiers of Reason: The RAND Corporation and the Rise of the American Empire, New York: Mariner Books, May 2009, p. 14.

${ }^{32}$ May, 1998, pp. 25-26.

${ }^{33}$ Merton Davies and William F. Harris, RAND's Role in the Evolution of Balloon and Satellite Observation Systems and Related U.S. Space Technology, Santa Monica, Calif.: RAND Corporation, 1988, p. 6 .

${ }^{34}$ May, 1998, pp. 22-23.

${ }^{35}$ Spires, 1998, p. 11.
} 
the peacetime strategic reconnaissance problem and potential solutions to it. After General Arnold's retirement, RAND and the SAB became critical partners for promoting innovation in the field of reconnaissance. The institutional frameworks that he had established before his retirement, combined with an ethos that promoted scientists and long-term research inside and outside the USAF, ensured that the USAF made major contributions to solving the national problem of peacetime strategic reconnaissance of the Soviet Union. The next section explores how these institutions kept the USAF involved in peacetime strategic reconnaissance problem-solving for decades until 1972, when satellites were finally recognized as the primary means for monitoring the Soviet Union.

\section{6-1971: Developing Operational Solutions for Peacetime Strategic Reconnaissance}

Shortly before retiring in 1946, General Arnold took one last step to solidify the USAAF's legacy of long-term innovation. He brought his protégé, Col Bernard Schriever, to the Pentagon to serve as chief scientific liaison, acting as the main contact between the USAAF and the SAG. ${ }^{36}$ After General Arnold's retirement, Colonel Schriever became a leading voice in USAF leadership to continue peacetime strategic reconnaissance efforts and U.S. intercontinental ballistic missile (ICBM) development as hedges against the Soviet Union. He joined Colonel Leghorn, RAND, ARDC, and the scientific community in a push to develop operational solutions to the strategic reconnaissance problem. The result was the USAF's first satellite program: WS-117L.

\section{The Beginnings of the WS-117L Program}

In 1951, Colonel Leghorn became commander of the Reconnaissance Systems Branch at WADC, where he was in charge of coming up with new ideas for spy planes. ${ }^{37}$ In his push to solve the peacetime reconnaissance problem, he assembled a five-page memo concluding that either manned aircraft, balloons, guided missiles, or drones offered the most immediate way forward. ${ }^{38}$ His thoughts became the basis for the findings of the so-called Beacon Hill Study Group, which was tasked by the Air Staff, also in 1951, to assess the options for reconnaissance behind the Iron Curtain.

\footnotetext{
${ }^{36}$ Philip Taubman, Secret Empire: Eisenhower, the CIA and the Hidden Story of America's Espionage, New York: Simon and Schuster, 2003, pp. 52-53.

${ }^{37}$ Taubman, 2003, p. 48.

${ }^{38}$ Peebles, 1997, p. 11; L. Parker Temple III, Shades of Gray: National Security and the Evolution of Space Reconnaissance, Reston, Va.; American Institute of Aeronautics and Astronautics, 2004, p. 50; Davies and Harris, 1988, p. 37.
} 
The Beacon Hill Study Group, named for its headquarters location on Beacon Hill in Boston, ${ }^{39}$ went to work at the urging of Colonels Leghorn and Schriever, who had contracted with the Massachusetts Institute of Technology to manage the group as an expansion of the university's Project Lincoln study on air defense. ${ }^{40}$ Major General Saville, from his new Development position on the Air Staff, added 15 reconnaissance experts to the group, which included Colonel Leghorn and Edwin Land, the founder of Polaroid. The group endorsed Colonel Leghorn's proposals, including the idea of using a high-altitude manned aircraft for reconnaissance. ${ }^{41}$ Conspicuously absent from his proposals, though, was any reference to satellites. ${ }^{42}$

In 1952, Colonel Schriever brought Colonel Leghorn to the Air Staff to develop longterm planning objectives for reconnaissance. ${ }^{43}$ Once Colonel Leghorn arrived, he met with Merton Davies, from RAND. Davies and other RAND researchers had been pursuing a series of satellite studies even as the Air Staff had focused on other reconnaissance concepts, thanks to the intellectual freedom General Arnold had built into the independent organization. After talking with Davies, Colonel Leghorn came to realize that satellites had long-term promise for strategic reconnaissance missions, even if the technology was not yet ready. ${ }^{44}$

With Colonel Leghorn's support, the Air Staff's War Plans Division tasked RAND to conduct a series of studies to define the engineering specifications for a reconnaissance satellite. ${ }^{45}$ Known as "Project Feedback," the studies convinced the USAF leadership, including CSAF Gen Nathan Twining and retired Gen Jimmy Doolittle, then head of the $\mathrm{SAB}$, to build a reconnaissance satellite based on RAND's technical specifications. The satellite was known as WS-117L. ${ }^{46}$

By late 1954, WS-117L development was already under way at ARDC's Western Development Division (WDD), a new organization that had been championed by Undersecretary of the Air Force Trevor Gardner. WDD was in charge of rapidly developing both ballistic missiles and satellites, enabled by a congressional mandate that specifically allowed it to bypass the slow procurement procedures of AMC. ${ }^{47}$ Schriever became the first commander of the WDD in 1954.

\footnotetext{
${ }^{39}$ Temple, 2004, p. 50.

${ }^{40}$ Taubman, 2003, p. 54.

${ }^{41}$ Taubman, 2003, p. 55.

${ }^{42}$ Davies and Harris, 1988, pp. 37-38.

${ }^{43}$ Taubman, 2003, pp. 53-54.

${ }^{44}$ Peebles, 1997, p. 12.

${ }^{45}$ Davies and Harris, 1988, p. 44.

${ }^{46}$ Taubman, 2003, p. 70.

${ }^{47}$ Peebles, 1997, p. 14; Taubman, 2003, p. 70.
} 


\section{U-2 Spy Plane and Scientific Satellite Development}

Initially the Eisenhower administration was skeptical of the WS-117L satellite, which involved a complex film readout system that could theoretically transmit imagery back to earth within hours. At the same time, President Eisenhower knew that better intelligence data on Soviet military activities would be essential to prevent strategic surprise. The threat crystallized on August 12, 1953, when the Soviet Union tested its first hydrogen (thermonuclear) bomb, just nine months after the United States had conducted its own first test and much sooner than the administration had anticipated. ${ }^{48}$

The Eisenhower administration's alarm spurred the USAF to take steps beyond the WS-117L. Consequently, the service played a critical role in the development of both the U-2 spy plane and a "scientific satellite" (which would, ironically, help bring to fruition the original promise of the elder WS-117L satellite). The USAF did not pursue these innovations alone, however; in fact, it ended up playing a secondary role to the CIA in the U-2 program. Nevertheless, both the U-2 and the scientific satellite would move forward largely because of the vision of Colonel Leghorn, the support of Colonel Schriever, and the advocacy of Undersecretary Gardner, working closely with private industry, the SAB, and an external scientific committee convened by Eisenhower.

\section{The U-2 Program}

The U-2's genesis can be traced to 1953, when the WADC launched a contracting competition for a high-altitude reconnaissance aircraft based on the recommendations of the Beacon Hill Study Group. ${ }^{49}$ WADC limited itself to considering just small aircraft contractors, worried that larger companies like Lockheed would not have the time necessary to put into the project. But the CIA was also interested in a strategic reconnaissance aircraft and did not hesitate to contact Lockheed engineer Kelly Johnson. ${ }^{50} \mathrm{He}$ devised the U-2 prototype called the CL-282, a single-engine, glider-like airplane with an altitude ceiling of 65,000 to 70,000 feet and speeds approaching Mach .8 , making it capable of avoiding Soviet air defenses. ${ }^{51}$ Before leaving his Air Staff position to take command of the WDD in 1954, Colonel Schriever heard about Lockheed's proposal and asked Johnson to brief the USAF leadership at the Pentagon in April of that year. ${ }^{52}$

\footnotetext{
${ }^{48}$ Taubman, 2003, p. 2. Only in 1996 were new records released indicating that the Soviets had actually been working on a thermonuclear weapon even before the United States. See John Carey and Patricia Krantz, "Secrets of the Soviet H-Bomb," Business Week, October 27, 1996.

${ }^{49}$ Taubman, 2003, pp. 77-78.

${ }^{50}$ Chris Pocock, Dragonlady: The History of the U-2 Spyplane, Shrewsbury, UK: Airlife Publishing, 1989, pp. 5-6.

${ }^{51}$ Pedlow and Welzenbach, 1998, pp. 8-10.

${ }^{52}$ Pocock, 1989, p. 6.
} 
General LeMay, then SAC commander, rejected Johnson's proposal and walked out of the briefing. ${ }^{53} \mathrm{WADC}$ would eventually reject the CL-282, too, on the grounds that it was too unconventional and, most significantly, had just one turbojet engine. The USAF preferred two-engine aircraft for redundancy and questioned whether a turbojet could work reliably in the thin air above 60,000 feet. ${ }^{54}$ A SAB panel did endorse the CL-282 proposal, but the panel reported to the USAF, which ultimately rejected the proposal.

USAF civilians were far more receptive to the CL-282 than were the uniformed USAF leaders, with the exception of Colonel Schriever. Undersecretary Gardner, who had championed the WDD, also supported the CL-282. ${ }^{55}$ Gardner and his staff would now have to do an end-run around the uniformed USAF leadership. With the support of Colonel Schriever, ${ }^{56}$ they decided to formally pitch the CL-282 to the CIA, which until then had no official involvement in the effort. While CIA officials were interested, the Director of Central Intelligence (DCI), John Foster Dulles, was hesitant to run a military program and preferred to focus on the CIA's traditional human intelligence assets. ${ }^{57}$ Once again, the USAF's relationships with outside scientists and researchers would be key to keeping strategic reconnaissance technology development alive. In the end, the CL-282 would also need White House support to overcome USAF resistance. At the urging of Gardner, who had grown increasingly worried about Soviet bomber and missile developments, MIT President James Killian asked Eisenhower in 1954 to convene a new external committee, the Technological Capabilities Panel (TCP), to examine the problem of surprise attack. ${ }^{58}$ Eisenhower complied. The TCP members, especially Edwin Land, became convinced of the CL-282's potential to photograph the Soviet Union's Bison bomber fleet and thereby end the "bomber gap" controversy. ${ }^{59}$

Land approached the CIA again, convinced that the civilian agency should run the program, rather than the military, to limit the risk of hostilities. Dulles still balked, so Land went over his head to gain support from Eisenhower, who agreed that the CL-282 should be a civilian operation and approved the CIA's management of it. ${ }^{60}$ Knowing that Land had tacit presidential support, Dulles eventually capitulated.

The USAF was another matter. The CL-282 was basically the embodiment of the ideas of a now-retired USAF officer, Colonel Leghorn, and enjoyed support from

\footnotetext{
${ }^{53}$ Pedlow and Welzenbach, 1998, p. 12.

${ }^{54}$ Pedlow and Welzenbach, 1998, p. 12; Pocock, 1989, p. 6.

${ }^{55}$ Pedlow and Welzenbach, 1998, p. 15; Pocock, 1989, p. 6.

${ }^{56}$ Craig Kuhl interview with Colonel Richard Leghorn, The Cable Center Oral History Project, May 20, 2008.

${ }^{57}$ Pedlow and Welzenbach, 1998, pp. 16-17.

${ }^{58}$ Taubman, 2003, p. 85.

${ }^{59}$ Pedlow and Welzenbach, 1998, p. 31.

${ }^{60}$ Pedlow and Welzenbach, 1998, pp. 31-32.
} 
Colonel Schriever. But there was still resistance in the service. WADC continued to question CL-282's technical feasibility, preferring the designs it had evaluated under its own contracting competition. Air Force Secretary Harold Talbott resisted the idea of allowing the CIA to take the lead on an aviation program. ${ }^{61}$ Ultimately, however, knowing the CL-282 program had Eisenhower's support, Secretary Talbott and CSAF General Twining agreed to support the CIA. ${ }^{62}$ Thanks to the persistence of Colonel Leghorn, Colonel Schriever, Undersecretary Gardner, and the external scientific community, the U-2 program was born.

\section{The Scientific Satellite Program}

The U-2 was not the only strategic reconnaissance asset to receive a major boost from the TCP. The panel also called for establishing a small scientific satellite programseparate from the USAF's WS-117L - to establish freedom in space as a precursor to military reconnaissance missions. ${ }^{63}$ Worried about the possibility of elevating tensions with the Soviets, Eisenhower liked the idea of establishing a peaceful precedent in space with a "stalking horse" scientific satellite that would also clear the way for the WS-117L, which was still under development. His administration made a formal request for a small scientific satellite to be developed in time for the International Geophysical Year (IGY), scheduled to take place between July 1957 and December 1958.

With the groundwork laid in 1954 for the scientific satellite program and with U-2 and WS-117L development under way, Eisenhower began to prepare for the July 1955 Geneva Summit. There, he intended to ask the First Secretary of the Communist Party, Nikita Khrushchev, for an “Open Skies” agreement based on Colonel Leghorn's ideas about surprise attack, as articulated in the colonel's 1946 BUORL speech nearly a decade earlier. The Open Skies agreement would have allowed for mutually supervised overflights of strategic assets. Khrushchev rejected the proposal, as expected, and Eisenhower immediately announced that the United States would fly a small scientific satellite as part of the IGY. ${ }^{64}$

Eisenhower also decided to move forward with the U-2 overflights, despite his concerns about the risks of starting a war, if detected. ${ }^{65}$ The USAF and the CIA began to assign responsibilities for the CIA-led U-2 program, initially code-named AQUATONE, with the CIA paying for the airframes and cameras while the USAF provided the engines. The CIA would have overall responsibility for the Lockheed contract, the cameras,

\footnotetext{
${ }^{61}$ Taubman, 2003, pp. 100-101.

${ }^{62}$ Taubman, 2003, pp.105-108.

${ }^{63}$ Peebles, 1997, p. 22.

${ }^{64}$ Peebles, 1997, pp. 23-24.

${ }^{65}$ Pedlow and Welzenbach, 1998, p. 96.
} 
security, film processing, and arrangements at foreign bases, while the USAF would provide weather information, mission plotting, operational support, and pilot selection and training. ${ }^{66}$ Initially, Eisenhower wanted to use foreign pilots to minimize the political risks, but he eventually agreed to use SAC reservists since not enough foreign pilots were available. ${ }^{67}$

\section{From Balloons to CORONA}

As preparations for the U-2 flights progressed, the USAF launched a campaign in early 1956 to conduct reconnaissance over Eastern Europe, the Soviet Union, and China. This campaign was based on a series of 1951 RAND studies on high-altitude, cameracarrying balloons. Known as the GENETRIX campaign, it was considered a failure because wind blew the balloons off course, provoking a Soviet protest when they landed. ${ }^{68}$ Nevertheless, the concept yielded technological advancements for satellites, as well as new information about the Soviet Union. The balloon campaign pioneered a camera system and a midair image-recovery system that would both be used in CORONA, America's first operational photoreconnaissance satellite program. ${ }^{69}$ The balloons' cameras also provided the most complete imagery of the Soviet Union seen since World War II. As icing on the cake, a steel bar on the balloons just happened to resonate with the radio frequency of Soviet TOKEN radars, and so this serendipitous resonance provided valuable data on Soviet radar tracking accuracy, which would be directly applicable to the U-2 program. ${ }^{70}$

A formal Soviet protest lodged on February 4, 1956 led Eisenhower to stop GENETRIX, but he still faced the increasingly pressing challenge of obtaining quality intelligence on the Soviet Union's nuclear arsenal. ${ }^{71}$ On Capitol Hill, General Twining, still CSAF, was now claiming that the Soviets had more Myasishchev M-4 Bison bombers than the United States had B-52s. ${ }^{72}$

The president authorized the U-2's first missions with the intent of clearing up the bomber gap controversy. Eight of the ten U-2 flights conducted between June 20 and July 10, 1956 took place in the Soviet bloc, including five over the Soviet Union itself. ${ }^{73}$ The U-2 imagery proved that General Twining was wrong, showing there were no Bisons at

\footnotetext{
${ }^{66}$ Pedlow and Welzenbach, 1998, p. 60.

${ }^{67}$ Pedlow and Welzenbach, 1998, p. 74.

${ }^{68}$ Pedlow and Welzenbach, 1998, pp. 85-86.

${ }^{69}$ Peebles, 1997, p. 32 and p. 46.

${ }^{70}$ Pedlow and Welzenbach, 1998, p. 87.

${ }^{71}$ Peebles, 1997, p. 32.

72 Pedlow and Welzenbach, 1998, p. 99; Sheehan, 2009, p. 151.

${ }^{73}$ Pedlow and Welzenbach, 1998, p. 111.
} 
any of the nine long-range bomber bases photographed. ${ }^{74}$ However, Soviet radars had been able to track the U-2 even on its very first mission (although MiG fighters could not intercept it because of its high altitude), and the Soviet Union lodged a protest against the flights on July $10,1956 .{ }^{75}$ It was becoming clearer than ever that the U-2 was only an interim solution.

After the Soviet protest in July 1956, Eisenhower authorized U-2 flights only along the borders of Iron Curtain countries and flights over the Soviet Union only on a tightly controlled and limited basis, owing to his concerns about diplomatic repercussions. ${ }^{76}$ Less worried about diplomatic fallout than Eisenhower, the Soviet Union pressed ahead with two successful SS-6 ICBM flights in late August and early September 1956, clearing the way for the launch of its first satellite, Sputnik, on October 4, 1957. ${ }^{77}$

\section{Sputnik and the Birth of CORONA}

The Sputnik launch stoked U.S. fears of a missile gap, with the U.S. intelligence community producing increasingly gloomy estimates of American ICBM production relative to the Soviets'. ${ }^{78}$ Concerned about the threat of a surprise attack and craving more information on Soviet ICBM numbers to calibrate U.S. ICBM force levels, the White House made satellite development a top priority. But the USAF's WS-117L project was nowhere near operational; the technology was complicated, and it had been sitting on the back burner because the White House had focused its energy on the scientific satellite program. ${ }^{79}$

As a result, the White House began to look for an interim satellite that could be ready more quickly than the WS-117L. At the same time, RAND resubmitted a report to the USAF, recommending a film-recovery variant of the WS-117L that could be produced much more quickly. The USAF had previously rejected this concept, which involved physically recovering satellite film in capsules once they re-entered the earth's atmosphere. The service had preferred to stick with the WS-117L's original, much more complex film read-out system. ${ }^{80}$ In light of Sputnik, however, the Air Staff immediately requested that the Pentagon approve the development of a prototype of RAND's film-

\footnotetext{
${ }^{74}$ Pedlow and Welzenbach, 1998, p. 111.

75 Peebles, 1997, p. 34.

${ }^{76}$ Pedlow and Welzenbach, 1998, pp. 122-144.

${ }^{77}$ Peebles, 1997, p. 38.

${ }^{78}$ Peebles, 1997, p. 39.

${ }^{79}$ Peebles, 1997, pp. 24-25.

${ }^{80}$ Peebles, 1997, p. 27.
} 
recovery satellite. ${ }^{81}$ Air Force Secretary Donald Quarles and DCI Dulles jointly recommended the film-recovery satellite to Eisenhower as an interim solution. ${ }^{82}$

Eisenhower was eager to build the interim satellite, but he also was still determined to maintain a peaceful approach to space. Concerned that the WS-117L was associated with military reconnaissance, he decided to separate RAND's idea for a film-recovery satellite from the USAF's WS-117L. The film-recovery satellite program henceforward became known as CORONA and was jointly managed by the CIA and the USAF. Richard Bissell, the Special Assistant to the DCI for Planning and Development, ran CORONA for the CIA, while Brig Gen Osmond Ritland handled the USAF project branch. ${ }^{83}$ The USAF would retain its control of the newly separate WS-117L program, which would become known as SAMOS, short for Satellite and Missile Observation System. ${ }^{84}$

To maintain secrecy, CORONA would not be identified by its real name in public. Rather, CORONA would be described to the public as an effort called DISCOVERER to conduct biomedical research in outer space. DISCOVERER test flights, starting in early 1959, produced a string of early failures. The CIA and USAF did not give up on the satellite program, however, and it eventually became the definitive answer to the peacetime strategic reconnaissance problem.

But in the meantime, missile gap fears reached a fever pitch, and the CIA and State Department implored Eisenhower to allow more U-2 overflights of the Soviet Union. USAF Assistant Chief of Staff Maj Gen James H. Walsh claimed that the Soviets had a huge intercontinental missile force, formally dissenting from CIA reports that Soviet ICBM numbers were small. ${ }^{85}$ Eisenhower finally agreed to a few more U-2 missions, with the final two scheduled to take place in the spring of $1960 .{ }^{86}$ The second of those flights, piloted by Francis Gary Powers on May 1, was brought down by a Soviet SA-2 Guideline surface-to-air missile. ${ }^{87}$ A public embarrassment to Eisenhower, the event marked the last time a U-2 would fly over the Soviet Union.

\section{SR-71 Aircraft and Drone Projects}

The USAF and the CIA continued to work together to develop alternatives to the U-2 while waiting for satellite technology to mature. Advances in the CORONA program,

\footnotetext{
${ }^{81}$ Davies and Harris, 1988, p. 86.

${ }^{82}$ Peebles, 1997, p. 43.

${ }^{83}$ CIA fact sheet, "A Look Back: The Nation's First Photoreconnaissance Satellite," undated.

${ }^{84}$ Peebles, 1997, pp. 45-47.

${ }^{85}$ Peebles, 1997, p. 77; Leonard F. Parkinson and Logan H. Potter, "Closing the Missile Gap," in Joan Bird and John Bird, eds., Penetrating the Iron Curtain: Resolving the Missile Gap with Technology, 2011, pp. 113-117.

${ }^{86}$ Peebles, 1997, pp. 77-78.

${ }^{87}$ Peebles, 1997, p. 78.
} 
discussed later, quickly overshadowed these alternative programs, including the highand fast-flying A-12/SR-71 Blackbird aircraft and several drone projects. Nevertheless, they are worthy of mention because they reflect the USAF's continuing and multipronged commitment to peacetime strategic reconnaissance.

As had been the case with the U-2, Lockheed played a major role in spurring the CIA and USAF to develop new strategic reconnaissance platforms. In 1958, well aware of the U-2's vulnerability, Lockheed's Johnson pitched a fast-flying successor aircraft with a smaller radar cross-section to the CIA. ${ }^{88}$ After winning a CIA contracting competition for a U-2 successor in $1959,{ }^{89}$ Lockheed flew the A-12 for the first time in February $1962 .{ }^{90}$ The following year, the USAF bought a two-seater version of the A-12, the SR-71 Blackbird.

Also in 1963, Johnson began working on another A-12 development, the M/D-21 Tagboard, which involved launching a drone from the SR-71. Johnson pitched the idea to the National Reconnaissance Organization (NRO), a jointly run USAF/CIA agency established in 1961 to oversee overhead reconnaissance and to minimize bureaucracy. ${ }^{91}$ The Tagboard project ended when the D-21 drone rolled into the M-21 mother ship during a flight test, killing the launch operator seated in the SR-71's second cockpit. ${ }^{92}$

Senior Pentagon officials were still interested in the drone concept and asked Lockheed to pursue SENIOR BOWL, an effort to launch a drone from a B-52H Stratofortress bomber. ${ }^{93}$ In yet another effort, the Air Force Systems Command, which had been created in 1961 as the successor to ARDC when it was given responsibility for acquisition as well as R\&D, issued a contract in 1966 for a separate reconnaissance drone effort called COMPASS ARROW. ${ }^{94}$ None of these drone efforts came to fruition, however, as reconnaissance satellites by this time offered more mature technology and lower political risks.

\section{CORONA Success: Cracking the Strategic Reconnaissance Problem}

In August 1960, three months after the shoot-down of Francis Gary Powers in his U2, the CIA and USAF's CORONA program started yielding results, following a series of

\footnotetext{
${ }^{88}$ Paul Crickmore, Lockheed A-12: The CIA's Blackbird and Other Variants, New York: Osprey Publishing, 2014, p. 12.

${ }^{89}$ Taubman, 2003, p. 281.

${ }^{90}$ Taubman, 2003, p. 341.

${ }^{91}$ The balance of power between the USAF and the CIA within the NRO has shifted back and forth over time; see Bruce Berkowitz, The National Reconnaissance Office at 50 Years: A Brief History, Chantilly, Va.: National Reconnaissance Office (NRO), 2011, p. 15.

${ }^{92}$ Crickmore, 2014, p. 84.

${ }^{93}$ Thomas P. Ehrhard, Unmanned Aerial Vehicles in the United States Armed Services: A Comparative Study of Weapons System Innovation. ” Ph.D. Dissertation, Johns Hopkins University, 2000, pp. 122-124.

${ }^{94}$ Ehrhard, 2000, pp. 126-127.
} 
promising DISCOVERER flight tests. The first fully successful flight, DISCOVERER 14, provided photographic coverage of more of the Soviet Union than all $24 \mathrm{U}-2$ overflights combined. ${ }^{95}$ Rather than the narrow slices of images provided by the U-2, CORONA satellites would be able to provide film coverage of everything that passed below the camera.

By the time DISCOVERER 25 launched in June 1961, the new Kennedy administration was able to definitively say that the Soviets had far fewer ICBMs than the United States and were not pursuing a crash program. ${ }^{96}$ That same month, when Khrushchev issued Kennedy an ultimatum to withdraw from West Berlin, the White House was able to use the information from DISCOVERER as crucial leverage in negotiations with Khrushchev during the Berlin crisis, which culminated in August 1961 with the construction of the Berlin Wall. ${ }^{97}$ The results of DISCOVERERS 25, 26, and 30 gave the Kennedy administration confidence to hold its ground against Khrushchev, who subsequently backed down from his effort to compel the removal of Western forces from West Berlin once newspaper leaks revealed that the United States had already known that the Soviets did not have enough ICBMs to launch a surprise attack. ${ }^{98}$ Thanks to the DISCOVERER imagery, in other words, Kennedy could call Khrushchev's bluff.

By 1964, the results of myriad scientific programs and projects conducted in pursuit of solving a national strategic problem had shifted the future of strategic reconnaissance away from aircraft such as the U-2 or the A-12 toward the field of satellites. ${ }^{99}$ In the end, it was the CORONA series of satellites, designated "KH" for KEYHOLE, which paved the way for cracking the problem of strategic reconnaissance of the Soviet Union as a means of preventing a surprise attack. CORONA provided intelligence and, with it, confidence to the White House in the early Cold War years, which were riddled with uncertainty. CORONA also paved the way for future reconnaissance satellites in the KEYHOLE series, from GAMBIT to HEXAGON and, by the early 1970s, to KENNAN, an electro-optical satellite that finally achieved the original aim of the WS-117L, which had been to provide film readouts rather than merely rely on film recovery. The legacy of these reconnaissance satellites would lie not only in the critical mission of preventing strategic surprise. In the SALT I Treaty of 1971, reconnaissance satellites would be formally recognized as the "national technical means" for monitoring arms control

\footnotetext{
95 Peebles, 1997, p. 91.

${ }^{96}$ Peebles, 1997, p. 114.

${ }^{97}$ Peebles, 1997, pp. 111-112.

${ }^{98}$ Peebles, 1997, pp. 118-120.

${ }^{99}$ Peebles, 1997, p. 138.
} 
agreements. Indeed, by then, reconnaissance satellites were providing more imagery than analysts had time to process. ${ }^{100}$

\section{Findings and Implications}

With the establishment of the NRO in 1961, uniformed USAF leadership was mostly frozen out of satellite development. Nevertheless, the service played a central role in the early development of a peacetime reconnaissance capability to monitor the Soviet Union, building the tools that later became necessary to begin arms limitation treaties in the early 1970s. The USAF's early contributions to strategic reconnaissance - in terms of its strategic vision and operational solutions - provided the kind of long-term innovation focus that was essential to the establishment of CORONA and its successor satellite programs.

This case study has two main implications for innovation in the USAF today. First, it highlights how major innovation begins with clearly framing a strategic problem. General Arnold first began to communicate the importance of strategic reconnaissance in a letter to Secretary of War Patterson in 1945. Colonel Schriever's recognition of the problem and his decision to move Colonel Leghorn to the Air Staff created further opportunities to refine and articulate strategic reconnaissance concepts. Undersecretary Gardner played a key role in supporting strategic reconnaissance. By framing the peacetime reconnaissance problem as a long-term, strategic issue, these uniformed and civilian USAF leaders established the rationale for the USAF to remain involved in strategic reconnaissance for the duration, persevering even when their initial operational concepts, such as the GENETRIX balloons or the film readout satellite, did not prove effective right away.

Second, this case study underscores the importance of building institutional frameworks to support innovation. Uniformed leaders on the Air Staff, such as General Arnold, Colonel Schriever, and Major General Saville, as well as Gardner, a USAF civilian, pushed for the establishment of important institutional touchstones, both inside and outside the USAF. ARDC, and eventually ARDC's WDD, as well as outside entities - including RAND, the SAB, the Beacon Hill Study Group and the BUORLsustained the momentum for peacetime innovation in the field of strategic reconnaissance.

Ultimately, this case study demonstrates that innovation often hinges on the USAF's senior leadership. These leaders must define strategic problems, articulate them, and create institutional frameworks with the wherewithal to stay focused on operational solutions for many years, if not decades - even when other parts of the USAF may have short-term incentives to undermine that work.

\footnotetext{
${ }^{100}$ Cargill Hall, "Sputnik, Eisenhower and the Formation of the United States Space Program," Quest, Vol. 14, No. 4., 2007, p. 38.
} 


\section{Close Air Support (1945-1951)}

\section{Introduction}

This chapter describes the evolution of USAF CAS capabilities in the years between World War II and the Korean War. The first section briefly describes the CAS capability developed by the Army Air Forces (AAF) during the latter stages of World War II, providing a baseline for assessing subsequent adaptation and innovation. The second section examines how the Air Force CAS capability evolved slowly between 1945 and 1950 while the service as a whole energetically fielded new doctrine and new types of aircraft. The third section describes the effect of the Air Force's new doctrine and aircraft on CAS during the first year of the Korean War.

The fourth section outlines the key insights relevant to the contemporary Air Force innovation conversation. The central insight is an empirical one: The USAAF and USAF failed to innovate in the CAS mission area between World War II and the Korean War. This stagnation is remarkable given the overall record of rapid Air Force innovation during the same period. The primary reason for stagnation was that the Air Force prioritized other mission areas for innovation. The USAF did not intend to allow its CAS capability to stagnate, but it devoted little effort to CAS innovation or even to preserving the capability it already possessed. Stagnation was therefore the result of tacit strategic decisions about the relative prioritization of other strategic and operational problems to be solved.

\section{CAS in World War II}

The United States entered World War II with insufficient CAS capabilities. Compared to the air arms of other belligerents, the AAF of 1941 possessed neither the appropriate types of aircraft nor the organizations, tactics, techniques, and procedures to effectively conduct CAS in any theater. ${ }^{101}$ In North Africa and other early U.S. operations, the organizational and communications connections between ground commanders and air units were confused and inefficient at the tactical and operational levels. ${ }^{102}$ The aircraft chosen for the CAS mission in North Africa, the A-20 Havoc light

\footnotetext{
${ }^{101}$ R. M. Muller, "Close Air Support: The German, British, and American Experiences, 1918-1941,” in W. Murray and A. R. Millett, eds., Military Innovation in the Interwar Period, Cambridge, UK: Cambridge University Press, 1996, pp.144-190.

${ }^{102}$ D. R. Mortensen, A Pattern for Joint Operations: World War II Close Air Support-North Africa, Washington, D.C.: Army Center of Military History, 1987, pp. 17-28.
} 
bomber, was poorly suited to the mission. ${ }^{103}$ The combination of ineffective organizations, communications, and aircraft resulted in poor performance and a series of controversies in 1943 and 1944. ${ }^{104}$

In the last two years of the war, however, the AAF developed significantly improved CAS capabilities through painful adaptation in combat. The contributions of the XIXth Tactical Air Command (TAC), particularly Gens Elwood P. Quesada and Otto P. Weyland, were particularly important to this process. ${ }^{105}$ Under Generals Quesada and Weyland, the XIXth developed tactics, techniques, and procedures for effective CAS under the stressing conditions of the European Theater of Operations (ETO) in late 1944 and 1945. ${ }^{106}$ The AAF approach was built around the principle of centralized control of airpower. ${ }^{107}$ Ground attack aircraft were concentrated in numbered tactical air forces associated with identically numbered Army Ground Force field armies. ${ }^{108}$ Air Support Parties (ASPs) were positioned at regimental and divisional levels, while airborne Forward Air Controllers (FACs) coordinated the majority of CAS attacks. ${ }^{109}$ Just as importantly, the AAF found the P-47 Thunderbolt fighter-bomber to be an excellent CAS platform, with a rugged airframe, powerful air-cooled engine, and large payload capacity for bombs and rockets. ${ }^{110}$

In 1944 and 1945, AAF doctrine for tactical air operations emphasized air superiority, interdiction, and CAS as priority missions, in that order. By mid-1944, though, the allies' numerical advantage in tactical aircraft was so overwhelming that commanders rarely found it necessary to prioritize among these missions. ${ }^{111}$ There were often so many Allied aircraft available on good flying days that ground commanders could generally count on having CAS available despite the fact that it was the third of three priorities.

In Europe, the AAF assigned ASPs to the combat command, division, corps, and, sometimes, lower echelons. Candidate target areas for CAS were nominated each day through the ASP chain and adjudicated each evening at the Combined Operations Center

\footnotetext{
${ }^{103}$ Muller, 1996, p. 180.

${ }^{104}$ D. Syrett, "The Tunisian Campaign: 1942-1943," in B. F. Cooling, ed., Case Studies in the Development of Close Air Support, Washington, D.C.: Office of Air Force History, 1990, pp. 153-192.

105 See, for example, Thomas A. Hughes, Overlord: General Pete Quesada and the Triumph of Tactical Airpower in World War II, New York: Free Press, 1995.

${ }^{106}$ Will A. Jacobs, "The Battle for France, 1944," in Benjamin F. Cooling, ed., Case Studies in the Development of Close Air Support," Washington, D.C.: Office of Air Force History, 1990, pp. $237-294$.

${ }^{107}$ David Spires, Airpower for Patton's Army: XIX Tactical Air Command in the Second World War, Washington, D.C.: Air Force History and Museums Program, 2002, pp. 56-62.

${ }^{108}$ Jacobs, 1990, pp. 251-254.

${ }^{109}$ Jacobs, 1990, pp. 251-254.

${ }^{110}$ For an excellent overview, see "The Fighter-Bomber Weapon, 1943-1945" in Ian Gooderson, Air Power at the Battlefront: Allied Close Air Support in Europe, 1943-1945, London: Cass, 1998, pp. 57-83.

${ }^{111}$ Jacobs, 1990, p. 251.
} 
(COC), which was operated jointly by each numbered tactical air command and each identically numbered field army. The COC assigned the approved target areas to fighterbomber groups, which were held aside to conduct CAS the next day. The next morning, the aircrews received briefings on the missions and executed them at the requested time on target. Immediate requests were handled through the same chain, on an expedited basis, either to remit aircraft or commit fighters from the TAC reserve. ${ }^{12}$ It was not a particularly flexible and responsive system for immediate CAS requests, but the sheer

number of aircraft available often made it possible to fulfill urgent requests effectively. ${ }^{113}$

The AAF in the ETO made two major innovations in tactical control of CAS missions. The first was the advent of "Rover" ground teams, which were equipped to accompany forward ground columns and call in fighters from nearby assembly points. The Rover teams, which included experienced fighter pilots, addressed the primary weaknesses of a centralized and somewhat inflexible system, bringing CAS to bear on emerging targets quickly and precisely. ${ }^{114}$

The other innovation was the advent of "Horsefly" observers in L-5 liaison aircraft. Positioned forward, Horseflies could quickly respond to immediate calls for support from ground troops in contact. Once overhead, the Horsefly observers could act as airborne FACs, communicating with the ground units as well as any fighter-bombers arriving on station. With the benefit of altitude and loiter, the Horsefly observers developed the ability to call in CAS quickly and very accurately. They therefore addressed many of the target identification and "talk on" accuracy challenges that had afflicted AAF fighterbombers in the complex terrain of Western Europe. ${ }^{115}$

By 1945, the AAF had developed an effective CAS capability built on centralized allocation of deliberate CAS missions, ASPs at regimental through division echelons, and terminal attack control by Rover ground parties and Horsefly airborne FACs. This capability provided the foundation for further innovation and adaptation after the war.

\section{CAS Between World War II and Korea}

The Air Force evolved considerably during the years immediately following World War II. ${ }^{116}$ The newly independent service moved quickly to embrace new missions, such as peacetime strategic reconnaissance and continental air defense. It also sought to push the rapidly advancing frontier of jet-age aerospace engineering, fielding a remarkable number of new aircraft types with a bewildering array of engines, planforms, and aircraft

\footnotetext{
112 Jacobs, 1990, p. 255.

113 Jacobs, 1990, pp. 260-261.

${ }^{114}$ Jacobs, 1990, pp. 273-274.

115 Jacobs, 1990, pp. 273-274.

${ }^{116}$ Of course, it was the Army Air Forces until 1947.
} 
configurations. The overall picture is of aggressive Air Force innovation during this period. ${ }^{117}$

Within the CAS mission area, however, USAF efforts were, at best, evolutionary. The AAF had published a revised field manual on air-ground operations, FM 31-35, in the summer of $1946 .{ }^{118}$ This revised manual essentially codified the CAS approach developed in the ETO in 1944 and 1945. Tactical mission priorities remained air superiority, interdiction, and CAS, in that order. CAS would be centrally controlled and allocated, typically on a deliberate timeframe so that aircrews could be thoroughly briefed on their assigned missions. The Air Force would provide one Tactical Air Control Party (TACP) per Army regiment and an additional TACP to the division headquarters. Airborne FACs in liaison-type aircraft would provide terminal attack control once air superiority had been achieved. ${ }^{119}$

The Air Force was more aggressive on the materiel side, fielding at least six new types of fighters during the five years between the wars. Most of these were, of course, jet fighters with significantly improved performance, by many measures, over pistonengine fighters. Within the fighter category, however, the Air Force tended to focus on interceptors rather than fighter-bombers. The F-89 Scorpion and F-94 Starfire were, for example, all-weather interceptors with relatively high wing loadings designed for high speed and modest maneuverability at medium altitudes. ${ }^{120}$

A more important fighter, from the perspective of operations in Korea, was the F80C Shooting Star. Developed in the late 1940s, the F-80 was initially designed as a short-range interceptor. Early models of this type were not even equipped with pylons for air-ground weaponry. The F-80 was a relatively fragile aircraft that was restricted, in Far East Air Forces (FEAF) service, to operating from main operating bases in Japan, sharply limiting its operational utility over Korea. Nevertheless, the FEAF fighter groups were equipped with the straight-winged F-80 in 1949, and it would end up playing a prominent role in the early months of the Korean War, as discussed in the next section. ${ }^{121}$

The F- 80 was complemented in service by the straight-winged F-84 Thunderjet day fighter. The F-84 possessed somewhat better maneuverability and range than the F- 80 and, after substantial reinforcement to fix severe structural issues, could carry a useful

\footnotetext{
${ }^{117}$ See Mercelle S. Knaack, Encyclopedia of US Air Force Aircraft and Missile Systems, Volume 1: Fighters, 1947-1975, Washington, D.C.: Office of Air Force History, 1978.

${ }^{118}$ W. T. Y'blood, Down in the Weeds: Close Air Support in Korea, Washington, D.C.: Air Force History and Museums Program, 2002, pp. 1-2.

${ }^{119}$ Y'blood, 2002, pp. 1-2.

${ }^{120}$ Also, the F-82 Twin Mustang long-range escort fighter.

${ }^{121}$ On F-80C performance, see Williamson Murray, "Korea, 1950-1953," in B. F. Cooling, ed., Case Studies in the Development of Close Air Support, Washington, D.C.: Office of Air Force History, 1990, pp. 361-363. On F-80C basing, see Judy G. Endicott, The USAF in Korea: Campaigns, Units, and Stations, 1950-1953, Washington, D.C.: Air Force History and Museums Program, 2001, pp. 45-57.
} 
payload in the fighter-bomber role. The F-84 would become the workhorse of Air Force interdiction missions in Korea, focusing on the second tactical priority. ${ }^{122}$

As the Korean War began, the Air Force was also fielding its first swept-wing jet fighter, the F-86 Sabre. Initially designed as a fast, short-range day fighter that nonetheless retained reasonable high-speed maneuverability due to its swept wings and all-moving tailplane, the F-86 would become the most famous American air superiority fighter of the Korean War. It did not play a significant role in CAS, however, as it focused on the first tactical priority. ${ }^{123}$

The new USAF doctrine and aircraft affected CAS capabilities less than one might expect, largely because CAS remained a tertiary tactical priority. As for strategic priorities, the USAF leadership was firmly focused on strategic bombardment, with atomic weapons as the top priority for combat development. Air defense against Soviet strategic bombardment ran a close second priority. Air support to conventional operations fell well down on the list, leaving CAS as the lowest priority within the support category.

One result of the low priority accorded to CAS was that, unlike other missions such as heavy bombardment, medium bombardment, and air defense interceptor, there were no combat organizations dedicated to CAS. This meant, among other things, that there was no community of operators dedicated to improving (or even maintaining) the state of Air Force CAS capabilities.

The low priority accorded to CAS was reflected in the instructions issued to Air Force MAJCOMs. As Air Force historian William Y'blood wrote about the FEAF,

Before the war began in Korea, the primary mission of Lt. Gen. George E. Stratemeyer's FEAF had been to maintain an active air defense for FEAF's area of operations, which included Japan, the Ryukyus, the Marianas, and the Philippines. Secondary missions, of which there were many, included maintaining "a mobile air striking force of such size and composition as may be prescribed from time to time" and providing "air support of operations as arranged with appropriate Army and Navy commanders." 124

The result was that Air Force operational units did not spend much time or energy preparing for the CAS mission. There is very little evidence of experimentation with how the revised CAS manual might have worked with the new fighter aircraft entering the operational units. In fact, USAF fighter units devoted little time or energy to maintaining CAS capability even at its baseline level. In the year prior to the beginning of the Korean

\footnotetext{
${ }^{122}$ E. Mark, Aerial Interdiction: Air Power and the Land Battle in Three American Wars, Washington, D.C.: Center for Air Force History, 1994, pp. 261-322.

${ }^{123}$ W. T. Y'blood, MiG Alley: The Fight for Air Superiority, Washington, D.C.: Air Force History and Museums Program, 2000.

${ }^{124}$ Y'blood, 2002, p. 1.
} 
War, for example, FEAF squadrons conducted a grand total of only 14 CAS training sorties, of which only three were controlled from the ground. ${ }^{125}$

\section{CAS in Korea}

North Korea launched its invasion of the south on June 25, 1950, throwing the Republic of Korea Army into disarray and threatening the rapid reunification of the peninsula under Pyongyang's control. The USAF flew its first CAS sorties three days later, on June 28, marking the beginning of a major CAS effort that would entail over 123,000 sorties over the next three years. ${ }^{126}$

But as of June 1950, the FEAF had a total assigned strength of 553 aircraft, most of which were poorly suited to CAS. Nearly two-thirds of the aircraft, or 365 of them, were F-80C fighters that had recently replaced F-51 Mustangs in the FEAF fighter groups. ${ }^{127}$ In the early months of the war, most CAS sorties were flown by the F-80s carrying 5inch rockets and light bomb loads. ${ }^{128}$ Because the F-80 was too fragile to operate from forward airfields and required a very long runway at operational takeoff weight, the Air Force restricted F-80 operations to Japanese bases. ${ }^{129}$ Even when equipped with large external fuel tanks and a light load of stores, the F-80s flying CAS sorties were often limited to about ten minutes in the target area. This was often too brief even to find the target, let alone prosecute an effective attack. ${ }^{130}$

During the initial weeks of the war, U.S. and allied ground forces in Korea were scathingly critical of the CAS support provided by FEAF. ${ }^{131}$ The criticism was sufficiently severe that FEAF took the extreme step of converting fighter squadrons back to the F-51 Mustangs that had been used the previous year. ${ }^{132}$ The Mustangs were scraped together from Air National Guard units and storage facilities in the United States and ferried to Japan on an aircraft carrier. The urgency of the need was underscored by the fact that unit reconversions began on July 23, less than a month after the North Korean invasion on June $25 .^{133}$

\footnotetext{
${ }^{125}$ Y'blood, 2002, p. 1.

${ }^{126}$ K. F. Kopets, "The Close Air Support Controversy in Korea," in Jacob Neufeld and G. M. Watson, Jr., eds., Coalition Air Warfare in the Korean War, 1950-1953, Washington, D.C.: Air Force History and Museums Program, 2005, p. 122.

${ }^{127}$ Y'blood, 2002, p. 2.

${ }^{128}$ Y'blood, 2002, p. 2.

${ }^{129}$ Kopets, 2005, p. 123.

${ }^{130}$ Murray, 1990, p. 361.

${ }^{131}$ D.W. Boose, "The Army View of Close Air Support in the Korean War," in Jacob Neufeld and G.M. Watson Jr., eds., Coalition Air Warfare in the Korean War, 1950-1953, Washington, D.C.: Air Force History and Museums Program, 2005, pp. 99-121.

132 Y'blood, 2002, p. 3.

${ }^{133}$ Murray, 1990, p. 362.
} 
Though better suited to the CAS role than the F-80, the F-51 was by no means an ideal CAS aircraft. It had a longer range than the F-80 and could operate from Korean airfields and therefore enjoyed much greater endurance over target areas. However, it also had a reputation for vulnerability to ground fire, particularly due to a liquid-cooled engine that would not tolerate battle damage. ${ }^{134}$ As one historian notes,

Although the FEAF pilots were told that the change from F-80s to the F51 was necessary because the Mustang was a "better" ground attack aircraft, most held a jaundiced view of this rationale. One group history recorded, "A lot of pilots had seen vivid demonstrations of why the F-51 was not a ground support fighter in the last war and weren't exactly intrigued by the thought of playing guinea pig to prove the same thing over again." $" 135$

Inferior aircraft were, however, not the primary cause of the Air Force's limited CAS effectiveness in Korea. Much of the blame can be laid on Air Force doctrine. As air operations ramped up, FEAF put in place the familiar air-ground system defined in 1946 in FM 31-35, with air superiority receiving top priority, followed by interdiction, with CAS last. ${ }^{136}$ FEAF dutifully planned CAS missions deliberately, with ground units nominating target areas for coverage the following day. This allowed Air Force fighter crews to be briefed on the missions and also to plan deliberately at their airfields in Japan or, later, Korea.

But the CAS approach embodied by FM 31-35 was problematic in at least two ways. First, a centralized and deliberate approach to managing CAS was a poor fit for a highly dynamic United Nations ground force on the defense. While there certainly had been intense fighting in the European theater during World War II, the situation in Korea during the first year of the war there was significantly more fluid and perilous for U.S. ground forces. The need for rapid and dynamic CAS was correspondingly greater. ${ }^{137}$

Second, the effectiveness of the FM 31-35 approach was at least implicitly premised on the availability of large numbers of fighter aircraft that could be allocated to CAS even when air superiority and interdiction missions were taking place. Yet FEAF possessed just $187 \mathrm{~F}-51 \mathrm{~s}$ and $252 \mathrm{~F}-80 \mathrm{~s}$ when its buildup was essentially complete in February 1951. Given the fickle nature of early fighter jets and the distance from Japanese airfields to the front lines, the number of fighters available over potential target areas in Korea at any given point in time was normally quite modest. Air superiority and interdiction, meanwhile, consumed many sorties that might have been allocated to CAS.

\footnotetext{
${ }^{134}$ Murray, 1990, p. 363.

${ }^{135}$ Y'blood, 2002, p. 3.

${ }^{136}$ Murray, 1990, p. 363.

${ }^{137}$ Kopets, 2005, p. 124.
} 
From a ground commander's perspective, Air Force CAS sorties were too few in number and too slow to react to battlefield needs. ${ }^{138}$

Training deficiencies compounded the materiel and doctrinal shortfalls. At the start of the war, FEAF had no preexisting TACPs formed and assigned to Army units, as called for in doctrine. ${ }^{139}$ When these teams were hurriedly established and embedded with ground units, their equipment and communications systems proved inadequate. ${ }^{140}$ After becoming popular targets for the North Koreans, the TACPs were also restricted to the rear with Army regimental headquarters. This prevented them from directly controlling strikes. ${ }^{141}$ It took many months for Air Force TACPs to regain the competence that had been routine in 1945, because FEAF had not exercised their capabilities in peacetime.

Neither did FEAF possess the airborne FACs called for by doctrine. ${ }^{142}$ In the early weeks of the war, Air Force pilots attempted to use Army L-5 liaison aircraft for this role but found them more vulnerable in Korea than they had been in Europe. ${ }^{143}$ To its credit, FEAF adapted to this challenge by adopting the T-6 Texan training aircraft as the preferred platform for FAC duties, adopting the code name "Mosquito" to replace the ETO "Horsefly." Relying on Mosquitoes, FEAF formed the provisional 6147th Tactical Air Control Squadron in late summer 1950 to command the airborne FAC operations. ${ }^{144}$

TACPs and airborne FACs were not the only capabilities to have eroded between 1945 and 1950. The Air Force had also lost the knowledge needed to conduct nighttime airstrikes guided by radar beacons positioned along the forward trace of friendly ground forces, an operation conducted routinely in Europe in 1945, and did not rediscover the technique until November $1950 .{ }^{145}$ Proximity-fused bombs had to be reinvented by operational squadrons in Japan. ${ }^{146}$ Aircrews also discovered that the Air Force's 5-inch rockets flew a completely different trajectory than the subcaliber training rounds used in peacetime. ${ }^{147}$ And, most importantly, early CAS operations in Korea revealed that the USAF had already lost the USAAF connection to, and understanding of, ground operations, which had been the source of much of the success enjoyed by World War II leaders such as Generals Quesada and Weyland. ${ }^{148}$

\footnotetext{
${ }^{138}$ Murray, 1990, p. 361.

${ }^{139}$ Murray, 1990, p. 364.

${ }^{140}$ Murray, 1990, p. 364.

${ }^{141}$ Boose, 2005, p. 103.

${ }^{142}$ Murray, 1990, p. 364.

${ }^{143}$ Murray, 1990, p. 364.

${ }^{144}$ Murray, 1990, p. 364.

${ }^{145}$ Y'blood, 2002, p. 30.

${ }^{146}$ Y'blood, 2002, p. 31.

${ }^{147}$ Y'blood, 2002, p. 2.

${ }^{148}$ Boose, 2005, p. 104.
} 
The problems experienced by the Air Force during the early months of the Korean War might be excused as the normal frictions associated with the transition from peacetime to wartime were it not for the far greater effectiveness exhibited by Marine Corps CAS during the same time period. The Marine Corps retained the robust F4U Corsair aircraft in service throughout the interwar period and committed three squadrons to support the Marine brigade in Korea. ${ }^{149}$ The Corsairs sat alert near the front line and responded to calls for support within minutes, loitering for hours if necessary. ${ }^{150}$ The Marine brigade in Korea was provided with 14 Marine Corps TACPs, compared with just four Air Force TACPs allocated to each Army regiment. The Marine Corps communications systems worked effectively, because the Marines had routinely exercised the capability in peacetime. ${ }^{151}$ Marine Corps aircrews received thorough training for CAS, and the mission was their top priority in theater. ${ }^{152}$

At one point in the fighting, Marine Corps CAS (rather than Air Force CAS) was allocated to support the Army's X Corps. In the words of historian Williamson Murray,

The result was a four-week virtuoso performance in close air support. . . .

Marine air strikes arrived quickly and devastated NKPA defensive complexes, mobile formations, and artillery positions. More than half the Marine sorties came against targets only a half mile from the frontlines. It was the kind of close air support Marines expected, but it came as a revelation to the Army officers who shared the experience. ${ }^{153}$

When X Corps was subsequently instructed to revert to the Air Force CAS system, it refused. ${ }^{154}$ By November 1950, the Army Chief of Staff had lodged a formal complaint with the CSAF. ${ }^{155}$

\section{Findings and Implications}

The primary empirical finding in this chapter is that Air Force CAS capabilities stagnated during the period between 1945 and 1950. Generally speaking, this period was marked by significant Air Force innovation, including the widespread introduction of jet aircraft, the development of atomic strike capabilities, and the growth of new missions, such as continental air defense. Where CAS is concerned, however, the USAF did not

\footnotetext{
${ }^{149}$ F. H. Allison, "Black Sheep in Korea: A Reflection of Mission Transformation," in Jacob Neufeld and G. M. Watson, Jr. (eds.), Coalition Air Warfare in the Korean War, 1950-1953, Washington, D.C.: Air Force History and Museums Program, 2005, pp. 82-92.

${ }^{150}$ Murray, 1990, pp. 349-353.

${ }^{151}$ Kopets, 2005, p. 105.

${ }^{152}$ Murray, 1990, p. 367.

${ }^{153}$ Murray, 1990, p. 367.

${ }^{154}$ Murray, 1990, p. 370.

${ }^{155}$ Murray, 1990, p. 371.
} 
innovate or adapt significantly. In fact, its fighter units were significantly less capable of conducting effective CAS in 1950 than they had been in 1945.

The primary reason for this stagnation is that the Air Force chose to prioritize the innovation, adaptation, and readiness of other capabilities. This decision appears to have been implicit in nature. There is little evidence that the USAF or its MAJCOMs made any explicit or deliberate decisions to allow CAS capabilities to erode. The erosion appears, instead, to have been a byproduct of decisions to focus time, energy, and resources elsewhere. These tacit choices reflected at least implicit calculations of the capabilities most likely to be needed in future conflicts. They were, therefore, inherently strategic choices.

This case study has three important implications for the contemporary Air Force conversation on innovation. First, this case underscores that innovation cannot be defined in technological terms alone. In many regards, the aircraft fielded by the USAF between 1945 and 1950 were more technically capable than their predecessors - faster, higherflying, and equipped with more sophisticated mission systems. For the particular operational problem of CAS in Korea, however, the aircraft would prove less capable than predecessor aircraft. More importantly, the new aircraft were employed by combat organizations less capable in human terms, having forgotten crucial tactics and techniques and having failed to practice those that were remembered. Innovation and adaptation contain human and organizational factors as well as technological ones.

Second, this case underscores that Air Force innovation begins with strategy. The USAF of the late 1940s was an exceptionally innovative organization. It was manned by innovative airmen and possessed innovative technologies. Yet stagnation still occurred in CAS, with real tactical and operational impacts in the war the Air Force was asked to conduct in 1950. For the senior leadership of the Air Force, choosing the operational problems that will motivate and direct innovation is at least as important as making the organization innovative generally.

Finally, this case study highlights the greater complexity of innovation in multirole combat organizations. For a service in which combat organizations are predominantly single-role, it may be generally feasible to assess day-to-day operational capabilities by evaluating the readiness of each organization in its discrete, assigned mission. For a service in which most combat organizations are assigned multiple roles, however, assessing aggregate servicewide capabilities is more complicated. Such an assessment requires the service leadership to assess the choices being made about the relative prioritization among multiple assigned missions at lower unit levels, in MAJCOMs, and within the combat organizations themselves. This is certainly possible to do, but the potential for unintentional stagnation is unquestionably greater. In a service comprising multirole combat organizations, it may be particularly important for the service leadership to communicate strategic priorities clearly and forcefully to the MAJCOM and 
unit levels. As the Air Force continues to shift toward multirole platforms and multirole combat organizations, it will increasingly require such clarity and consistency of purpose. 


\section{Nuclear Deterrent Survivability (1950-1957)}

A furious pace of military innovation characterized the decade and a half following the end of World War II. The advent of jet-powered aircraft, the atomic bomb, thermonuclear weapons, and guided and ballistic missiles were all genuinely revolutionary developments for air power, and for U.S. national security and the international system as well. The origins and consequences of each of these developments have been the subjects of many histories; this chapter focuses on one of the implications of these developments and how the United States and, in particular, the USAF adjusted to it: the possibility of nuclear attacks against forces and bases that had never before faced serious threats to their survival. ${ }^{156}$

\section{Strategic Discontinuity}

During World War II, the USAAF quickly grew from an underdog - taking heavy losses in combat against the battle-hardened German and Japanese air services and struggling to live up to a prewar vision of bringing victory through the application of innovative capabilities - into the world's most modern and powerful air force, laying waste to the Axis powers. With the end of the war came the beginning of the nuclear revolution and of an American monopoly on atomic weapons that seemed to promise even greater military preeminence in the postwar years in spite of the size and might of the Soviet Army.

It was expected that the Soviet Union would eventually develop its own nuclear arsenal, perhaps in a decade, but the first Soviet A-bomb test, in 1949, came as a rude shock to the West. Strategists - foremost among them historian Bernard Brodie - had already begun to contemplate the implications of the nuclear revolution, arguing that, in the atomic age, the fundamental purpose of military power must be to prevent a world war even more horrible than the last. ${ }^{157}$ As early as 1946, Brodie had proffered the idea that

\footnotetext{
${ }^{156}$ For an overview of the development of U.S. nuclear strategy, see Lawrence Freedman, The Evolution of Nuclear Strategy, 3rd edition, London: Macmillan, 1983; Steven E. Miller, ed., Strategy and Nuclear Deterrence, Princeton, N.J.: Princeton University Press, 1984; or, more concisely, Karl P. Mueller, "Strategic Airpower and Nuclear Strategy: New Theory for a Not-Quite-So-New Apocalypse," in Phillip S. Meilinger, ed., The Paths of Heaven: The Evolution of Airpower Theory, Maxwell AFB, Ala.: Air University Press, 2000, pp. 279-320.

${ }^{157}$ Barry H. Steiner, Bernard Brodie and the Foundations of American Nuclear Strategy, Lawrence, Kan.: University Press of Kansas, 1991.
} 
the first and most vital step in any American security program for the age of atomic bombs is to take measures to guarantee to ourselves in case of attack the possibility of retaliation in kind. . . . Thus far the chief purpose of our military establishment has been to win wars. From now on its chief purpose must be to avert them. It can have almost no other useful purpose. ${ }^{158}$

The bedrock of nuclear deterrence would be building the capability to strike back at an attacker with such powerful retaliation that starting a war would appear prohibitively costly to a prospective aggressor. Not only would a nation that could be disarmed by an enemy who struck first risk losing a war through a surprise attack, it might well invite such an attack because of its vulnerability. ${ }^{159}$

The problem of survivability was one that the USAAF had never had to face to a serious degree. By 1943 — when the American bombing of Germany was just getting under way - enemy attacks on U.S. air bases had become a rarity. ${ }^{160}$ The bombing campaigns against Germany and Japan were conducted from networks of bases and supporting infrastructure that became vast systems for generating sorties, with little direct interference from the enemy.

Atomic weapons changed the picture, since a single bomber carrying one could potentially destroy a major airbase just as it could raze the heart of a city. The problem was exacerbated in the $1950 \mathrm{~s}$ by the coming of the hydrogen bomb. The vastly greater destructive power of thermonuclear weapons meant that a detonation anywhere in the general vicinity of a base or other installation could destroy it. The H-bomb also made building long-range ballistic missiles militarily feasible: Early long-range missiles were not very accurate, but thermonuclear warheads produced such a wide swath of destruction that they could be effective weapons anyway. Ballistic missiles, in turn, compounded the military vulnerability problem by making it possible for their owners to launch a powerful long-range attack even against a state with a far superior air force.

Thus, in the 1950s, the U.S. Air Force faced a mounting problem of potential vulnerability to a Soviet nuclear attack. Strategic logic dictated that maintaining the power of the U.S. nuclear deterrent required countering this new peril. There were multiple possible responses, but seriously addressing the possibility of enemy attack against U.S. airpower represented a profound change in outlook and behavior for airmen who had always before been able to operate from bases essentially beyond the enemy's

\footnotetext{
${ }^{158}$ Bernard Brodie, The Absolute Weapon, New York: Harcourt, Brace, 1946, p. 76 (quoted in Bernard Brodie, "The Development of Nuclear Strategy," International Security, Vol. 2, No. 4, 1978, p. 65.

${ }^{159}$ For a general discussion, see Karl P. Mueller, Jasen J. Castillo, Forrest E. Morgan, Negeen Pegahi, and Brian Rosen, Striking First: Preemptive and Preventive Attack in U.S. National Security Policy, Santa Monica, Calif.: RAND Corporation, MG-403-AF, 2006.

${ }^{160}$ The most prominent exception to this pattern was Operation Bodenplatte, a wave of Luftwaffe surprise attacks launched against U.S., British, and Canadian fighter bases in Belgium, the Netherlands, and France on January 1, 1945, in which several hundred Allied aircraft were destroyed.
} 
reach. ${ }^{161}$ At the strategic level, this predicament prompted what could be described as a macro-level innovation, if not the most fundamentally innovative development in U.S. airpower during the early Cold War.

\section{Coming to Terms with Vulnerability}

Even in revolutions, there is continuity. The Air Force of 1950 was a newly minted armed service, whose existence revolved around a weapon - the atomic bomb - that had not existed ten years earlier. ${ }^{162}$ Yet the Air Force resembled its wartime predecessor in many ways. The giant Convair B-36 Peacemaker bomber had entered service in 1949 , but the B-36 was not altogether a product of the atomic age. Rather, it represented a further incremental step (albeit an impressive one) along the path that had previously led to the Boeing B-29 Superfortress, initially designed to meet a requirement from early 1941 for a very long-range bomber that could strike Europe from continental U.S. bases in the event that Germany were to defeat Great Britain.

Strategic Air Command (SAC) war plans were also firmly rooted in history. When General Curtis LeMay replaced George Kenney as commander-in-chief of SAC in 1948, he found (but rejected) a targeting effort focused on identifying key industrial sectors in the Soviet Union for potential attack, including electric power generation - a strategy very reminiscent of the planning for strategic bombing of Germany in 1942. ${ }^{163}$

\section{Rise of the Analysts}

In 1950, CSAF Gen Hoyt Vandenberg and Vice CSAF Gen Lauris Norstad persuaded Brodie, then the dean of U.S. nuclear strategy experts, to come from Yale University to the Pentagon to review SAC's nuclear war plans. Brodie was appalled at the lack of strategic thinking he found represented in them. SAC was planning to fight a future war against the U.S.S.R. by launching an all-out strike with as many aircraft and weapons as possible. Brodie argued that it was not inflicting the greatest possible damage against the Soviets at the outset of a conflict that would pressure them to capitulate in a war, but threatening more damage in the future if they did not surrender, and he therefore recommended a more restrained approach that would not seek to annihilate Russia's

\footnotetext{
${ }^{161}$ Many readers will note a marked parallel between this situation and the one currently facing U.S. military planners in the Pacific, where growing Chinese long-range strike capabilities now pose risks of powerful missile attack against U.S. bases that until recently were regarded as being essentially invulnerable.

${ }^{162}$ On the early development of the USAF bomber force, see Walton S. Moody, Building a Strategic Air Force, Washington, D.C.: Air Force History and Museums Program, 1995.

${ }^{163}$ LeMay's lack of enthusiasm for this approach to strategic targeting also echoed his preferences in the Second World War, when he recast the USAAF bombing strategy against Japan after taking command of the XXIst Bomber Command in the Pacific to focus on area bombing of cities.
} 
cities at the outset of a war, instead holding them hostage for subsequent leverage. The suggestion of such restraint often met with incredulous responses from Air Force officers accustomed to thinking in terms of targets destroyed at the operational level rather than larger effects at the strategic level. ${ }^{164}$

In late 1950, General Norstad was transferred to Europe to take command of U.S. Air Forces in Europe (USAFE). Brodie, less popular with the other Air Staff generals, departed the Pentagon the following spring, his plans to chair a Special Advisory Panel on Strategic Bombing Objectives having been canceled. ${ }^{165}$ Brodie ended up at the RAND Corporation, where he would spend the next 15 years.

As mentioned in Chapter 2, RAND had been established in 1946 at the behest of USAAF chief Gen H. H. "Hap" Arnold, who was concerned that, with the end of the war, the academic experts upon whom the U.S. military had come to depend heavily over the preceding four years would return to their campuses and laboratories, just as the Air Force was going to have to wrestle with a raft of challenging intellectual problems presented by the dawning of the nuclear age. Initially set up at the Douglas Aircraft Corporation as Project RAND, the RAND Corporation became an independent think tank in 1948, comprising an interdisciplinary group of physical and social scientists and engineers conducting research and analysis for the Air Force. ${ }^{166}$

The organization would take center stage in the consideration of Air Force vulnerability to a Soviet nuclear attack once a study of that subject was launched in 1952, ordered by Maj Gen Harold R. Maddux, chief of the Air Base Division of the Office of the Deputy Chief of Staff for Operations. Albert Wohlstetter led the project. He and his colleagues found that USAF planning for a war with the Soviet Union was making no allowances for the possibility that the Soviets would try to prevent the United States from carrying out an attack at its leisure.

According to SAC's plans of the early 1950s, it would go to war in the late 1950 s with a force of slightly fewer than 2,000 bombers, more than 80 percent of which would be medium-range B-47 Stratojets. The plan called for forward deploying these aircraft from the United States to 82 bases (many at the time yet to be constructed) around the Soviet periphery, where they would be armed, fueled, and prepared for operations, with the attack beginning on the order of a week after the operation began. All of the bases were within range of Soviet Tu-16 Badger medium-range bombers, and even shorterrange Soviet aircraft could reach one third of the bases. Many of the bases had no early warning radar coverage to warn of an incoming attack during the prolonged period while

\footnotetext{
${ }^{164}$ Fred Kaplan, The Wizards of Armageddon, New York: Simon and Schuster, 1983, pp. 45-48.

${ }^{165}$ Kaplan, 1983, p. 49.

${ }^{166}$ The first study published by Project RAND was a study of the potential uses of artificial satellites, Preliminary Design of an Experimental World-Circling Spaceship, 1946.
} 
the U.S. bombers would be staging for their own attack. SAC was assuming that its aircraft would suffer no losses on the ground, but Wohlstetter's team calculated that the Soviets, by delivering 12040 -kiloton atomic bombs against these forward bases in a preemptive strike, could destroy about 80 percent of the B-47s before they could launch their strike against the U.S.S.R. ${ }^{167}$

The RAND team compared SAC's existing scheme to two alternative concepts of operation (CONOPs), based either on striking directly from U.S. bases and relying on aerial refueling or landing only briefly at hardened overseas bases to refuel en route to the targets. The team concluded that, because the tanker force required for the former option would be very expensive, the latter one would be the most cost-effective. The results were assembled by early 1953 into a briefing, which Wohlstetter presented scores of times to different audiences in the Air Force.

Responses varied. The Air Force installations command was staunchly opposed to the idea of redesigning the overseas basing plan. SAC reaction was mixed: On one hand, it was hostile to outsiders interfering in its domain; but on the other hand, the RAND recommendations were generally consistent with General LeMay's desire for investment in longer-range B-52 bombers and new KC-135 tankers to reduce U.S. dependence on the cooperation of other, potentially unreliable countries to execute its war plans. ${ }^{168}$

Official Air Staff approval of the project's report hinged on an ad hoc committee coming to consensus in support of it. When this consensus failed to materialize, a protocol-violating meeting was engineered in which Wohlstetter presented the results directly to the Acting CSAF, Gen Thomas D. White, who was persuaded by the analysis and pushed the issue forward. By the end of the year, he and Secretary of the Air Force James A. Douglas Jr. had approved a directive that included instructions that base vulnerability be formally taken into account in all Air Staff planning, that bases be hardened against atomic attack, and that new overseas bases be designed and built as minimal-footprint, hardened refueling locations. ${ }^{169}$

\section{Implementing Survivability}

In the end, despite this bureaucratic coup de main, a number of the programmatic recommendations were overtaken by events and never implemented. The 1953 test of the first Soviet $\mathrm{H}$-bomb called into question the idea that even hardened overseas refueling bases would be able to survive in a future conflict involving such powerful weapons. Meanwhile, in an impressive example of bottom-up innovation, a planner at McDill Air

\footnotetext{
${ }^{167}$ Kaplan, 1983, pp. 98-99.

${ }^{168}$ Kaplan, 1983, pp. 102-103.

${ }^{169}$ Kaplan, 1983, pp. 104-106. White was Acting CSAF because General Vandenberg was terminally ill and hospitalized.
} 
Force Base in Florida, following an instruction during an exercise to draw up a plan for intercontinental medium-bomber operations, developed a new CONOP for the B-47. This CONOP entailed flying missions directly from the United States using tanker support and then recovering to overseas bases after the strike. ${ }^{170}$ This would eliminate the window of vulnerability to a Soviet strike en route to the bombers' targets even while SAC remained reliant on the relatively short-range B-47s for the bulk of its striking power.

General LeMay would always see launching a U.S. preemptive attack as the best way to deal with the threat of a Soviet nuclear strike, and he believed there would be sufficient warning to make this possible. ${ }^{171}$ In 1957, he famously told Robert Sprague, vice chairman of the Gaither Commission to study U.S. civil defense, that he planned to launch a nuclear first strike if he saw the Soviets preparing to launch an attack. When Sprague argued that this was contrary to national policy, LeMay replied, "It's my policy. That's what I'm going to do." ${ }^{172}$ It was therefore unsurprising that LeMay was not interested in the recommendation of a subsequent Wohlstetter-led RAND study, which proposed that the Air Force should build hardened underground shelters to protect its bombers at their bases. For LeMay, the shelters were superfluous to a first strike.

General LeMay treated the newly official recognition of potential losses because of enemy action, embodied in the 1953 directive from General White, as a justification to request greater investment in B-52s and $\mathrm{KC}-135 \mathrm{~s}$ to offset potential attrition. The B-52 Stratofortress had been in the works as a successor to the B-36 since late 1945, with the early design goal of "carrying out the strategic mission without dependence upon advanced and intermediate bases controlled by other countries," although the design would evolve dramatically before it stabilized in $1948 .{ }^{173}$ The KC-135 was similarly intended to replace a slower, piston-engine predecessor, the $\mathrm{KC}-97$; the program to develop the KC-135 began in 1954. To LeMay and SAC, these aircraft were, first and foremost, means of increasing SAC's offensive striking power and strategic flexibility. Yet by enabling large-scale nuclear attacks against the Soviet Union from bases in the continental United States, they also contributed heavily to the creation of a robust second-strike deterrent capability.

\footnotetext{
${ }^{170}$ Kaplan, 1983, p. 108.

${ }^{171}$ Nor was LeMay alone in his vision of applying decisive force against the U.S.S.R. In a 1954 speech, USAF Chief of Staff General Nathan Twining declared, "We can now aim directly to disarm an enemy rather than to destroy him as was so often necessary in wars of the past." (Quoted in Robert Frank Futrell, Ideas, Concepts, Doctrine: Basic Thinking in the United States Air Force, 1907-1960, 1989, pp. 433-434.

${ }^{172}$ Kaplan, 1983, pp. 133-134.

${ }^{173}$ Marcelle S. Knaack, Post-World War II Bombers, 1945-1973, Washington, D.C.: Office of Air Force History, 1988, pp. 205-215. General LeMay played a central part in defining the requirements for the program as Deputy Chief of Air Staff for Research and Development, prior to his assignment as commander of USAFE in 1947.
} 
By the late 1950s, SAC's nuclear force looked quite different from its force structure ten, or even five, years earlier. Intercontinental-range B-52 jet bombers began entering service in 1955 (toward a total production run of over 700 by 1961), followed two years later by the first of hundreds of KC-135 tankers. In late 1958, SAC began its first flights under Operation Head Start, in which a small number of armed B-52s were maintained on rotating 24-hour airborne alert to assure that even a successful surprise attack could not catch all of the bombers on the ground. ${ }^{174}$ In 1959, the Air Force's Atlas intercontinental ballistic missile (ICBM) entered service, followed in 1961 by the Navy's Polaris submarine-launched ballistic missile (SLBM), carried by a growing force of nuclear-powered ballistic missile submarines. ${ }^{175}$

Survivability would continue to be a driving consideration in the evolution of the U.S. nuclear arsenal in the years that followed, with ICBMs moving into nuclearhardened underground silos. Soon, the Kennedy administration would embrace the principle of nuclear sufficiency, reining in the rate of growth of the strategic nuclear arsenal on the grounds that the deterrent effect of a survivable second-strike retaliatory capability powerful enough to assure effective destruction of the U.S.S.R. following a Soviet first strike would not be substantially improved by making the force larger.

\section{Leadership and Innovation}

The Air Force response to the vulnerability of the bomber force involved a variety of agents - insiders and outsiders, acting from above and below. Wohlstetter and the other RAND analysts framed the problem and campaigned with impressive energy to call attention to what they had found, in spite of resistance from entrenched interests in the USAF. It is also noteworthy that there were voices at SAC, including General LeMay, raising the issue of vulnerability in parallel, albeit primarily as a rationale for building larger and more capable bomber and tanker forces. The systems that General LeMay most actively championed, the B-52 and $\mathrm{KC}-135$, would provide the basis for the airbreathing leg of the strategic nuclear triad for the subsequent three decades, and indeed beyond.

Senior Air Force leaders beyond SAC played a major part in the story as well. This is most obvious, and most direct, in the case of General White's October 1953 directive accepting the RAND analysis over the objections of its opponents and directing that the Air Force redesign its basing posture and concept of operations to reduce vulnerability.

\footnotetext{
${ }^{174}$ Operation Head Start I and II were airborne-alert, proof-of-concept operations flown, respectively, from Loring AFB, Maine, in 1958, and Fairchild and Ellsworth AFBs in 1959. These were followed by other airborne-alert operations, including Operations Steel Trap I and II and Operation Chrome Dome (The SAC Alert Program, 1956-1959, Historical Study No. 79, Headquarters, Strategic Air Command, 1960).

${ }^{175}$ The of the last B-36s were retired in 1959; the B-47 continued to serve as a bomber until 1965 (Knaack, 1988).
} 
Actions by earlier visionary Chiefs of Staff also stand out, as when Generals Norstad and Vandenberg enlisted Brodie to examine Air Force war plans with an outside expert's eye. $^{176}$

\section{Evaluating the Outcome}

It is common when discussing military innovations to classify their outcomes as successes or failures, or sometimes a combination of the two, but in this case, it is difficult to reach a clear summary assessment. (This is true, even making allowances for misperceptions of Soviet military capabilities at some points in the story and recognizing that survivability was a moving target in the 1950s, as developments in nuclear warheads and delivery systems made it progressively more difficult to avoid being damaged by an attack but also easier for a small surviving force to inflict a powerful retaliatory strike.)

Ultimately, the U.S. nuclear force did achieve survivability. The nuclear triad that became familiar in the second decade of the Cold War-ICBMs in hardened underground silos, ballistic missile submarines that were essentially invisible on patrol, and strategic bombers ready for quick takeoff (or sometimes on airborne alert) - emerged in the early 1960s. With diverse basing modes and hardening against nuclear strikes, this force was never vulnerable to anything close to being disabled by a Soviet first strike. ${ }^{177}$ Yet even before the 1960 s — certainly by 1957 - SAC had successfully deployed a strategic nuclear deterrent force that Soviet nuclear bombers and missiles could not realistically hope to degrade decisively in a first strike (although because intelligence information about the very limited state of Soviet intercontinental strike capabilities was closely held, few Americans were sanguine about the relative invulnerability of SAC, setting aside the possibility that the Soviet long-range arsenal would expand in the future).

What is less clear is the extent to which there ever was meaningful U.S. strategic vulnerability earlier in the 1950s. Even at its most vulnerable, when a preemptive Soviet attack might in theory have reduced SAC to a relative handful of bombers at forward bases and a small number of B-36s flying from the continental United States, a U.S. second strike could have been expected to deliver scores or hundreds of nuclear weapons against the Soviet Union. Would Moscow have seen the retaliatory potential of these residual forces as small enough to make launching a first strike an acceptable option

\footnotetext{
${ }^{176}$ Other RAND analyses also played important roles in shaping related USAF innovations during this period. A noteworthy example was modeling, which determined that the accuracy requirements initially specified for the Atlas missile program were unnecessarily demanding; adjusting these requirements accelerated the development and service entry of the first U.S. ICBM system (Kaplan, 1983, pp. 113-117).

${ }^{177}$ Whether either side's nuclear retaliatory capabilities were vulnerable to being disabled through attacks against strategic command and control is a separate question that we will not delve into here. See Bruce G. Blair, Strategic Command and Control: Redefining the Nuclear Threat, Washington, D.C.: Brookings Institution Press, 1984.
} 
under any plausible circumstances? At the time, U.S. leaders appeared to find the possibility of even a very small Soviet nuclear attack against North America to be powerfully deterrent, far more than many strategists' calculations might have expected. ${ }^{178}$ Even with the benefit of post-Cold War reminiscences from Soviet decisionmakers, the answer must remain largely speculative. However, it is certainly clear that U.S. leaders and airmen saw the risk as not merely real, but severe and urgent, and ultimately did innovate to address it.

${ }^{178}$ Richard K. Betts, Nuclear Blackmail and Nuclear Balance, Washington, D.C.: Brookings Institution Press, 1987. 


\section{Suppression of Enemy Air Defenses (1965-1985)}

This chapter describes the USAF's efforts to develop solutions to the operational problems posed by Soviet integrated air defense systems (IADS). It examines four periods. The first is the interwar era between the Korean and Vietnam Wars, when the strategic and tactical communities in the Air Force approached the problem in different ways. The second is Operation Rolling Thunder, the air campaign over North Vietnam from early 1965 to late 1968, when the USAF Tactical Air Force (TAF) fighter units stationed in Thailand tried to solve the operational problems created by Soviet proxy IADS north of the 17th parallel. The third is Operation Linebacker, a 1972 air campaign that marked the first continuous bombing effort against North Vietnam since Operation Rolling Thunder. The fourth is the post-Vietnam era of the late 1970s through the mid1980s, when the Air Force sought to counter increasingly capable Soviet IADS in Europe.

The chapter utilizes primary and secondary sources to describe Air Force efforts to innovate and adapt in response to evolving Soviet and North Vietnamese capabilities. The conclusion extracts several generalizable insights for the contemporary Air Force innovation conversation.

\section{The Air Force and the IADS Problem Before Vietnam}

The USAAF first confronted integrated air defenses during World War II. The Luftwaffe's radar, fighter, and antiaircraft artillery (AAA), or "flak" units, imposed substantial losses on the 8th Air Force during the Combined Bomber Offensive. ${ }^{179}$ Axis air defenses over Italy and Japan were less powerful but nevertheless significant. ${ }^{180}$ The USAAF countered these defenses with a mix of escort fighters and electronic warfare techniques applied during individual raids on Axis targets. ${ }^{181}$ This raid-centric approach met with distinctly limited success until the final months of the war, when attrition largely drove Axis air arms from the skies. ${ }^{182}$

\footnotetext{
${ }^{179}$ K. P. Werrell, Archie to SAM: A Short Operational History of Ground-Based Air Defense, Montgomery, Ala.: Air University Press, 2005, pp. 24-41.

${ }^{180}$ S. J. Zaloga, Defense of Japan: 1945, London: Osprey, 2010; B. R. Sullivan, "The Downfall of the Regia Aeronautica," in R. Higham and S. J. Harris, eds., Why Air Forces Fail: The Anatomy of Defeat, Lexington, Ky.: University Press of Kentucky, 2006; Werrell, 2005, pp. 53-57.

${ }^{181}$ W. F. Craven and J. L. Cate, eds., The Army Air Forces in World War II: Europe, Volume Two: Torch to Point Blank, Washington, D.C.: Office of Air Force History, 1983, pp. 694-969; Werrell, 2005, pp. 4348.

${ }^{182}$ Werrell, 2005, pp. 42-45.
} 
In Korea, the IADS problem was less severe than it had been in the World War II ETO. North Korean and Chinese air defenses were capable but localized, particularly along the Yalu River and in a Chinese airbase cluster near Antung. ${ }^{183}$ The USAF responded to the challenge with fighter sweeps and "flak-busting" in the context of individual raids. ${ }^{184}$ B-29 raids employed limited electronic warfare. ${ }^{185}$ In general, the USAF's approach reflected a continuation of the raid-centric approach from World War II: temporary neutralization of air defenses in support of a discrete strike package.

The IADS threat began to grow in the late 1950s as the Soviets developed integrated point defense systems for key strategic targets in the homeland. ${ }^{186}$ These air defense systems combined early warning, target acquisition, and engagement radars with landline communications to create an integrated capability to track and engage high-altitude U.S. strategic bombers. The engagement element of the system included a range of AAA guns from small-caliber, low-altitude, rapid-fire weapons to large-caliber, high-altitude, radarguided cannon. ${ }^{187}$ Soviet Air Defense Forces also fielded radar-guided surface-to-air missiles (SAMs), introducing the SA-1 in 1956 and the SA-2 in $1958 .{ }^{188}$ New types of fighters, fielded at an impressive rate, complemented the AAA and SAMs. The MiG-15 day fighter was introduced in 1949, followed by an improved "bis" version in 1950, the MiG-17 in 1952, the MiG-19 in 1955, and the MiG-21 in $1958 .{ }^{189}$ The first Soviet jet allweather interceptors, Sukhoi Su-9s, were fielded in 1959. ${ }^{190}$

These developments did not escape the notice of SAC. Its preferred solution to the Soviet IADS problem in the late 1950s was to fly bombers high and fast, protecting them with radar jammers and chaff. ${ }^{191}$ The B-47, fielded in the early 1950s, was equipped with three types of jammers. ${ }^{192}$ The B-52, fielded in 1955, was equipped with two radar-

\footnotetext{
${ }^{183}$ James T. Quinlivan, Soviet Strategic Air Defense: A Long Past and an Uncertain Future, Santa Monica, Calif.: RAND Corporation, P-7975, 1989, p. 8.

${ }^{184}$ Y'blood, 2000.

${ }^{185}$ D. T. Kuehl, The Radar Eye Blinded: The USAF and Electronic Warfare, 1945-1955, Ph.D. dissertation, Duke University, 1992.

${ }^{186}$ Quinlivan, 1989, p. 10.

${ }^{187}$ See Central Intelligence Agency, National Intelligence Estimate 11-3-65, Soviet Strategic Air and Missile Defenses, Document C00278469, November 18, 1965, declassified by CIA Historical Review Program, 1965.

${ }^{188}$ Quinlivan, 1989, p. 9.

${ }^{189}$ Bill Gunston, The Encyclopedia of World Air Power, New York: Crescent, 1987, pp. 210-214.

${ }^{190}$ Quinlivan, 1989, p. 9.

${ }^{191}$ Until 1957, SAC also planned to employ escort fighters. See Robert J. Boyd, SAC's Fighter Planes and Their Operations, Office of the Historian, Strategic Air Command, August 1, 1988. And, of course, SAC was also fielding its first ICBMs during this period. The first Atlas unit was declared operational in September 1959; see Jacob Neufeld, The Development of Ballistic Missiles in the United States Air Force, 1946-1960, Washington, D.C.: Office of Air Force History, 1990, p. 208.

${ }^{192}$ The AN/ALT-7, AN/ALT-6A, and AN/ALT-8. See M. Streetly, Airborne Electronic Warfare: History, Techniques, and Tactics, London: Janes, 1988, p. 34.
} 
warning receivers, tail-warning radar, chaff dispensers, and more than a dozen jamming transmitters. ${ }^{193}$ The B-58, fielded five years later, carried a radar-warning system, chaff dispensers, and a radar-tracking jammer that used a new "range gate pull-off" approach to breaking lock. ${ }^{194}$ To operate the electronic warfare systems onboard the bombers, SAC developed a robust electronic warfare community and exercised the capability regularly. ${ }^{195}$ In 1959, the command began experimenting with low-altitude penetration tactics, which would negate much of the Soviet air defense system by significantly shortening surveillance radar range, flying under the SA-2's minimum altitude, and exploiting the lack of a "look-down" radar on Soviet interceptors. ${ }^{196}$ What is clear, then, is that during the late $1950 \mathrm{~s}$, SAC was focused on the emerging IADS problem and was adapting and innovating against it. SAC's approach remained, however, raid-centric.

The Navy and Marine Corps were also paying attention to the Soviet IADS problem. From 1940 onward, naval task forces had been exposed to IADS equipped with radars, guns, and, in 1961, the Soviet SA-N-1 Goa ${ }^{197}$ To deal with this threat, the Navy operated EA-3B electronic warfare aircraft, while the Marine Corps operated EF-10B escort jamming aircraft equipped with internal jammers. ${ }^{198}$ Naval air forces also developed radar-warning receiver and electronic countermeasure (ECM) pods to be carried by strike aircraft, an innovation the USAF declined to pursue. ${ }^{199}$ Perhaps most notably, the Navy developed the AGM-45 Shrike antiradiation missile (ARM) beginning in $1957 .{ }^{200}$ The USAF declined to develop an ARM.

Given the intense focus at SAC and in the naval air forces, it is notable that the USAF TAF - consisting of the Tactical Air Command (TAC), Pacific Air Forces (PACAF), and U.S. Air Forces in Europe (USAFE) — all but ignored the IADS problem during the late 1950s and early 1960s. The primary focus of the TAF at this time fell on the counter-air mission, in its day-fighter and interceptor variants, and on the low-level toss bombing of free-fall nuclear bombs. To the extent that the TAF was focused on the IADS problem at all, it was in the nuclear delivery mission, and so TAF aircrews were trained to simply

\footnotetext{
${ }^{193}$ The AN/APR-9 receiver, AN/APR-14 receiver, AN/APS-54 radar, AN/ALE-1 dispensers, and AN/ALT-6B jammers. See Streetly, 1988, p. 34.

${ }^{194}$ Streetly, 1988, p. 34. Range gate pull-off fed erroneous range data to the tracking radar by recording its signal and sending a return at the incorrect time interval.

${ }^{195}$ Kuehl, 1992.

${ }^{196}$ Quinlivan, 1989, pp. 11-12.

${ }^{197}$ See CIA, National Intelligence Estimate 11-10-69, Trends and Prospects in Soviet Maritime Activities, June 12, 1969, declassified by CIA Historical Review Program, 1994.

${ }^{198}$ On the EA-3B, see Streetly, 1988, p. 132. On the EF-10B, see A.M. Thornborough and F.B. Mormillo, Iron Hand: Smashing the Enemy's Air Defences, Somerset, UK: Patrick Stephens, Ltd., 2002, p. 26.

${ }^{199}$ Streetly, 1988, p. 35.

${ }^{200}$ F. Knemeyer, "Shrike's Forgotten Lessons," The China Laker: Newsletter of the China Lake Museum Foundation, Vol. 10, No. 4, Fall 2004.
} 
penetrate Soviet air defenses at very low altitudes. The jet fighters that the TAF introduced during this period, with the partial exception of the F-100 Super Sabre, were optimized for high-speed interception or penetration. ${ }^{201}$ They generally featured very high wing loadings and thus were poorly suited to maneuvering to evade ground-based air defenses. The TAF did write doctrine for electronic warfare and acquired a small number of ECM pods but did not exercise the capability, build a dedicated electronic warfare community, or deal with the IADS problem in operational planning or training. ${ }^{202}$ In sum, the TAF was unprepared to encounter sophisticated IADS in a conventional war setting.

\section{Adapting to the IADS Threat in Vietnam (1965-1968)}

The Johnson administration initiated Operation Rolling Thunder in March 1965 with the objectives of coercing the Hanoi regime in North Vietnam to halt support for the Viet Cong in South Vietnam and bolstering the morale of the regime in Saigon.

The initial weeks of Rolling Thunder raids were conducted against a moderate air defense threat. The USAF portion of Rolling Thunder relied primarily on tactical fighter wings operating from Takhli, Korat, and Udorn Royal Thai Air Force Bases. ${ }^{203}$ The air defenses fielded by the People's Army of Vietnam (PAVN) in early 1965 were relatively unsophisticated, limited to about 1,500 light and medium AAA guns. ${ }^{204}$ As a result, USAF strike aircraft were able to operate relatively safely at medium altitude. As a 7th Air Force assessment noted at the time, "Since the effective altitude limits of many of these weapons were below 5,000 feet, pilots had little difficulty in locating and using permissive flight envelopes. Only during the strikes themselves, when dictates of accuracy made descent in to the legal range of these weapons necessary, were hits taken with any regularity." 205

The threat began to intensify in April 1965, when the PAVN committed its MiG-15 and MiG-17 fighter force to the contest. The Soviets had delivered the MiGs to North Vietnam the previous August, but they were initially withheld from challenging U.S. strike packages. This changed on April 4, 1965, when two elements of MiG-17s engaged a package of USAF F-105 strike aircraft and downed two. ${ }^{206}$ PACAF responded with

\footnotetext{
201 These were the century series: F-100 Super Sabre dayfighter, F-101 Voodoo interceptor, F-102 Delta Dagger interceptor, F-104 Starfighter interceptor, and F-105 Thunderchief fighter-bomber. See Knaack, 1978, pp. 113-222.

${ }^{202}$ Kuehl, 1992, pp. 232-250.

203 The wing-level organization was not rationalized until 1966.

${ }^{204}$ Air Tactics Against NVN Air/Ground Defenses, Honolulu, Hawaii: PACAF Tactical Evaluation Directorate, Project CHECO, February 27, 1967, p. 2. Originally SECRET//NOFORN, declassified by AF/HOH IAW E.O. 13526 November 26, 2010.

${ }^{205}$ Air Tactics Against NVN Air/Ground Defenses, 1967, p. 2.

${ }^{206}$ Air Tactics Against NVN Air/Ground Defenses, 1967, p. 4.
} 
increased MiG combat air patrols (CAPs). USAF F-4C Phantoms downed the first MiG17 s on July $10,1965 .{ }^{207}$

The IADS problem in North Vietnam escalated dramatically during the summer of 1965. Leading up to this, the Soviets had begun to deploy the SA-2 Dvina (NATO code name Guideline) SAM battalions to North Vietnam in April. ${ }^{208}$ U.S. reconnaissance flights had revealed the construction activity in May, identified the location of a ring of SA-2 sites being built around Hanoi in June, and detected the SA-2's "Spoon Rest" search radar emissions in mid-July. ${ }^{209}$ The Johnson administration had decided not to strike the emerging sites because of fears of killing Soviet technicians and in the hope that the Soviets might prove unwilling to employ the weapons against American aircraft. ${ }^{210}$ But on July 23, USAF RB-66 electronic intelligence aircraft detected emissions from an SA-2 "Fan Song" tracking radar. On July 24, two SA-2 missiles engaged a flight of four F-4s on MiG CAP, destroying one of the aircraft. ${ }^{211}$

Three days later, in response to the downing, USAF units in Southeast Asia conducted a large-scale raid on two SA-2 battalions located outside the Hanoi perimeter. The strike package consisted of 46 F-105s supported by 56 other aircraft. With medium altitude now denied because of the SAMs, the F-105s reverted to TAF doctrine for major war, relying on very low-level penetration to the target, rapid low-level delivery of the ordnance, and low-level departure from the target area. The result was a debacle for the United States, with six F-105s lost to AAA batteries arrayed around the SA-2 sites. Adding insult to injury, the SAM sites were later determined to have been decoys. ${ }^{212}$

With the failure of the TAF's preferred low-level solution to the IADS problem, the USAF and the PAVN became locked in competing cycles of adaptation and innovation. USAF units in theater sought to adapt their tactics to the new threat, while USAF headquarters and acquisition organizations worked to develop new technical solutions. The Soviet and PAVN air defenders also adapted their tactics, while the Soviet government completed building out the North Vietnamese IADS. ${ }^{213}$ Within six months, the IADS encompassed 16 battalions of SA-2s; integrated early warning, surveillance,

\footnotetext{
${ }^{207}$ Air Tactics Against NVN Air/Ground Defenses, 1967, pp. 5-6.

${ }^{208}$ Air Tactics Against NVN Air/Ground Defenses, 1967, p. 27.

${ }^{209}$ Air Tactics Against NVN Air/Ground Defenses, 1967, p. 28.

${ }^{210}$ Air Tactics Against NVN Air/Ground Defenses, 1967, p. 28.

211 Air Tactics Against NVN Air/Ground Defenses, 1967, p. 29.

212 Jacob Van Staaveren, Gradual Failure: The Air War Over North Vietnam, 1965-1966, Washington, DC: Air Force History and Museums Program, 2002, pp. 165-167.

${ }^{213}$ Pacific Air Forces, USAF Tactics Against Air and Ground Defenses in SEA: November 1968-May 1970, Honolulu, Hawaii: PACAF Tactical Evaluation Directorate, September 25, 1970, originally classified SECRET, declassified by Air Force Declassification Office IAW E.O. 12958 on August 15, 2006.
} 
and engagement radars; and a Ground Control Intercept center at Kep to oversee countrywide air defense operations. ${ }^{214}$

The growing IADS threat presented an operational dilemma. As one report from late 1965 stated,

General war tactics have been developed around low altitude penetration of SAM-defended areas. This is a valid general war tactic, but does not automatically apply to a limited war. The difference in the two situations centers around the factors of geography. Intense AAA and small arms can be concentrated in a small area with relative ease. This represents a major threat to low flying aircraft in the defended area. This is the case in SEA. . . Some recent press releases have indicated that the SAM's in North Vietnam have been ineffective as air defense weapons when compared to conventional AAA. This is true in terms of aircraft destroyed, but does not reflect a true picture at all. The SAM exposure in many areas of North Vietnam initially dictated low altitude penetrations, resulting in losses to conventional weapons which would not have occurred had we been able to overfly at higher altitudes. Obviously a compromise [has] to be developed between the high and low altitude penetrations which would keep strike and reconnaissance aircraft above the conventional weapon envelopes and at the same time provide for escape in the event of a SAM engagement. ${ }^{215}$

The initial attempts to find a medium-altitude solution to the IADS problem revolved around the RB-66B/C electronic intelligence and ECM aircraft of the 41st Tactical Reconnaissance Squadron (TRS). Six RB-66s had been sent to Thailand in the spring of 1965, and these were reinforced quickly with another eight from stateside and USAFE units after the events of July. ${ }^{216}$ The RB-66s became important escorts for strike packages to jam early warning, acquisition, and guidance radars. However, the PAVN air defense radar operators adapted to the RB-66 by employing antijam techniques, jamming crossplots, and cross-communicating among different types of sensors in different areas. The 41st TRS soon found it necessary to employ multiple RB-66s in complex crossing tracks to have much hope of jamming all the necessary radars in the target area. ${ }^{217}$ It was not a robust solution.

In Washington, the Air Force leadership became involved immediately after the July 27 debacle. On August 13, CSAF Gen John McConnell formed the Dempster Commission-led by Brig Gen Kenneth Dempster, Director of Operational Requirements and Development at Headquarters Air Force (HAF) — to solve the SA-2 problem. Dempster's office oversaw the Quick Reaction Capability program, with authority to procure new equipment on accelerated timelines. After consulting with PACAF, the

\footnotetext{
${ }^{214}$ Air Tactics Against NVN Air/Ground Defenses, 1967, p. 10.

215 Air Tactics Against NVN Air/Ground Defenses, 1967, p. 7.

${ }^{216}$ Van Staveren, 2002, p. 196.

${ }^{217}$ Air Tactics Against NVN Air/Ground Defenses, 1967, pp. 4-15.
} 
commission recommended that the USAF procure Radar Homing and Warning Systems (RHAWSs), ECM pods, and Navy Shrike ARMs. These systems had already been developed by SAC and the Navy and therefore represented "off the shelf" technical solutions. More ambitiously, the Dempster Commission also called for the development of a dedicated SAM-hunting fighter called the Wild Weasel. ${ }^{218}$

The USAF initially chose the two-seater F-100F for the Wild Weasel program due to its durability, all-around aerodynamic performance, and availability in large numbers. The prototype Wild Weasel carried an AN/APR-25 RHAWS, an ALQ-71 ECM, the IR133 panoramic scan receiver, and the AN/APR-26 launch warning receiver. The prototype aircraft were modified on an accelerated schedule, test-flown at Eglin Air Force Base in Florida, and certified ready for deployment on November 19, 1965. Three days later, they arrived at Korat Royal Thai Air Force Base, where they were assigned to a detachment under the 6234th Tactical Fighter Wing. The Wild Weasel detachment developed a tactical approach in which a single Wild Weasel F-100F would team with four conventionally equipped F-105Fs for work against SAMs and AAA sites. The F$100 \mathrm{~F}$ Weasel would locate the air defense sites, mark them with rockets or cannon, and the F-105Fs would destroy them with conventional bombs.

The first confirmed destruction of an SA-2 site by a Wild Weasel occurred on December 22, 1965. Despite some early successes, it quickly became evident that the F$100 \mathrm{~F}$ was not the ideal platform for the Wild Weasel mission. In particular, it was much too slow to keep up with the F-105s, which made composite formations and tactics over an active air defense site very problematic. Additionally, the push to accelerate the deployment of the F-100s had unfortunate secondary consequences. For example, the wiring for the new components on the F-100F did not stand up well to the heat and humidity of Southeast Asia. ${ }^{219}$ As a result, the USAF continued to experiment with other aircraft for the Wild Weasel role. In January 1966, just a few weeks after the F-100F's first successful engagement, CSAF General McConnell approved the "Wild Weasel III" program to convert two-seater F-105Fs into Weasels to replace the F-100F "Weasel Is."

The Wild Weasel III F-105s were significantly more capable than the F-100F Wild Weasel Is. In addition to the radar warning and ECM systems carried by the F-100F, the F-105Gs were also equipped with the QRC-317, which detected whether a SAM launch was imminent and which U.S. aircraft in a formation was specifically being targeted. ${ }^{220}$ The F-105Gs also carried the AE-100 system, which depicted the location of radar emitters on the pilot's gun sight, allowing much quicker engagement of fleeting targets. Perhaps most importantly, the F-105Gs were equipped, from April 1966 onward, with the

\footnotetext{
${ }^{218}$ Van Staaveren, 2002, pp. 195-197.

219 Thornborough and Mormillo, 2002, p. 45.

${ }^{220}$ Thornborough and Mormillo, 2002, p. 50.
} 
Navy's AGM-45 Shrike ARM. As was the case with the F-100Fs, the F-105Gs worked in composite formations, now with two Wild Weasels accompanied by two F-105Ds carrying rockets and bombs to attack targets identified by the Weasels. These formations were more effective primarily because of the commonality of the F-105 airframe.

Despite the improved capabilities, the F-105Gs suffered heavy losses. The first five were deployed to Korat at the end of May 1966. A second batch of six followed in June. Ten of these 11 aircraft had been lost by mid-August, underscoring the dangers of prototyping a new capability in combat. ${ }^{221}$ Despite these heavy losses, the USAF ordered that 80 more F-105Fs be converted to F-105Gs in 1966 and $1967 .{ }^{222}$

The deployment of the Shrike-armed Wild Weasels marked a turning point in the adaptation-counteradaptation contest between the tactical fighter wings based in Thailand and the PAVN air defense system. Each side now posed a threat to the other, and each struggled to maintain the initiative by adapting quickly.

The competition surrounding the Shrike ARM was representative of this struggle. When the Shrike was fielded with F-105Gs in mid-1966, the missile proved very difficult to employ effectively. It required a distinctive maneuver to "cage" the missile sensor on the target radar. The Shrike was slower than the SA-2, shorter-ranged, and flew toward the target radar only as long as that radar was emitting. If the radar ceased emitting its signal, the Shrike would break lock and fly off course. As a result, the PAVN air defense crews quickly learned to employ their radars intermittently and, particularly, to turn off their radars when they detected the distinctive Shrike caging maneuver and the missile separation on their screens. To capitalize on this response, Wild Weasel aircrews began to carry unguided Zuni rockets and to routinely simulate the Shrike caging maneuver before launching a Zuni, fooling the PAVN aircrews into shutting off their radars for a time. PAVN crews eventually caught on to this trick and responded by mastering the technique of sharing data among radars, and different types of radars, to enable SA-2 shots at Wild Weasels with minimum exposure for any individual radar. The USAF achieved a more durable advantage in this contest in 1968, with the deployment of the AGM-78 Standard ARM, developed by the Navy and capable of continuing to the location of a target's radar even after it stopped emitting. ${ }^{223}$

During Operation Rolling Thunder, which lasted from March 1965 until November 1968, the Air Force displayed at least two types of adaptation. The immediate, sortie-bysortie adaptation of the aircrews based in Thailand sought to make maximum use of the technical tools available in theater. In a sense, this was a tit-for-tat competition between TAF aircrews and the PAVN air defense units. At the same time, the USAF leadership

\footnotetext{
${ }^{221}$ Thornborough and Mormillo, 2002, p. 51.

222 Thornborough and Mormillo, 2002, p. 49.

223 Thornborough and Mormillo, 2002, p. 84.
} 
sought to adapt to the challenge posed by the PAVN IADS by developing and procuring new technical tools. The Wild Weasel programs were the most prominent results.

It is interesting, however, that the adaptation at both levels of the USAF continued to focus on solving the Soviet IADS problem at the level of the individual raid. The idea of conducting a broader, strategic Suppression of Enemy Air Defenses (SEAD) campaign to neutralize the entire PAVN air defense system was not seriously considered, either in the field or at the HAF.

\section{Operation Linebacker (1972)}

Between 1968 and 1972, U.S. bombing over North Vietnam was limited. While U.S. aircraft were very active over South Vietnam, they conducted few strikes over the North. This changed in March 1972, when the PAVN launched its Easter Offensive into South Vietnam. In response, President Richard Nixon ordered a surge of TAC aircraft into bases in South Vietnam and Thailand and additional SAC B-52s to Guam. Large-scale strikes on targets in North Vietnam began in April and continued until October in a campaign called Operation Linebacker I. ${ }^{224}$

The measure/countermeasure contest between PAVN air defenses and U.S. defense suppression aircraft continued apace during Linebacker I. PAVN air defenses now consisted of more than 200 radar installations, 300 SAM sites, and several thousand AAA sites. ${ }^{225}$ Matched against them were F-105G Wild Weasels flying from bases in Thailand, Marine Corps jamming aircraft from Danang, and Navy jammers and strike aircraft aboard the ships of Task Force $77 .{ }^{226}$

The United States also implemented a number of new tactics during Linebacker I, including the use of F-4 "chaff bombers" to lay a corridor of aluminum strips five miles wide and up to 100 miles to the target, as well as mixed "hunter-killer" flights of F105Gs and F-4Es. The chaff effectively prevented PAVN radars from detecting aircraft in the strike package, but the chaff bombers themselves were quite vulnerable. ${ }^{227}$

The PAVN employed a spectrum of countermeasures, including MiG-21 interceptors, large numbers of decoy SAM sites, rapid switching among networked search and target acquisition radars, and the use of passive electronic receivers for surveillance and initial target acquisition. ${ }^{228}$ Perhaps most dangerously, the Soviets provided the PAVN with an

\footnotetext{
${ }^{224}$ A. J. C. Lavalle, ed., Airpower and the 1972 Spring Invasion, Washington, D.C.: Office of Air Force History, 1985, pp. 15-19.

225 Thornborough and Mormillo, 2002, p. 100.

${ }^{226}$ Lavalle, 1985, p. 26.

227 Thomas Withington, Wild Weasel Fighter Attack: The Story of the Suppression of Enemy Air Defences, Yorkshire, UK: Pen and Sword Press, 2008, p. 62.

228 Thornborough and Mormillo, 2002, p. 102.
} 
upgraded SA-2F, which incorporated a Moving Target Indicator and the capability to guide the missile optically from the launch site. ${ }^{229}$

When negotiations between the United States and North Vietnam resumed in October 1972, bombing in the North was again scaled back. When talks faltered in mid-December 1972, President Nixon ordered a series of "maximum effort" late-December raids against 34 strategic targets in North Vietnam, most in the Hanoi area, in an operation dubbed Linebacker II. ${ }^{230}$

In the two short months between the two Linebacker operations, both sides rushed to field new capabilities for the next round. The USAF deployed the new F-4C Wild Weasel IVs, and the Navy sent its first EA-6B Prowler electronic warfare aircraft. ${ }^{231}$ For its part, the PAVN deployed a new I-band radar, dubbed T-8209, and perfected techniques for using Fan Song tracking radars in passive mode to direct SA-2s toward the sources of airborne jamming. This created a crisis for the USAF because the jammers carried by B52 bombers could not block the new system. New tactics were immediately developed for employing Marine Corps EA-6As, which did have a system that could jam the new radar, and operating them in conjunction with large-scale chaff corridors and new versions of AGM-45 Shrike and AGM-78 Standard ARMs tuned to the new PAVN signal. These Marine Corps aircraft were flown to bases in Thailand in an emergency airlift. $^{232}$

The air defense suppression battles over Hanoi in late December 1972 were the most intense of the war. SAC's initial confidence in the ability of its B-52s to survive, relying primarily on their own jamming systems, was quickly shaken. On the first night of the Linebacker II raids on December 18, 1972, the USAF lost three B-52s, two were damaged, and a new F-111 was shot down over Hanoi. SAC B-52 crews, who employed the same ingress and egress routes on successive nights, insisted on tight turns away from their targets that masked the B-52 jammers. On the second night, the PAVN air defenses were minimal, and no B-52s were lost. On the third night, however, the USAF sent $99 \mathrm{~B}-$ 52 s from Guam, and eight were shot down. From that point, SAM launches and USAF losses declined quickly, as the PAVN stocks of SA-2s were being depleted. ${ }^{233}$

After 11 days of bombing, the North Vietnamese government agreed to return to the negotiating table, and Nixon halted Linebacker II. In all, 15 B-52s had been destroyed.

\footnotetext{
${ }^{229}$ Thornborough and Mormillo, 2002, p. 113.

${ }^{230}$ Wayne Thompson, To Hanoi and Back: The United States Air Force and North Vietnam, 1966-1973, Washington, D.C.: Air Force History and Museums Program, 2000, p. 243.

231 Thompson, 2000, p. 231.

232 Thornborough and Mormillo, 2002, p. 136.

233 Thompson, 2000, pp. 255-257.
} 
These were staggering losses that had major strategic and political ramifications. ${ }^{234}$ It is worth noting, however, that no F-105G Wild Weasels were lost during Linebacker II. ${ }^{235}$

In retrospect, Operation Linebacker I and II represented the apotheosis of the raidcentric approach to defeating Soviet IADS. Through remarkable creativity and adaptation U.S. aircrews managed to maintain a thin margin of advantage in the fierce measure/countermeasure competition with the Soviets and PAVN, but the nearly unsustainable B-52 losses signaled that Soviet IADS posed an enduring problem that required a broader solution.

\section{Innovating Against Soviet IADS (1975-1985)}

As the United States withdrew from Vietnam and entered a period of reduced defense budgets, the Soviet Union continued to upgrade its air defense capabilities. The Soviets modified the SA-2 to improve its low-altitude capabilities, including optical guidance, and deployed more shorter-range, low-altitude SA-3s as point defenses. ${ }^{236}$ The Soviets also fielded the MiG-23 and MiG-25 fighters, along with the Su-15 interceptor, which possessed a limited look-down/shoot-down capability. ${ }^{237}$ More important, perhaps, were Soviet developments in battlefield air defenses. During the late 1960s and 1970s, the Soviets deployed the SA-4 Ganef and SA-6 Gainful mobile SAMs, the SA-7 Grail manportable SAM, and the ZSU-23-4 mobile AAA system. Together, these systems greatly raised the threat facing low-altitude strike aircraft. The growing threat was highlighted by the Israeli experience in the 1973 October War, when Israeli A-4s and F-4s were unable to detect the engagement radar of SA-6s operated by Soviets and Egyptians. The SA-6 systems felled the majority of the 96 Israeli Air Force aircraft lost during the war. ${ }^{238}$

The 1973 Arab-Israeli War finally spurred the USAF to accelerate its efforts to innovate against the expanding IADS threat of the mid-1970s. One primary result was the USAF Pave Strike initiative. The strategic purpose of Pave Strike was to preserve the capability of Air Force strike aircraft to accomplish their mission against the Warsaw Pact's evolving IADS threat in Eastern Europe. Pave Strike included a series of programs, three of which were directly relevant to the SEAD mission.

The first of these programs was the AGM-88 High-Speed Anti-Radiation Missile (HARM). The earlier AGM-45 Shrike, developed in the late 1950s by the Navy, had continued to play a useful role in SEAD through the mid-1970s, but its short range, low speed, and inability to continue to prosecute a target after the radar ceased emitting

\footnotetext{
${ }^{234}$ Thornborough and Mormillo, 2002, p. 140.

${ }^{235}$ Thornborough and Mormillo, 2002, p. 140.

${ }^{236}$ Quinlivan, 1989, pp. 15-16.

${ }^{237}$ Quinlivan, 1989, p. 17.

${ }^{238}$ Thornborough and Mormillo, 2002, p. 156.
} 
sharply curtailed its effectiveness. The Standard ARM (STARM), developed by the Navy in the 1960s, was more effective but large, slow, and exceptionally expensive. As part of the Pave Strike initiative, the Air Force decided to replace the Shrike and STARM with a faster, more flexible weapon. The AGM-88B was a long-range supersonic ARM that was reprogrammable in flight (to deal with pop-up targets) and capable of prosecuting a target even after the radar stopped emitting. The Navy developed the original AGM-88, and the Air Force procured the Block III version of the AGM-88B. ${ }^{239}$

The second major Pave Strike program related to SEAD was the development of a dedicated USAF tactical jamming aircraft. The RB-66 jammers were rapidly being retired, and, in any case, their capabilities were limited. The Navy and Marine Corps had steadily invested in the EA-6B Prowler tactical jamming aircraft during the 1960s and 1970s, but the Air Force lacked an equivalent. As part of the Pave Strike initiative, the Air Force decided to convert 42 F-111 airframes to EF-111 Raven tactical jamming aircraft. The EF-111 offered long range and internal space for an ALQ-99E jamming suite similar to that carried by the EA-6B. ${ }^{240}$

The development of the EF-111 built on a number of other technical innovations achieved by the USAF in the early to mid-1970s. One of these was a digital radar warning receiver (RWR). The USAF had linked its APR-25 Radar Homing and Warning System and APR-37 Laser Warning Receiver with a digital processor, resulting in the ALR-46 digital RWR with the ability to scan numerous bands and present an integrated threat picture on a single screen to Wild Weasel Weapon System Operators. ${ }^{241}$

The USAF had also made significant progress with its ECM pods, developing the ALQ-119 jamming pod, which combined a number of defensive capabilities against enemy tracking radars, including noise jamming, deception jamming, and downlink jamming. The new pods also enabled a variety of new offensive jamming techniques, including range gate pull-off, inverse conical scan jamming, velocity gate pull-off, and transponder mode deception. All of these techniques were aimed at defeating the final target tracking of SAMs and radar-guided AAA. The ALQ-119 integrated them into a single aircraft with a processor that prioritized threats and selected appropriate responses, allowing the aircrew greater flexibility and the freedom to operate in any formation. ${ }^{242}$

However, the most important Pave Strike program for the SEAD mission was the development of the F-4G Wild Weasel V aircraft. The new Wild Weasel was an F-4E with several modifications, most notably the replacement of the internal $20 \mathrm{~mm}$ cannon with the APR-38A ECM suite. The APR-38 allowed the Weapon System Operator to

\footnotetext{
239 Thornborough and Mormillo, 2002, p. 178.

${ }^{240}$ Thornborough and Mormillo, 2002, p. 161.

${ }^{241}$ Thornborough and Mormillo, 2002, p. 143.

242 Thornborough and Mormillo, 2002, pp. 144-145.
} 
employ several different jamming techniques against several radars simultaneously. A total of 115 F-4Es were modified to the Wild Weasel fit and redesignated F-4Gs. Just as important as the technical capabilities contained inside the aircraft, the Wild Weasel platform itself was preserved as a distinct force structure and airframe community. The 35th Tactical Fighter Wing at George Air Force Base in California hosted three Wild Weasel squadrons. This "pooled" Wild Weasel expertise allowed the Weasel units to operate routinely at the electronic warfare ranges at China Lake and Tonopah. ${ }^{243}$

Beyond the Pave Strike initiative, another important response to the Soviet IADS threat in Europe was the development of stealthy strike aircraft. The U.S. Office of the Secretary of Defense and the Defense Advanced Research Projects Agency played key roles in driving the development of stealthy manned aircraft through the HAVE BLUE and SENIOR TREND programs. HAVE BLUE was a demonstration program to produce two demonstrators of stealthy manned aircraft at one-quarter scale. The program began in 1976 and concluded in 20 months after a successful test, though both demonstrator aircraft were lost. HAVE BLUE was followed by SENIOR TREND, which aimed to produce an operational stealth fighter within four years. According to DoD sources, the Air Force leadership initially saw little point in developing stealthy aircraft but agreed to participate as long as DoD provided the funding. The first F-117 was delivered, on schedule, in $1981 .^{244}$

In addition to technological innovation, TAC responded to the Soviet IADS threat in Eastern Europe with development of the SEAD campaign concept. One key figure in this story is General Wilbur Creech, who commanded TAC for an unprecedented tenure of more than six years, from May 1, 1978 to November 1, 1984. During his tenure, General Creech revolutionized the TAF's approach to the IADS problem and, more importantly, laid the foundation for ongoing adaptation and innovation to overcome the problem.

General Creech began by recognizing the strategic and operational problem posed by Soviet and proxy IADS. By 1978, live exercises and operational analyses increasingly indicated that TAF strike aircraft could not survive against the emerging Soviet IADS. ${ }^{245}$ No matter how low the strike aircraft flew, the SA-6, SA-7, and ZSU-23-4 would make the airspace unsurvivable. ${ }^{246}$ "We were using tactics that weren't going to work," General Creech recalled in subsequent interviews. ${ }^{247} \mathrm{He}$ decided to make a strategic change.

\footnotetext{
243 Thornborough and Mormillo, 2002, p. 146.

${ }^{244}$ M. J. Lippitz and R. H. Van Atta, "Stealth Combat Aircraft," in R. H. Van Atta et al., Transformation and Transition: DARPA's Role in Fostering an Emerging Revolution in Military Affairs, Vol. 2, Arlington, Va.: Institute for Defense Analysis, November 2003, Chapter I, pp. 1-9.

${ }^{245}$ J. C. Slife, Creech Blue: General Bill Creech and the Reformation of the Tactical Air Forces, 19781984, Montgomery, Ala.: Air University Press, 2004, p. 26.

${ }^{246}$ Many would give primary credit for this realization to Major Richard "Moody" Suter, who shepherded the development of dissimilar training, and RED FLAG in particular. See, generally, C. R. Anderegg,
} 
General Creech called a Warfighter Conference soon after taking over at TAC in May 1978. The key issue at the conference was his conviction that TAC suffered from "go low disease." 248 As his biographer would later write, "General Creech was privy to the very latest intelligence concerning modern Soviet SAMs, and he had heard firsthand accounts from Israeli pilots about the futility of attempting to underfly the SA-6. His own experiences and thinking led him to the conclusion that to enable other air operations, air defenses had to be rolled back rather than avoided. Once the air defense threat was degraded, operations could adjust to higher, more survivable altitudes and take advantage of precision munitions. $" 249$

The Warfighter Conference in mid-1978 led to four major decisions. In General Creech's words,

We're going to dramatically change our approach, simply because it's wrong. We're now going to make defense roll-back and taking the SAMs out our first order of business. No more trying to fly past SAM sites to get to other targets. That can't be done. Taking them out can be done, and it will be easy if we go about it right. We need to get up out of the weeds as soon as possible to avoid the AAA, a far more formidable threat. We'll train at low altitude, sure, but we'll also emphasize training at high altitude with the munitions that work there. We'll go on a full court press to develop and field the systems and munitions that fit our new tactics. Our fixation on low-altitude ingress, egress, and delivery and the systems and munitions that fit solely that approach is over. We'll also launch a major effort to educate tactical people throughout the Air Force on this major shift and the reasoning that lies behind it.

General Creech implemented this vision by altering the Red Flag series of exercises held at Nellis Air Force Base in Nevada. Red Flag had emerged as the Air Force's premier live training venue for "aggressor" units as well as the central hub for TAF development of new tactics. In 1978, Creech modified the Red Flag model to match his vision of a future air campaign. Rather than starting each day of the two-week exercise with a completely regenerated adversary IADS, Creech mandated that the exercises play out as two-week air operations beginning with a SEAD campaign. ${ }^{250}$ Any adversary IADS "killed" in the exercise would be removed from the field on subsequent days. ${ }^{251}$

Sierra Hotel: Flying Air Force Fighters in the Decade After Vietnam, Washington, D.C.: Air Force History and Museums Program, 2001.

${ }^{247}$ Slife, 2004, p. 27.

${ }^{248}$ Slife, 2004, p. 28.

${ }^{249}$ Slife, 2004, p. 28.

${ }^{250}$ Slife, 2004, p. 29.

${ }^{251}$ Slife, 2004, p. 29. 
General Creech also helped institutionalize the Blue Flag exercises at Nellis. Blue Flag was an operational-level exercise collocated with Red Flag to train not just the

"aggressor" fighter pilots of Red Flag but also the numbered air force and other operational-level commanders and staffs in the conduct of entire air campaigns. Blue Flag naturally provided some operational-level campaign focus to the training and experimentation occurring at Nellis.

General Creech then instituted Green Flag exercises at Nellis as well. Green Flags focused on the electronic warfare battle, bringing together all the various intelligence, jamming, and electronic warfare platforms that would be needed to overcome a sophisticated IADS. Green Flags lasted six weeks, simulating a grueling campaign against a Soviet-level capability.

By defining a new CONOP and building the Red, Blue, and Green Flag exercises around it, General Creech effectively created the capacity for the TAF to combine technical innovation with the kind of field adaptation that normally occurs only during wartime operations - and to focus all of these efforts on solving an evolving, strategically important problem. In essence, he institutionalized a new type of innovation that we describe elsewhere in this volume as "short-cycle" innovation.

By the early 1980s, the TAF units rotating through Nellis had worked through most of the key elements of a SEAD campaign, having coordinated the tactics, organization, and technologies in a manner historically restricted to combat theaters. The results of each evolutionary advancement were distributed throughout TAC, PACAF, and USAFE in the Fighter Weapons Bulletin and, later, the USAF Fighter Weapons Review. These articles, combined with the program of instruction at Nellis, became a de facto new TAF doctrine. At the heart of this new doctrine lay a major innovation: the SEAD campaign. The importance of this innovation is attested to by the SEAD campaigns that have dominated the beginnings of every major U.S. air campaign since the late 1980s.

\section{Conclusion}

In this chapter, we have described four distinct phases of USAF innovation and adaptation against the Soviet IADS problem between 1955 and 1985. In the pre-Vietnam phase, SAC (along with the Navy and the Marine Corps) worked on the IADS problem; however, the TAF essentially failed to realize that IADS posed a problem for its mission. The result was a failure to adapt or innovate by the TAF. During the Operation Rolling Thunder and Linebacker phases in Vietnam, the TAF units based in Thailand rapidly adapted to the IADS problem as they became locked in an adaptation-counteradaptation contest with PAVN air defense crews. Simultaneously, HAF was attempting to implement a short-cycle innovation initiative with the development of the Wild Weasel. Unfortunately, HAF lacked the necessary ingredient for successful short-cycle 
innovation, specifically a field experiment facility with an IADS foe against which to experiment and adapt. What resulted were technical solutions deployed to the field, where they proved somewhat useful but at enormous cost. In the post-Vietnam phase, Gen Wilbur Creech created both a new CONOP for future air campaigns and a mechanism, in the form of regular exercises at Nellis Air Force Base, to drive an ongoing process of short-cycle innovation. The result was the SEAD campaign. 


\section{Precision Strategic Attack (1990-1999)}

In the 1990s, the USAF demonstrated the ability to conduct a type of air campaign that had not previously been seen, involving the sustained application of precision, conventional, air-to-ground attack against large numbers of targets in an enemy nation. The 1991 Gulf War air campaign against Iraq, followed by major air campaigns in the Balkans in 1995 and 1999, led to declarations that air power had "come of age." Military affairs scholars wrote books with titles such as Revolution in Warfare? and The Transformation of American Air Power. ${ }^{252}$

Some two decades later, it is easy to forget how significant this advance was. Genuinely revolutionary developments change the rules; in this case, the "military revolution" label genuinely applies. Where air power had for decades been described as a "blunt instrument," it now became a seemingly scalpel-like tool enabling U.S. leaders to strike adversaries with impressive force while minimizing risk to American military personnel and limiting civilian casualties among the enemy population to historically low levels. Air power did not become omnipotent, and precision attack did not become the panacea for winning wars, as prophesied by Giulio Douhet in the 1920s. Rather, precision attack became more of a first resort than a last resort for statesmen, and they would continue to turn to it as a way to project power with fewer or even no ground forces in subsequent wars in Afghanistan, Iraq, and Libya over the years that followed. This chapter analyzes the dimensions and history of the precision strike innovation.

\section{Anatomy of the Innovation}

Three general features characterize an idealized precision strategic attack campaign. First, of course, is the precision needed both to translate numerous attacks into extensive damage and to apply force with discrimination while limiting collateral or unintended destruction and casualties to low levels. Second is intensity, the ability to attack a large number of targets with conventional weapons, more or less anywhere in the enemy's territory, on a sustained basis that will exceed the opponent's ability to adapt to them. ${ }^{253}$ Finally, the attacker enjoys relative impunity to enemy defenses, enabling the campaign

\footnotetext{
${ }^{252}$ Thomas A. Keaney and Eliot A. Cohen, Revolution in Warfare? Air Power in the Persian Gulf, Annapolis, Md.: Naval Institute Press, 1995; Benjamin Lambeth, The Transformation of American Air Power, Ithaca, N.Y.: Cornell University Press, 2000. The former was a republication of the summary volume of the Gulf War Air Power Survey, an independent study commissioned by the USAF to study the use of air power in the Gulf War.

253 John A. Warden, III, “The Enemy as a System, ” Airpower Journal, Vol. 9, No. 1, Spring 1995.
} 
to be carried on as long as it appears to be worthwhile. ${ }^{254}$ These characteristics are related to each other: For example, impunity makes prolonged, intense campaigns affordable, and precision makes them more politically palatable as well as militarily potent. This definition of precision strategic attack campaigns notably avoids specifying particular types of targets, even though strategic bombing advocates for nearly a century have argued for the importance of one target set or another. ${ }^{255}$ Instead, the essence of a precision capability lies partly in being able to attack a variety of potential target types depending on the circumstances and the preferences of the campaign strategists.

No air campaign prior to the Gulf War truly fits this template. The Combined Bomber Offensive against Germany involved the use of massive force but against relatively few targets and with little precision, requiring several years before crippling the German war economy at the cost of tens of thousands of airmen's lives. ${ }^{256}$ Bombing was used far more selectively against North Vietnam, but precision attack capabilities were scarce, and strikes in general remained limited to small numbers of targets, while U.S. losses were substantial. ${ }^{257}$ In the 1980 s, punitive U.S. air strikes in Lebanon and Libya employed precision weapons but were isolated actions directed against mere handfuls of targets.

In contrast, Western air campaigns since the Gulf War have seen precision-guided munitions (PGMs) employed by the thousands, often against targets far from the front lines. This has not always led to strategic triumphs, even when the individual air attacks have been conducted with tactical success and few or no losses. But precise, intensive, wide-ranging air campaigns have often achieved at least their operational objectives in wars on three continents and have done so at manageable cost in blood and treasure for those conducting them.

\section{The Technological Dimension}

The capability to conduct such air campaigns depends on three suites of technological innovations, two of which are addressed in other chapters of this report (and will therefore be addressed only briefly here). First, being able to strike with relative impunity

\footnotetext{
${ }^{254}$ What constitutes minimal losses among the attacking forces depends on the enemy. A rate of attrition that would be remarkably low in a war against China might appear intolerably high against a weak adversary such as Iraq or Libya. Here, we focus on campaigns against inferior regional powers rather than near-peer adversaries, as all major U.S. air campaigns since 1945 have been directed against such foes, but the concept could be extended to conflicts with more substantial opponents.

${ }^{255}$ Phillip S. Meilinger, Airwar: Theory and Practice, London: Frank Cass, 2003, pp. 170-186.

${ }^{256}$ Alfred C. Mierzejewski, The Collapse of the German War Economy, 1944-1945, Chapel Hill, N.C.: University of North Carolina Press, 1988; Adam Tooze, The Wages of Destruction: The Making and Breaking of the Nazi Economy, New York: Viking, 2006; Richard Overy, The Bombing War: Europe, 1939-1945, London: Allen Lane, 2013.

${ }^{257}$ Robert A. Pape, Bombing to Win: Air Power and Coercion in War, Ithaca, N.Y.: Cornell University Press, 1996, pp. 174-210; Thompson, 2000.
} 
in the face of capable air defenses depends on some combination of SEAD, electronic warfare, offensive counterair capabilities, and stealth sufficient to reduce the enemy's ability to inflict losses on attacking aircraft or to prevent those attacks. The beneficial effects of these technologies overlap; for example, stealthy aircraft are extremely useful for penetrating air defenses, but if the enemy's early warning radars and radar-guided SAMs can be neutralized by other means, every aircraft in effect becomes stealthy. ${ }^{258}$

Second, it is necessary to find and identify the targets to be attacked, which depends on a high degree of intelligence, surveillance, and reconnaissance (ISR) capability when targets are numbered in the hundreds or thousands. These ISR capabilities are also central to a sustained air campaign for damage assessment after attacks. The sensor platforms in question typically range from satellites to manned and unmanned aircraft ${ }^{259}$ —all fields of extensive technological innovation over the past 75 years - though intelligence is also likely to be collected by other means. Imagery, electronic intelligence, and other data are useful only to the extent that they can be analyzed and applied to the campaign, so it is not unusual for analysts and their tools, rather than data collectors, to be the limiting factors in the ISR chain. This is particularly true when discrimination is strongly emphasized in targeting, demanding a much deeper understanding of targets and their surroundings than would be required merely to destroy the target without regard to risks of collateral damage, as repeatedly demonstrated in air campaigns, from the Gulf War to Libya and beyond.

Finally, precision strategic air campaigns depend on the availability of abundant and, ideally, ubiquitous PGMs. ${ }^{260}$ The most important of these have been laser-guided bombs (LGBs), such as the U.S. Paveway series, and, more recently, satellite-guided weapons, preeminently the Joint Direct Attack Munition (JDAM), supplemented by electrooptically guided, infrared-guided, or radar-guided weapons, such as Maverick and Hellfire missiles. ${ }^{261}$ The great virtue of these weapons, aside from their precision, is their affordability (on the order of tens of thousands of dollars apiece), which makes it possible to acquire them in great quantities and employ them against large numbers of targets. Not every target in a precision air campaign calls for the use of a PGM, since

\footnotetext{
${ }^{258}$ As described in Chapter 5, U.S. SEAD capabilities came into their own during and after the Vietnam War. Stand-off weapons, such as cruise missiles, can also substitute for other means of penetrating enemy air defenses at low risk, but the expense of very long-range munitions typically prevents them from forming the backbone of sustained air campaigns.

${ }^{259}$ See Chapters 2 and 7.

${ }^{260}$ More precisely, what is required is abundant precision strike capabilities that can be employed without subjecting strike aircraft to unnecessary risk. In practice, this has translated to a large degree into PGMs, although other advances, such as highly accurate satellite-linked inertial navigation systems, can also provide great improvements in accuracy in the delivery even of unguided weapons.

${ }^{261}$ Anti-radiation missiles, discussed in Chapter 5, can also be considered PGMs but are useful against only a limited class of targets due to their guidance system.
} 
some targets are located where collateral damage is not a serious concern. The goal is simply to have enough precision weapons and compatible aircraft that desired attacks do not have to be forgone because of a shortage of PGMs. At the same time, the proportion of PGMs among weapons employed in such campaigns has risen rapidly since the Gulf War, reaching virtually 100 percent in the Libyan air campaign of 2011.

U.S. development of LGBs began in the early 1960s, with the Paveway I first being used in combat in Vietnam in 1968. Other munitions that figure prominently in modern precision air campaigns have their roots in Cold War programs focused on defending against a Soviet mechanized invasion of Western Europe. The early designers of these weapons sometimes did not foresee their modern virtues, as in the cases of the Maverick and Hellfire missiles, which were originally intended to destroy Soviet tanks but whose relatively small antiarmor warheads have proven well suited to attacking a variety of fixed targets while limiting the destruction of nearby structures and objects. In contrast, the development of satellite-guided weapons depended upon the invention of the Global Positioning System. Development of the JDAM, for instance, started in 1992 in response to Gulf War experiences in which LGBs could not be used due to the unfavorable environmental conditions, with the JDAM being first employed against Serbia in 1999.

\section{The Conceptual Dimension}

While technological innovations made precision air campaigns possible, the emergence and maturation of the capability at the strategic level depended on corresponding conceptual innovations. These had important precursors in earlier decades. In the 1920s and 1930s, the Air Corps Tactical School (ACTS) developed theories of precision bombing - theories that focused on disabling enemy nations by unhinging their economies through attacks on carefully selected vital centers. ${ }^{262}$ During the Combined Bomber Offensive against Germany, American and British strategists wrestled with this ideal in practice when faced with limited intelligence information, inaccurate bombs, and an enemy adept at improvising in spite of Allied air attacks. ${ }^{263}$ In the mid-1960s, U.S. leaders wanted to develop subtle coercive strategies to strike selected North Vietnamese targets; Operation Rolling Thunder failed to achieve this goal for several reasons, ${ }^{264}$ although the painful experience did spur development of SEAD and PGM capabilities.

In the years after Vietnam, enthusiastic visions of how conventional air power could take the lead in winning future wars, let alone win them alone, grew rare, even in the Air

\footnotetext{
${ }^{262}$ David E. Johnson, Fast Tanks and Heavy Bombers: Innovation in the U.S. Army, 1917-1945, Ithaca, N.Y.: Cornell University Press, 2003.

${ }^{263}$ Robert S. Ehlers, Jr., Targeting the Third Reich: Air Intelligence and the Allied Bombing Campaigns, Lawrence, Kan.: University of Kansas Press, 2009.

${ }^{264}$ Wallace J. Thies, When Governments Collide: Coercion and Diplomacy in the Vietnam Conflict, 19641968, Berkeley, Calif.: University of California Press, 1980.
} 
Force. These ideas began to reappear in the late 1980s, most notably in the writings of Col John A. Warden. As a student at the National War College in 1986 and 1987, Colonel Warden began formulating a set of arguments about how air campaigns could go beyond supporting ground operations, as envisioned in that era's Army-developed AirLand Battle doctrine. Warden argued, in very ACTS-like terms, that air strikes against properly selected targets could cripple an enemy's warmaking ability, its economy, and even its ability to maintain control over its populace. ${ }^{265}$ Many of his arguments would prove to be miscast, particularly with respect to an enemy's political, economic, and psychological fragility and the merits of trying to induce strategic paralysis. ${ }^{266}$ But his more foundational contentions about the potential of intensive, strategically targeted air strikes to have effects beyond the battlefield were central to the emergence of the precision strategic air campaign, directly in the case of Operation Desert Storm four years later and indirectly in the thinking of other airmen.

\section{The Organizational Dimension}

Overlapping both the technological and conceptual dimensions is the all-important emergence of the modern air operations center (AOC), the nerve system of the precision air campaign. Sustaining a complex air campaign is a demanding managerial task, and as PGM capabilities proliferate and smaller munitions enable aircraft to strike more targets per sortie, it is increasingly the case, as seen in Libya in 2011, that the intensity of an air campaign will be limited mostly by the ability of the AOC and its supporting organizations to process information and identify targets to be attacked. AOC efficiency hinges on a variety of investments in command and control systems, but its most precious component is its trained personnel. Providing enough AOC personnel for wartime demands is intrinsically challenging, since the hundreds or thousands of personnel needed for an air campaign are not needed in the AOC under other conditions.

Today's AOCs have evolved from the Tactical Air Control Centers (TACCs) of the Vietnam years, with much innovation having occurred in the 1980 s, when the Tactical Air Control System saw a transformation toward automated ways of generating the air tasking orders that are the lifeblood of the air campaign. TACCs gave way to AOCs in 1992, and the AOC has continued to evolve subsequently, with the USAF now designating it as a weapons system to facilitate better standardization and training. ${ }^{267}$

\footnotetext{
${ }^{265}$ John A. Warden, III, The Air Campaign: Planning for Combat, Washington, D.C.: Pergamon-Brassey's, 1989; John Andreas Olsen, John Warden and the Renaissance of American Air Power, Dulles, Va.: Potomac, 2007, chapter 5.

${ }^{266}$ Karl P. Mueller, "Strategies of Coercion: Denial, Punishment, and the Future of Air Power," Security Studies, Vol. 7, No. 3, Spring 1998, pp. 182-228; Olsen, 2007, pp. 74-80.

${ }^{267}$ J. Taylor Sink, Rethinking the Air Operations Center: Air Force Command and Control in Conventional War, master's thesis, School of Advanced Airpower Studies, June 1993.
} 
Other organizational innovations have contributed to the rise of the precision air campaign as well. Among these are the establishment and refinement of a variety of intelligence organizations, such as the Joint Warfare Analysis Center, established by the U.S. Navy in the 1980s and subsequently tasked with conducting detailed analyses of adversary targets to identify vulnerabilities and predict the second- and third-order effects of attacks on them. Further innovations have arisen in the professional military education system, ranging from curriculum reforms that place greater emphasis on air campaignrelated subjects to the establishment in 1990 of the School of Advanced Airpower Studies (SAAS), which provides graduate-level education to officers likely to be future air campaign strategists or commanders. Many of the officers who have planned and managed U.S. air campaigns since Operation Desert Storm have been SAAS alumni. ${ }^{268}$

\section{Emergence of the Innovation}

A host of factors set the stage for the emergence of the precision-attack air campaign as a centerpiece of U.S. military strategy in the 1990s, but it was Iraq's 1990 invasion of Kuwait that forged the crucible in which those factors would meld. In a sense, it was not American military leaders who initially framed the strategic problem as much as it was Saddam Hussein. With the Iraqi army occupying Kuwait and threatening an invasion of Saudi Arabia's northern oilfields, and the White House determined that the aggression would not be allowed to stand, Washington and U.S. Central Command (USCENTCOM) had to decide how to roll back Iraq's aggression at the most reasonable cost.

Attention soon turned to a proposal offered by Colonel Warden and officers serving under him in the Air Staff's Checkmate division to respond to a potential Iraqi invasion of Saudi Arabia with a fast-paced precision-attack campaign against 84 targets associated with Hussein's regime in Iraq, which Warden predicted would cause Hussein to capitulate to U.S. demands in a matter of days. Warden labeled the strategy "Instant Thunder" to contrast it with the gradual coercive approach employed against Hanoi 25 years earlier. The proposal was well received in Washington and by USCENTCOM commander GEN Norman Schwarzkopf, but less favorably by USCENTCOM Air Component Commander Lt Gen Chuck Horner, who considered it naïvely optimistic to assume that an Iraqi offensive into Saudi Arabia would not also need to be targeted directly. General Horner sent Colonel Warden back to the United States, but kept Warden's key planners in Riyadh to help design the air campaign that would ultimately be launched against Iraq in January 1991 as Operation Desert Storm. ${ }^{269}$

\footnotetext{
${ }^{268}$ In its second decade, SAAS was renamed the School of Advanced Air and Space Studies (SAASS).

${ }^{269}$ John Andreas Olsen, Strategic Airpower in Desert Storm, London: Routledge, 2003; Tom Clancy and Chuck Horner, Every Man a Tiger: The Gulf War Air Campaign, New York: Berkley, 2000. See also Diane T. Putney, Airpower Advantage: Planning the Gulf Air Campaign, 1989-1991, Honolulu, Hawaii:
} 
The Desert Storm air campaign placed its greatest weight of effort on attacks against Iraq's forces in and near Kuwait, which were bombed for five weeks before U.S. and allied ground forces launched their four-day counteroffensive into Kuwait. But the air campaign also included an intensive precision-attack campaign against targets in Baghdad and elsewhere in Iraq associated with air defense, government, internal security, military command and control, electrical power, and nuclear and chemical weapons development - an effort that looked very much like the Instant Thunder campaign on a larger scale. This effort made extensive use of stealthy and nonstealthy fighters, a variety of PGMs, plus some more-exotic munitions; soon, audiences around the world were watching USCENTCOM press conferences featuring video recordings of pinpoint strikes on targets in urban areas that were leaving nearby buildings virtually unscathed. Of the 85,000 tons of bombs dropped during the war, less than 10 percent were PGMs, but these were credited with three-quarters of the damage inflicted from the air against both "strategic" targets and fielded military forces. ${ }^{270}$

The precision-attack component of the air campaign against Iraq was an operational tour de force, yet ultimately turned out to be strategically peripheral to the outcome of the war, which was decided by air power and then ground forces attacking the Iraqi army in Kuwait. ${ }^{271}$ Under overwhelming pressure from a far more capable and determined enemy, the Iraqi forces crumbled, largely independent of the damage inflicted against government and infrastructure targets. Colonel Warden's hopes that attacks against Iraqi internal security forces would lead to domestic unrest and regime change were not fulfilled, in keeping with previous historical experience. ${ }^{272}$ However, the precision-attack effort showed what a modern air force that could effectively suppress the enemy's air defenses and deliver large numbers of accurate munitions could do to an enemy country in relatively short order, a demonstration reinforced by subsequent precision attacks against Iraqi fielded forces on or behind the front lines in Kuwait. ${ }^{273}$

University Press of the Pacific, 2006. In 1993, Warden became commandant of the USAF's Air Command and Staff College and embarked on a large-scale effort to increase the intensity of its educational program.

${ }^{270}$ Lambeth, 2000, p. 160. Progress in sensors and precision weapons enabled the emergence of "tank plinking" in the Gulf War, in which Iraqi vehicles and heavy weapons were efficiently destroyed by PGM attacks that could be launched from stand-off distances, beyond the reach of the short-range air defenses that had inflicted heavy losses against aircraft striking similar targets with unguided munitions in previous conflicts.

${ }^{271}$ Pape, 1996, chapter 7; Olsen, 2003, chapter 5.

${ }^{272}$ Stephen T. Hosmer, Operations Against Enemy Leaders, Santa Monica, Calif.: RAND Corporation, 2001.

${ }^{273}$ In Operation Desert Storm, it was relatively easy to differentiate between attacks on fielded forces and on "strategic" regime and other targets deep in Iraq. This is not always the case. However, military forces can also be attractive targets for strategic attack, not least because striking them is usually unambiguously legal under the laws of armed conflict. 
After the war, the Air Force embraced precision strategic attack as a mission of central importance. Doctrine manuals were revised to include it, PGM capabilities continued to expand, and the USAF launched the JDAM program to provide all-weather precision-attack capabilities for conditions that would frustrate the use of LGBs. Movement toward making precision strategic attack a core mission of SAC heavy bombers continued, a trend that had begun in the late 1980s with SAC leadership recognizing that the bomber force could play a major role in conventional theater war, as envisioned in AirLand Battle. The bomber force became part of the new Air Combat Command (replacing TAC) in 1992, and the B-1B Lancer soon lost its nuclear strike mission altogether so that it could concentrate on conventional bombing. ${ }^{274}$ The USAF took the unusual step of commissioning an extensive independent study of the Desert Storm air campaign, the Gulf War Air Power Survey, to gain a better understanding of what air power had accomplished — and to make others more aware of it as well. ${ }^{275}$

Four and a half years later, the ruins of Yugoslavia became the venue for the next precision air campaign, though under significantly different circumstances. ${ }^{276}$ This time, the enemy was the Bosnian Serb Army, which held most of the territory of war-ravaged Bosnia-Herzegovina and had recently committed the Srebrenica massacre, galvanizing the Western powers to take decisive action after several years spent trying to manage the Bosnian civil war more incrementally. Air power would be used in closer concert with ground forces this time, with a French-British-Dutch ground force in Sarajevo and, more importantly, a fast-moving but low-profile ground offensive launched by the Croatian army in parallel with the air campaign. But arguably, the greatest strategic difference was the perceived stakes: In 1991, the United States was prepared to attack the Iraqi army even if it meant several thousand U.S. soldiers being killed in action, whereas in 1995, the goal was to solve the festering problem in Bosnia with very few losses.

With Operation Deliberate Force, the precision air campaign innovation can be said to have fully taken hold. Further refinements would follow, as demonstrated in subsequent wars, but the Bosnian air campaign, together with shifting events on the ground, led directly to the enemy acceding to the coercive demands of the United States and its allies in the Dayton Accords, negotiated at Wright-Patterson Air Force Base. Although Deliberate Force was a smaller campaign than Desert Storm had been, involving attacks on 338 targets over three weeks and using just over 1,000 bombs, it displayed the defining hallmarks of the campaign type. Great attention was paid to minimizing collateral damage — starting even before the campaign planners received

\footnotetext{
${ }^{274}$ Lambeth, 2000, pp. 164-167.

${ }^{275}$ Gulf War Air Power Survey (5 vols.), Washington, D.C.: U.S. Government Printing Office, 1993.

${ }^{276}$ For background and details see Robert C. Owen, ed., Deliberate Force: A Case Study in Effective Air Campaigning, Maxwell AFB, Ala.: Air University Press, 2000.
} 
instructions to do so. Some 70 percent of the air-to-ground munitions used were PGMs. Attacks were intensive and sustained. (After the war, Western envoy Richard Holbrooke said that his greatest fear had been that the air strikes would taper off just as the Serbs were preparing to give in, weakening the coercive pressure on them, because the list of targets approved for the campaign was being depleted.) Aircraft losses were light, with only a single NATO strike aircraft shot down during the operation.

\section{Leadership and Innovation}

The invention of the precision strategic attack campaign was a response to a strategic problem that unexpectedly became the central preoccupation of U.S. military strategists in the 1990s. It was unexpected because very few had foreseen the sudden end of the Cold War. Most pre-1990 Air Force innovation efforts had focused on developing capabilities for a major war against the Soviet Union. It was fortunate that many of these capabilities proved to be well suited to the demands of defeating, punishing, and deterring regional aggressors in the years following the dissolution of the Soviet threat.

In this mix, the Air Force senior leadership did not figure conspicuously. Before the Gulf War, the service's image of its future role in combat operations had centered on supporting the Army in AirLand Battle. Air Force doctrine had included virtually no consideration of the potential use of conventional air power for precision attack as a central element in future conflicts, although this would quickly change after Operation Desert Storm provided a proof of concept. The strategists and planners who had initially envisioned air power as dominating future conflicts through conventional precision attack, such as Colonel Warden and Lt Col David Deptula, had been mavericks within the Air Force. Yet the service leadership deserves credit for having provided such mavericks the opportunity and elbow room to develop their ideas, which would lead indirectly and, in some respects, directly to creating the Desert Storm air campaign and, by extension, the air campaigns that followed it.

Even prior to Operation Desert Storm, the Air Force had also deepened its investment in its next generation of strategists, perhaps most visibly by launching SAAS as the most prominent part of revitalizing the intellectually moribund Air University. This effort had been catalyzed by the discontented director of the Air Force Research Institute, had been championed by such notable USAF officers as Maj Gen Charles G. Boyd, and had been supported by outsiders, including Congressman Ike Skelton. CSAF Gen Larry G. Welch chartered SAAS in 1988, and when Operation Desert Storm began, its faculty were preparing for the arrival of its inaugural class of students. Such actions are a far cry from a service leadership presenting a radical vision of transformation and then deliberately acting to bring it about, but such actions do play an important role in making it possible for innovation to flourish when unanticipated circumstances call for it. 


\section{An Overdetermined Outcome?}

With the benefit of hindsight, it is not hard to imagine that technological progress in aerial reconnaissance and strike capabilities, along with a shift in the strategic landscape that left the United States confronting much weaker regional powers when it went to war, would tend naturally to lead to the emergence of precision strategic attack campaigns as a staple of American foreign policy in the wake of the Cold War. ${ }^{277}$ Certainly, the stage had been set for this development (albeit mostly unwittingly) by the technological, conceptual, and organizational innovations of the preceding decade or more. Yet there appears to have been nothing inevitable about the emergence of this capability as a strategic-level innovation at the time it occurred; no other air force had hit upon the same innovation before the USAF demonstrated it in 1991. ${ }^{278}$

If independent-minded officers had not made the case for a precision strategic attack campaign —or for prolonged air attacks against the Iraqi army, for that matter—or if there had been different theater commanders, the United States and its allies might well have conducted Operation Desert Storm as a traditional combined-arms offensive. Without the precedent of the air campaign in the Gulf, the ensuing strategic options for Bosnia might have looked quite different a few years later. Instead, Kuwait and Bosnia were followed by additional air-centric campaigns (though each was unique in important ways) in Serbia, Afghanistan, and Libya. ${ }^{279}$ As U.S. leaders make decisions about whether and how to conduct military interventions in future conflicts, the idea that one option in many of these cases, indeed for many leaders the obvious default option, is to conduct a precision strategic attack air campaign has become so engrained as to be taken for granted.

\footnotetext{
${ }^{277}$ David E. Johnson, Learning Large Lessons: The Evolving Roles of Ground Power and Air Power in the Post-Cold War Era, Santa Monica, Calif.: RAND Corporation, MG-405-1-AF, 2007.

${ }^{278}$ To be sure, few other air forces possessed the scale or the advanced capabilities needed to conduct their own precision strategic attack campaigns at the time, but the U.S. Navy might plausibly have done so, and the Soviet air force could have contemplated comparable operations at least against its immediate neighbors.

${ }^{279}$ Benjamin S. Lambeth, NATO's Air War for Kosovo: A Strategic and Operational Assessment, Santa Monica, Calif.: RAND Corporation, 2001; Dag Henriksen, NATO's Gamble: Combining Diplomacy and Airpower in the Kosovo Crisis, 1998-1999, Annapolis, Md.: Naval Institute Press, 2007; Benjamin S. Lambeth, Air Power Against Terror: America's Conduct of Operation Enduring Freedom, Santa Monica, Calif.: RAND Corporation, MG-166-1-CENTAF, 2006; Karl P. Mueller, ed., Precision and Purpose: Airpower in the Libyan Civil War, Santa Monica, Calif.: RAND Corporation, RR-676-AF, 2015.
} 


\section{Airborne High-Value Targeting (1993-2001)}

This case study explores how the USAF's approach to high value targeting (HVT) operations from 1993 to 2001 both helped and hindered efforts to kill al Qaeda founder Osama bin Laden. The first section describes the emergence of HVT as a strategic problem and also the debate over using remotely piloted aircraft (RPA) to mitigate some of the challenges that have historically plagued HVT operations. The second section examines the USAF's participation in the CIA-led hunt for bin Laden; in particular, this section explores the extent to which the USAF's efforts to weaponize the Predator RPA were tied to a campaign-level effort to conduct an HVT operation against bin Laden. The final section addresses the implications of this case study for innovation in the USAF today.

\section{HVT as a Strategic Problem}

HVT operations have long been attractive to U.S. policymakers because of their perceived potential to yield strategic results. In his book on strategic manhunts, Benjamin Runkle identifies nearly a dozen cases since 1885 in which the United States has deployed military forces with the objective of killing a single man. ${ }^{280}$ The strategic value of HVT operations rests on the perception among American leaders that such operations may shorten wars, change enemy policy or behavior, degrade warfighting capability, or create a deterrent or coercive effect, since they threaten a leader's personal power and safety. $^{281}$

Since the terrorist attacks of September 11, 2001, the United States has increasingly relied on HVT, targeting terrorist leaders in Afghanistan, Iraq, Pakistan, Somalia, Yemen, and elsewhere. ${ }^{282}$ While U.S. policymakers have frequently turned to HVT operations with the hope of achieving strategic objectives, three significant operational problems have historically hampered their efforts: risk of civilian casualties; potential for U.S. combatant losses; and a lack of capabilities for time-sensitive targeting of HVTs.

\footnotetext{
${ }^{280}$ Benjamin Runkle, Wanted Dead or Alive: Manhunts from Geronimo to Bin Laden, New York: Palgrave MacMillan, 2011, p. 4.

${ }^{281}$ Hosmer, 2001, p. xi.

${ }^{282}$ Matt Frankel, "The ABCs of HVT: Key Lessons from High Value Targeting Campaigns Against Insurgents and Terrorists," Studies in Conflict and Terrorism, Vol. 34, No. 1, 2011, p. 18.
} 


\section{Obstacles to HVT Operations}

Concerns about civilian casualties - as well as actual civilian casualties-have frequently hamstrung HVT operations. In the final days of Operation Desert Storm in 1991, for example, air planners got "very good" intelligence about the location of Saddam Hussein in a residential area of Baghdad, but no attack was planned because of concerns about "widespread collateral damage. ${ }^{, 283}$ In 1993, UN efforts to target Somali warlord Mohammad Aideed suffered a serious setback when, during an attack on a house where Aideed was thought to be located, UN forces killed moderates meeting to discuss peace talks. The attack cemented support for Aideed, who was not at the house, and fueled outrage among the Somali people, in turn contributing to the carnage when Army Special Operations Forces tried to capture Aideed during the "Black Hawk Down" incident later that year. ${ }^{284}$ Concerns about civilian casualties also resulted in the cancellation of several attempts to target bin Laden between 1997 and 1999, as discussed later.

HVT operations have also been blocked because of the operational risk to U.S. forces. In response to intelligence warnings that al Qaeda was planning U.S. domestic attacks in late 1998, U.S. military leaders developed a plan to send Special Operations Forces either to Afghanistan to conduct a high-risk raid to capture bin Laden or to Sudan to catch a senior al Qaeda operative, Abu Hafs. ${ }^{285}$ General Hugh Shelton, the chairman of the Joint Chiefs of Staff (JCS), argued against the ground-based attack over concerns about the high risk of losing U.S. lives and the lack of adequate intelligence to conduct the mission. In his interview with the 9/11 Commission, he compared the 1998 plan for a ground-based HVT operation against bin Laden to the Black Hawk Down incident five years earlier in Mogadishu. ${ }^{286}$ That HVT mission had resulted in the shoot-down of two Black Hawk helicopters, 18 Americans killed, 73 wounded, and the image on TV of an American corpse dragged through the street by Somalis. ${ }^{27}$

Finally, HVT operations have frequently failed due to a lack of time-sensitive targeting capabilities. The subjects of HVT operations are often wily leaders adept at evading detection. Aideed evaded U.S. capture for three months, despite helicopter surveillance, by frequently changing his location, planting false information, and wearing disguises. ${ }^{288}$ Panamanian drug lord Manuel Noriega evaded capture by U.S. forces in the weeks prior to the U.S. invasion of Panama by using false messages and decoy

\footnotetext{
${ }^{283}$ Frontline, Interview with General Charles Horner, Commander of the U.S. Ninth Air Force ("The Gulf War"), 1997. Quoted in Hosmer, 2001, p. 43.

${ }^{284}$ Runkle, 2011, p. 141.

${ }^{285}$ National Commission on Terrorist Attacks upon the United States, The 9/11 Commission Report, New York: W.W. Norton and Company, 2004, p. 130.

${ }^{286}$ National Commission on Terrorist Attacks upon the United States, 2004, p. 130.

${ }^{287}$ Runkle, 2011, pp. 131-155.

${ }^{288}$ Hosmer, 2001, p. 44.
} 
convoys. ${ }^{289}$ During Desert Storm, Saddam Hussein frequently changed modes of transportation and slept in civilian houses rather than palaces. ${ }^{290}$

\section{Is an Armed RPA the Centerpiece of an HVT Capability?}

The introduction of an armed RPA, the MQ-1 Predator, ${ }^{291}$ in the opening days of the air campaign over Afghanistan in 2001 offered an unprecedented opportunity to mitigate the operational problems that have dogged HVT operations. RPAs potentially reduce the risk of civilian casualties, since they have a long "loiter time" that allows them to collect valuable information about where and when a strike would be least likely to harm bystanders. $^{292}$ By significantly reducing the need for "boots on the ground," armed RPAs also allow U.S. forces to avoid engaging in lethal ground battles during HVT operations. Finally, the real-time and predictive intelligence collected by RPAs can increase the odds that an HVT operation will result in a successful strike. Weaponized RPAs are particularly effective for time-sensitive targeting, since they can be equipped with both the sensors to track targets and the weapons to engage them at the time and place of a commander's choosing.

There are, of course, potential downsides to the use of armed RPAs in HVT operations. In the post-9/11 era, the discussion centers on the strategic question of whether targeted killings can degrade or destroy terrorist organizations. The prevailing view among academics is that HVT operations - whether they involve RPAs or notcannot achieve such strategic effects, and that they are quite ineffective and even counterproductive. ${ }^{293}$ In a 2013 Foreign Affairs article, Audrey Kurth Cronin extended the argument against HVT operations specifically to RPA strikes, asserting that the strikes do not hinder al Qaeda and may create more U.S. enemies among locals. ${ }^{294}$ Other

\footnotetext{
${ }^{289}$ Hosmer, 2001, p. 43.

${ }^{290}$ Hosmer, 2001, p. 42.

${ }^{291}$ This study uses the term "Predator" for simplicity's sake, but it should be noted that an unarmed Predator is designated the RQ-1, while the armed version is designated the MQ-1.

292 General James Cartwright, former Vice Chairman of the Joint Chiefs of Staff, discussed this advantage during a press briefing on the use of armed MQ-1 Predators in Libya in 2011. See U.S. Department of Defense, News Transcript: DoD News Briefing with Secretary Gates and Gen. Cartwright from the Pentagon, April 21, 2011.

${ }^{293}$ Pape, 1996; Robert A. Pape, “The Strategic Logic of Suicide Terrorism," American Political Science Review, Vol. 97, No. 3, August 2003, pp. 1-19; Hosmer, 2001; Paul Staniland, "Defeating Transnational Insurgencies: The Best Offense is a Good Fence," Washington Quarterly, Vol. 29, No. 1, 2005, pp. 21-40; Mohammed Hafez and Joseph M. Hatfield, "Do Targeted Assassinations Work? A Multivariate Analysis of Israel's Controversial Tactic During Al-Aqsa Uprising," Studies in Conflict and Terrorism, Vol. 29, No. 4, June 2006, pp. 359-382; Or Honig, "Explaining Israel's Misuse of Strategic Assassinations," Studies in Conflict and Terrorism, Vol. 30, No. 6, June 2007, pp. 563-577; Jenna Jordan, "When Heads Roll:

Assessing the Effectiveness of Leadership Decapitation," Security Studies, Vol. 18, No. 4, December 2009, pp. 719-755; Andrew Cockburn, Kill Chain: The Rise of the High-Tech Assassins, New York: Henry Holt, 2015.

${ }^{294}$ Audrey Kurth Cronin, "Why Drones Fail: When Tactics Drive Strategy,” Foreign Affairs, July/August 2013.
} 
scholars worry that the use of RPA strikes for HVT operations may lower the threshold for violence, since the physical absence of a pilot removes the risk of U.S. combatant casualties. $^{295}$ The fact that RPA strikes are meant to be lethal and preclude the possibility of capture also raises a host of legal issues, ${ }^{296}$ as well as concerns about the missed opportunity to interrogate suspected terrorists about their plans. ${ }^{297}$

Yet the fact is that U.S. policymakers have increasingly turned to HVT operations as part of broader counterinsurgency and counterterrorism strategies. As Daniel Byman notes in a 2013 Foreign Affairs article responding to Cronin, the Obama administration has relied on RPA strikes "for one simple reason: they work." 298 The introduction of new technologies — including RPAs and PGMs (as discussed in the previous chapter) — has provided a means for U.S. policymakers to overcome many obstacles that have hindered HVT operations historically. Since the beginning of the Obama administration armed RPAs have been employed to kill thousands of militants. ${ }^{299}$ Even if these are only "tactical" victories, as Cronin argues, RPA strikes have increasingly appealed to U.S. policymakers because they offer concrete results in the otherwise ambiguous worlds of counterinsurgency and counterterrorism. ${ }^{300}$ What's more, an emerging body of scholarship suggests that killing terrorist leaders can have strategic effects under a fairly broad set of circumstances. ${ }^{301}$ While RPA strikes are no perfect solution for the defeat of terrorist organizations, some scholars argue that the use of armed RPAs as part of a broader strategic campaign may increase the odds of success. ${ }^{302}$

\section{The USAF's Role in the Hunt for Bin Laden}

Starting in the mid-1990s, bin Laden had become an HVT of growing interest. By 1997, the CIA began to realize that bin Laden's mark could be found on terrorist attacks around the globe. The CIA opened a bin Laden unit, known as Alec Station, to track

\footnotetext{
${ }^{295}$ See, for example, Sarah Kreps and Micah Zenko, "The Next Drone Wars: Preparing for Proliferation," Foreign Affairs, March/April 2014.

${ }^{296}$ See, for example, Richard Murphy and Afsheen John Radsan, "Due Process and Targeted Killing of Terrorists," Cardozo Law Review, Vol. 31, No. 2, 2010, pp. 405-450; Andrew C. Orr, "Unmanned, Unprecedented, and Unresolved: The Status of American Drone Strikes in Pakistan Under International Law," Cornell International Law Journal, Vol. 44, 2011, pp. 729-745.

${ }^{297}$ Cronin, 2013, p. 7.

${ }^{298}$ Daniel Byman, "Why Drones Work: The Case for Washington's Weapon of Choice," Foreign Affairs, July/August 2013.

${ }^{299}$ International Security, International Security Data Site, "Drone Wars Pakistan: Analysis," and "Drone Wars Yemen: Analysis," Washington, D.C.: New America.

${ }^{300}$ Frankel, 2011, pp. 17-30.

${ }^{301}$ Patrick B. Johnston, "Does Decapitation Work? Assessing the Effectiveness of Leadership Targeting in Counterinsurgency Campaigns," International Security, Vol. 36, No. 4, Spring 2012, pp. 47-79; Bryan C. Price, "Targeting Top Terrorists: How Leadership Decapitation Contributes to Counterterrorism," International Security, Vol. 36, No. 4, Spring 2012, pp. 9-46.

${ }^{302}$ Johnston, 2012, p. 77; Frankel, 2011, p. 20 and p. 28.
} 
him. ${ }^{303}$ After the 1998 U.S. embassy bombings in Kenya and Tanzania, the White House quickly fixed responsibility on bin Laden and contemplated a series of plans to capture or kill him and his network between 1998 and 1999. These efforts ramped up in early 1999, as threat reporting began to indicate that al Qaeda might be planning attacks on U.S. targets at home and abroad. ${ }^{304}$

But progress was halting at best. Civilian and military efforts to run the terrorist leader to ground were hamstrung between 1997 and 1999 by the problems that had plagued HVT operations throughout the 1990s. After the 1998 embassy bombings, retaliatory Tomahawk Land Attack Missile (TLAM) strikes in Afghanistan and Sudan killed dozens of militants, but bin Laden escaped before the missiles had launched. The CIA tried to pay local Afghan tribes to capture bin Laden, but fears of civilian casualties forestalled those efforts. The White House cancelled three additional TLAM strikes against bin Laden during this time period because of concerns about local civilian casualties. Fears of U.S. combatant casualties also nixed a military plan for a groundbased Special Operations raid against bin Laden.

As the 9/11 Commission explained, the fundamental problem had been that "the United States did not have American eyes on target." ${ }^{\prime 305}$ The dearth of real-time and predictive intelligence created uncertainties about bin Laden's location and escalated the risks of hitting unintended targets. By late 1999, the CIA and Pentagon, as well as President Clinton, had all become frustrated with the fact that the U.S. fundamentally lacked options to track bin Laden and disrupt his network. ${ }^{306}$ In response, CIA and Pentagon officials began to cast about for ways to "get American eyes on bin Laden in a way that would reduce the lag time between sighting and striking." 307

\section{The USAF's Awareness of HVT Problems and Predator as Part of the Solution}

The USAF possessed the knowledge and the technology to confront the HVT problem that had been impeding the hunt for bin Laden in the late 1990s. What the service lacked, however, was a mechanism to frame novel national strategic problems, operationalize them, and push them through bureaucratic hurdles inside and outside the service. As a result, the USAF failed to draw a connection between its experience with Predator development and the White House's HVT efforts against bin Laden. Absent the

\footnotetext{
${ }^{303}$ National Commission on Terrorist Attacks upon the United States, 2004, p. 111.

${ }^{304}$ National Commission on Terrorist Attacks upon the United States, 2004, pp. 129-130.

${ }^{305}$ National Commission on Terrorist Attacks upon the United States, 2004, p. 188.

${ }^{306}$ For CIA frustration, see National Commission on Terrorist Attacks upon the United States, 2004, p. 142; for Clinton's frustration, see National Commission on Terrorist Attacks upon the United States, 2004, p. 189; for frustration of General Tommy Franks, head of U.S. Central Command; see Tommy Franks, American Soldier, New York: ReganBooks, 2004, p. 210.

${ }^{307}$ National Commission on Terrorist Attacks upon the United States, 2004, p. 189.
} 
articulation of a larger strategic purpose, Predator innovation was vulnerable to bureaucratic obstacles within the USAF as well as to political and technical barriers without.

While the USAF missed the strategic implications of Predator innovation, the service did have a deep understanding of the operational problems that had been plaguing HVT. Time-sensitive targeting and casualty sensitivity had posed increasingly difficult challenges in conventional air campaigns. During the 1991 invasion of Iraq, the USAF lacked a persistent airborne surveillance capability to track Iraq's mobile Scud launchers. ${ }^{308}$ Operation Deliberate Force in Bosnia and Operation Allied Force in Kosovo further revealed the scope of these challenges.

The USAF knew that the Predator presented a possible solution. In June of 1995, a Serbian SAM shot down USAF Capt Scott O'Grady's F-16 during Operation Deny Flight, a no-fly zone enforcement operation over Bosnia and Herzegovina. As a result, General Michael Ryan, then the commander of Allied Air Forces Southern (NATO) and of the 16th Air Force, USAFE, turned to RPAs - rather than manned aircraft - whenever he could during Operation Deliberate Force, the subsequent air campaign to bring Bosnian Serbs to the negotiating table. ${ }^{309}$ Both General Ryan, and, later, General Jumper, the USAFE commander during Operation Allied Force in 1999, relied on the Predator to collect time-sensitive intelligence for targeting. The notion of using the Predator for timesensitive targeting dated back, in fact, to 1995, when the U.S. Navy had planned tests to link Predator imagery to cruise missile-armed submarines offshore. ${ }^{310}$

\section{The Laser Designator}

During Allied Force in Kosovo, General Jumper was frustrated with the problem of how to move Predator imagery off-board to direct A-10 and F-16 strikes. ${ }^{311}$ Strike aircraft aircrews who were seeking Predator targeting assistance had to rely on voice communications with personnel at the USAF's Combined Air Operations Center (CAOC) in Vicenza, Italy, or with Predator pilots themselves. The Predator RPA's fullmotion video feeds were relayed via KU-band satellite data links to both the Predator pilots in their ground control stations in Tuzla Air Base in Bosnia and to the CAOC. CAOC planners could use the imagery, along with the GPS position of the Predator and

\footnotetext{
${ }^{308}$ William Rosenau, Special Operations Forces and Elusive Enemy Ground Targets, Santa Monica, Calif.: RAND Corporation, MR-1408-AF, 2001, pp. 29-41.

${ }^{309}$ Author interview with Gen. Michael Ryan, USAF (Ret.), June 18, 2014.

${ }^{310}$ Steve Coll, Ghost Wars: The Secret History of the CIA, Afghanistan, and Bin Laden, from the Soviet Invasion to September 10, 2001, New York: Penguin Books, 2004, p. 531; Daniel Benjamin and Steven Simon, The Age of Sacred Terror: Radical Islam's War Against America, New York: Random House, 2003, p. 530.

${ }^{311}$ Author interview with Gen. John Jumper, USAF (Ret.), July 31, 2013.
} 
digital terrain mapping programs, to get a rough idea of the location of the Predator RPA and the target. ${ }^{312}$ They then verbally relayed this targeting information to airborne forward air control aircraft - usually A-10s — providing a general longitude and latitude and a description of the geographical location of the target, using landmarks and terrain. (Sometimes, they would radio the strike aircraft directly). ${ }^{313}$ However, this "talk on" method was far from precise.

A-10 Thunderbolt II CAS pilots described how CAOC personnel would provide "rather comical" descriptions of tanks hiding in the woods. ${ }^{314}$ The Predator RPA's field of view is notoriously narrow — often called a "soda straw." But the A-10 pilots were looking out at a broad canopy at 20,000 feet. As a book about A-10 pilots flying in Kosovo described it: "The CAOC transmission sounded something like: 'the tank is in the woods near a dirt road'. . . however, the [A-10 pilot] saw dozens of woods and dirt roads from 20,000 feet and was still no closer to finding the tank."315

General Jumper knew a laser designator would eliminate this confusion by emitting a beam that seeker-equipped bombs and missiles would be able to follow right to the target. He told General Ryan, who by then had become the CSAF, about the targeting dilemma. ${ }^{316}$ General Ryan called retired Brigadier General Larry Mitchell, who was working at Raytheon, and asked him to coordinate with Big Safari on a solution. ${ }^{317}$ They developed the idea of using a laser designator, pitched it to General Ryan, and gained his approval to move forward around April 14, 1999-22 days after the start of the Kosovo air campaign. ${ }^{318}$ CSAF General Ryan tasked one of his special projects personnel on the Air Staff, Colonel Clark, to ensure that the laser designator concept came to fruition. ${ }^{319}$ The USAF's acquisition office directed Big Safari to modify the Predator and install the laser designator within three weeks. ${ }^{320}$

Normally, Big Safari programs are tested by the appropriate warfighting command. In the case of the laser-equipped Predator — known to Big Safari as the WILD Predator, short for Wartime Integrated Laser Designator Predator - the appropriate command was

\footnotetext{
312 Author interview with Lt. Col. Brian Raduenz, USAF (Ret.), former commander of Operating Location Detachment 4, 645th Aeronautical Systems Group, "Big Safari,” March 12, 2014.

${ }^{313}$ Richard Newman, "The Little Predator That Could," Air Force Magazine, March 2002; Jumper interview, July 31, 2013; Linda Shiner, "Predator: First Watch," Air and Space Magazine, May 2001.

${ }^{314}$ Christopher Haave and Phil M. Haun, A-10s Over Kosovo, Maxwell AFB, Ala.: Air University Press, December 2003, p. 211.

${ }^{315}$ Haave and Haun, 2003, p. 211.

316 Jumper interview, July 31, 2013.

${ }^{317}$ Grimes, 2014, p. 330.

${ }^{318}$ C4ISR, November 1, 2004, p. 14.

${ }^{319}$ Author interview with Col. Bill Grimes, USAF (Ret.), director of Big Safari from 1985 to 2002, November 4, 2013; Raduenz interview, September 13, 2013.

${ }^{320}$ Grimes, 2014, p. 330.
} 
ACC because it involved combat aircraft operations. But ACC officials declined to accept the laser-equipped RPA for Kosovo operations in the spring of $1999 .{ }^{321}$

At the operational level, the commander of ACC's Predator unit in Tuzla, the 11th Reconnaissance Squadron, declined to fly the WILD Predator because it lacked militarystandard technical manuals to ensure safety of flight. ${ }^{322}$ At the staff level, Predator program acquisition officials at ACC headquarters also balked on the grounds that there was no funding allocated to add a laser designator to an RPA that was not even an official USAF "program of record." 323

Still eager to test the WILD Predator in a combat setting, Big Safari flew it over Kosovo in "depot status" under the auspices of the Air Force Materiel Command, using its own handpicked pilots and operators from ACC Predator squadrons. ${ }^{324}$ Three WILD Predator vehicles were delivered to Tuzla Air Base to support operations over Kosovo in late May. ${ }^{325}$ The aircraft flew approximately 12 sorties before the air campaign ended. ${ }^{326}$ Once the Predator returned to the United States, ACC removed the laser designator because it was generating unplanned costs. ${ }^{327}$ Big Safari contested ACC's order to remove the laser designators for several weeks but ultimately acquiesced. ${ }^{328}$

By the time the laser designator had been introduced in the spring of 1999, it was clear that the Predator could provide long-dwell surveillance, reduce risks to civilians and aircrews, and provide time-sensitive targeting - at least partial solutions to all the problems that had plagued HVT. Moreover, the introduction of the laser designator was recognized as a precursor to weaponizing the Predator, which would have further mitigated the time-sensitive targeting problem. Recalled General Jumper: "I had always had it in the back of my mind that at some point we needed to arm the thing." 329 Yet ACC resisted the installation of the laser designator, slowing down the timeline for Predator weaponization as the CIA and White House grew increasingly anxious for an HVT solution to kill bin Laden.

\footnotetext{
${ }^{321}$ Grimes interview, November 4, 2013.

322 Grimes, 2014, p. 331.

323 Jumper interview, July 31, 2013.

${ }^{324}$ Grimes interview, November 4, 2013.

${ }^{325}$ Sean Frisbee, Weaponizing the Predator UAV: Toward a New Theory of Weapons System Innovation, Maxwell AFB, Ala.: Air University School of Advanced Air and Space Studies, 2004, pp. 62-63.

${ }^{326}$ Grimes, 2014, p. 331.

${ }^{327}$ Jumper interview, July 31, 2013; Grimes interview, November 4, 2013.

${ }^{328}$ Raduenz interview, September 13, 2013.

329 Jumper interview, July 31, 2013.
} 


\section{Afghan Eyes: The CIA-Led Predator Deployment to Track bin Laden}

In spring 2000 Richard Clarke, the top counterterrorism official on the National Security Council, proposed Afghan Eyes, a CIA-led Predator deployment to Afghanistan to track bin Laden. ${ }^{330}$ The "Small Group"- a panel of interagency officials with access to the most sensitive intelligence on bin Laden — approved a June 2000 deployment of an unarmed Predator for Afghan Eyes. ${ }^{331}$

The deployment would be politically and technologically challenging. Uzbekistan had agreed to host the Predator operations, but the country's president, Islam Karimov, who was facing his own Muslim insurgency supported from Afghanistan, could not politically afford a conspicuous U.S. presence. ${ }^{332}$ Therefore, the CIA asked the JCS if DoD could conduct Predator operations with a minimal footprint in Uzbekistan. The JCS contacted the J-39 Special Programs office in the Pentagon. From that office, USAF Brigadier General Scott Gration took the request to General Ryan, who was still serving as CSAF. ${ }^{333}$

In the spring of 2000, General Ryan approached both ACC and the Air Staff's Air and Space Operations Directorate about deploying the Predator to track bin Laden. ${ }^{334}$ Both organizations declined. By that spring, General Jumper had moved from USAFE to become ACC commander and had even begun a modest effort to weaponize the Predator. But even under General Jumper's charge, ACC turned down the CIA's request to support Afghan Eyes with just the unarmed version of the Predator due to the technological risks of the aircraft, which had shown promise in the Balkans but still suffered from reliability problems, particularly in poor weather. ${ }^{335}$ The Air Staff A3 Directorate recommended against the Predator deployment, citing technological risk. ${ }^{336}$

In late June, CSAF General Ryan approached the Director of Intelligence for Headquarters USAFE, Colonel Ed Boyle, who had gained experience with a variety of RPAs while working for General Jumper during Allied Force. Boyle flew to Washington, D.C., to meet with General Ryan, General Jumper, and the current USAFE commander, General Gregory Martin. The three generals asked the colonel to see if the current,

\footnotetext{
${ }^{330}$ Richard Clarke, Against All Enemies: Inside America's War on Terror, New York: Free Press, 2004, p. 220; National Commission on Terrorist Attacks upon the United States, 2004, p. 189.

${ }^{331}$ National Commission on Terrorist Attacks upon the United States, 2004, p. 189.

${ }^{332}$ Neil King, Jr. and David S. Cloud, “A Year Before September 11, U.S. Drones Spotted Bin Laden in his Camps but Couldn't Shoot," Wall Street Journal, November 23, 2001, p. A1.

${ }^{333}$ Author interview with Col. Ed Boyle, USAF (Ret.), February 11, 2015.

${ }^{334}$ Boyle interview, February 11, 2013.

${ }^{335}$ Boyle interview, February 11, 2015. For report on Predator reliability problems at the time, see Department of Defense Director of Operational Test and Evaluation, FY2001 Annual Report, 2002, pp. V100-V-102.

${ }^{336}$ Boyle interview, February 11, 2015.
} 
unarmed Predator system could be deployed to support the CIA. Boyle agreed to find out and requested 24 hours to assemble his team and answer the question.

Colonel Boyle reached across the USAF community for Predator expertise. The team he assembled included Major Mark Cooter, an intelligence officer on the Air Staff who had operated the Predator with ACC's 11th Reconnaissance Squadron; Capt Scott Swanson, the chief Predator operator for Big Safari; and other airmen and CIA operatives. ${ }^{337}$ They would eventually become the 32nd Expeditionary Airborne Intelligence Squadron (EAIS).

Having concluded that the deployment was achievable, Colonel Boyle then reached out to Big Safari to discuss the challenging job of minimizing the Predator's footprint in Uzbekistan. ${ }^{338}$ A Big Safari scientist proposed a solution that came to be known as "split operations." During takeoff and landing, the Predator is typically flown line-of-sight via a C-band data-link to minimize latency problems. But once the Predator reaches altitude, it is flown from a ground control station via a KU-band satellite data link that allows beyond-line-of-sight flight. Therefore, Big Safari proposed a communications fix that would allow the 32nd EAIS to operate only the Predator vehicles and a small launch and recovery element in Uzbekistan. But the conspicuous ground control stations, aircrews, and satellite earth terminal would operate from Ramstein Air Base in Germany. ${ }^{339}$ Big Safari and the 32nd EAIS referred to their support for Afghan Eyes as the "Summer Project." 340

\section{The bin Laden Sightings: What Might Have Been}

Between September and mid-November 2000, the 32nd EAIS flew approximately 15 Predator missions over Afghanistan. ${ }^{341}$ Clarke and CIA officials gathered at CIA headquarters in Langley, Virginia, to watch live video feeds from the RPA as it circled over bin Laden's beddown locations. ${ }^{342}$ On September 7, 2000, CIA officials observed a tall man in flowing white robes surrounded by a security detail at his primary compound, Tarnak Farms. ${ }^{343}$ CIA officials spotted him again on September $28 .{ }^{344}$ Clarke said bin

\footnotetext{
${ }^{337}$ Author interview with Colonel Mark Cooter, USAF (Ret.), May 22, 2014.

${ }^{338}$ Boyle interview, February 11, 2015.

339 Author interview with Big Safari scientist, August 20, 2013.

${ }^{340}$ Grimes interview, March 31, 2014.

${ }^{341}$ Coll, 2004, p. 322; National Commission on Terrorist Attacks upon the United States, 2004, p. 190.

${ }^{342}$ Clarke, 2004, p. 220; King and Cloud, 2001, p. A1.

${ }^{343}$ National Commission on Terrorist Attacks upon the United States, 2004, p. 190.

${ }^{344}$ George Tenet, At the Center of the Storm: My Years at the CIA, New York: HarperCollins, 2007, p. 127.
} 
Laden was spotted at least three times during the deployment. ${ }^{345}$ These sightings marked the first-ever real-time electro-optical images of the al Qaeda leader. ${ }^{346}$

Colonel Boyle and the other members of the 32nd EAIS were under the impression that if the Predator sighted bin Laden, the White House would authorize strikes from a U.S. Navy surface combatant or submarine. ${ }^{347}$ The team was mensurating the bin Laden imagery in real time for the purposes of weapons targeting. ${ }^{348}$ No strikes occurred, however. $^{349}$

Clarke, the White House counterterrorism adviser, was advocating for the use of cruise missiles to strike the coordinates developed by the EAIS. His deputy, Roger Cressey, wrote a memo to Sandy Berger, the National Security Adviser, noting that emergency meetings might be needed to decide on action if the Predator was able to pin down bin Laden's location. But the Clinton administration had been burned before when it had tried to use cruise missiles to go after bin Laden, so the bar had been set extremely high. "I will want more than a verified location," Berger wrote in the margins of the memo. "We will need, at least, data on pattern of movements to provide some assurance he will remain in place." The White House dynamics might have been different if the Predator had been armed. A weaponized Predator would have offered a superior alternative to cruise missiles, which would have taken longer to arrive on target.

\section{Predator Weaponization: "We Were Doing This for the Air Force, Not for Anybody Else"}

As mentioned, General Jumper had started a modest effort to weaponize the Predator in his position as ACC commander in the spring of 2000, a few months before the CIAled Afghan Eyes project began. But his effort proceeded on a drawn-out timeline and with a sense of purpose that was completely disconnected from the White House and CIA's hunt for bin Laden. ${ }^{350}$ The original USAF plan had been to test a live weapon from the Predator in May 2001, with a combat-ready armed Predator available, according to an ACC timeline, by 2004. ${ }^{351}$ As General Jumper told the author of a 2004 doctoral dissertation on RPA innovation: "We were doing this for the Air Force, not for anybody

\footnotetext{
${ }^{345}$ Clarke, 2004, p. 221.

${ }^{346}$ Boyle interview, February 11, 2015.

347 Boyle interview, February 11, 2015.

${ }^{348}$ Boyle interview, February 11, 2015.

${ }^{349}$ Boyle interview, February 11, 2015.

${ }^{350}$ For other authors who also concluded the USAF's weaponization effort was disconnected from the CIA/White House hunt for Bin Laden, see Frisbee, 2004, p. 79; also see Whittle, 2014, p. 169.

${ }^{351}$ Frisbee, 2004, p. 72; Clarke, 2004, p. 221; Henry A. Crumpton, The Art of Intelligence: Lessons From a Life in the CIA's Clandestine Service, New York: Penguin Press, 2012, pp. 155-156.
} 
else. ${ }^{, 352}$ General Jumper's original intent had been to find a way to attack fleeting targets like those he and General Ryan had encountered in the Balkans. ${ }^{353}$ General Jumper had framed the USAF's operational problem of time-sensitive targeting, but no one in the USAF had connected this service-specific problem to the CIA and White House's urgent national need for an airborne HVT solution.

General Jumper viewed the laser designator as a precursor to arming the Predator, but his concept for weaponization did not crystallize until March 2000, prompted by a completely separate initiative. USAF Major General Michael Kostelnik, head of the newly created Air Armaments Center (AAC) at Eglin Air Force Base in Florida, was seeking a funding source to test a new PGM, the Small Smart Bomb (SSB), which he believed would dramatically reduce collateral damage. He needed an airplane to test the SSB, and, as a career test pilot closely following USAF acquisition, he knew the Predator was a developmental program that might provide the perfect opportunity.

Major General Kostelnik developed a plan to test a weaponized Predator. His AAC would provide the SSB; Predator manufacturer General Atomics Aeronautical Systems, Inc. (GA-ASI) would provide the air vehicle; and Big Safari would supply the integration expertise. ${ }^{354} \mathrm{He}$ asked his deputy, Brigadier General Kevin Sullivan, to pitch the concept at an upcoming Air Armaments Summit. ${ }^{355}$ General Jumper attended the summit, where Brigadier General Sullivan briefed him on the idea of arming the Predator with the SSB. General Jumper approved the idea, as long as it could be conducted with existing resources. ${ }^{356}$

ACC's Aerospace Command and Control, Intelligence, Surveillance, and Reconnaissance Center (ACCISRC), responsible for Predator program requirements, balked at General Jumper's weaponization plan, citing the potential costs. ${ }^{357}$ Big Safari also expressed initial reservations but for a very different reason, arguing that an armed Predator was worth doing only if it could be operationalized immediately. ${ }^{358}$ Big Safari officials reviewed Major General Kostelnik's concept for arming the Predator with the SSB and decided that it would make more sense to arm it with an AGM-114 Hellfire missile, which was light enough for the Predator's fragile frame and, unlike the SSB, was

\footnotetext{
352 Jon J. Rosenwasser, "Governance Structure and Weapon Innovation: The Case of Unmanned Aerial Vehicles," Ph.D. dissertation, Tufts University, 2004, p. 362.

${ }^{353}$ Quoted in Frisbee, 2004, p. 77.

${ }^{354}$ Frisbee, 2004, p. 71.

${ }^{355}$ Author interview with Maj. Gen. Michael Kostelnik, USAF (Ret.), February 26, 2014.

${ }^{356}$ Kostelnik interview, February 26, 2014.

${ }^{357}$ Jumper interview, June 23, 2014; Frisbee, 2004, p. 73.

${ }^{358}$ Frisbee, 2004, p. 73.
} 
also combat-tested and readily available in the U.S. Army's inventory. ${ }^{359}$ Big Safari's growing interest in an operational armed Predator, as opposed to a mere demonstration of the capability, likely had something to do with the organization's involvement in the CIA-led Afghan Eyes project that same year.

\section{USAF Response to External Pressure}

The concept of tracking bin Laden with an unarmed Predator had first emerged in the White House in late 1999 or early 2000. A growing acknowledgement within the USAF of the CIA and White House's need for an airborne HVT capability may explain why General Jumper decided to accelerate the timeline for Predator weaponization in the summer of 2000. To be sure, he had started the Predator weaponization effort on a track completely separate from the CIA's and White House's need for an airborne HVT solution. But the pace of the USAF's effort began to pick up dramatically that summer, just as the White House and CIA were asking the USAF for help with the Afghan Eyes proposal.

On June 5, 2000, Lt Gen Robert Raggio, the head of the USAF's Aeronautical Systems Center (ASC), organized a meeting to coordinate the formal involvement of Big Safari and ASC in the Predator weaponization effort. He designated Big Safari, which already had responsibility for Predator acquisition, as the lead organization for Predator weaponization. $^{360}$

On June 21, 2000 - three days before ACC's General Jumper and two other generals would ask Colonel Boyle to run the unarmed Predator deployment for Afghan Eyes - the head of the ASC Reconnaissance Special Projects Office, Col Robert E. Dehnert Jr., briefed General Jumper on his weaponized Predator options, including Big Safari's pitch for the Hellfire. ${ }^{361}$ General Jumper picked the Hellfire, the most expedient option, and asked Big Safari officials to return in July with a detailed weaponization plan. He also ordered the reinstallation of the laser designator on the Predator and scolded ACC officials for having removed it in the first place. ${ }^{362}$

Big Safari officials, along with those from Predator manufacturer GA-ASI, returned to ACC in July 2000 to brief General Jumper on the details of Predator weaponization. General Jumper accelerated the timeline, telling the GA-ASI officials that ACC would pay the company $\$ 3$ million to launch a Hellfire from the Predator in three months (by October 2000) and develop an operational capability in about nine months (by April

\footnotetext{
${ }^{359}$ Grimes interview, March 31, 2014; Richard Whittle, "Predator's Big Safari," Air Force Association Mitchell Institute for Airpower Studies, Mitchell Paper 7, August 2011, p. 28.

${ }^{360}$ Frisbee, 2004, p. 73.

${ }^{361}$ Whittle, 2011, p. 18.

${ }^{362}$ Raduenz interview, September 13, 2013.
} 
2001). ${ }^{363}$ As Sean Frisbee notes in his thesis on the Predator: "This decision signified a mental leap that General Jumper had made, but others had not. General Jumper recognized the program not as a demonstration, but as one that could rapidly provide a new operational capability." 364

Pressure to weaponize continued to mount. As the Predator's Afghan Eyes deployment wound down in the fall of 2000, CIA counterterrorism officials, along with White House counterterrorism advisor Clarke, had become increasingly determined to arm the Predator quickly. ${ }^{365}$ "We had this situation where you could see the guy [bin Laden] but you had no way to reach out and touch him," recalled Lt Gen John "Soup" Campbell, the top USAF official on the CIA staff. "I think probably the idea of arming the Predator had been kicking around at a low level. But suddenly you had this clear requirement, and things really took off." ${ }^{, 366}$ Big Safari began work to weaponize the Predator in time for the spring of 2001, when they expected the CIA to take the RPA back to Afghanistan. ${ }^{367}$

\section{Later Barriers to Weaponization}

Even after the USAF sped up weaponization in response to external pressure, there were still a variety of obstacles to overcome. Initially, the USAF had pursued weaponization on its own timeline for its own purposes, encountering internal resistance from ACC. Once the CIA and White House became interested, the project was connected to the strategic problem of airborne HVT, and the timeline accelerated. But other obstacles, mostly external, would further delay weaponization. Afghan Eyes would end in the fall of 2000, and an entire year would go by with no operational armed Predator flights. On September 11, 2001, the armed version of the Predator was not yet in Afghanistan.

The first additional obstacle, which was both internal and external, emerged at the end of the summer of 2000. The USAF was planning to test Hellfire missiles from the Predator starting that fall. ${ }^{368}$ But USAF lawyers issued a legal opinion prohibiting "touch labor" until the USAF received permission to weaponize the Predator from the U.S.

\footnotetext{
363 Jumper interview, July 31, 2013; Frisbee, 2004, p. 75.

${ }^{364}$ Frisbee, 2004, p. 74.

${ }^{365}$ Crumpton, 2012, pp. 156-157.

${ }^{366}$ Author interview with Lt. Gen. John Campbell, USAF (Ret.), April 3, 2014.

${ }^{367}$ Grimes interview, March 31, 2014; a December 2000 CIA memo to Clarke suggested resumption of Predator flights in March 2001. See National Commission on Terrorist Attacks upon the United States, 2004, p. 197.

${ }^{368}$ Amy Butler, "Predator Will Rain Hellfire in Weaponization Demonstration," Inside the Air Force, August 11, 2000.
} 
Congress. ${ }^{369}$ The USAF cleared up the issue by September 21, after a 10-day shutdown of weaponization work. ${ }^{370}$

The second additional obstacle was the interpretation of the 1987 Intermediate Range Nuclear Forces Treaty banning the development of, among other systems, new groundlaunched cruise missiles. Big Safari was ordered to stop Predator weaponization on October 17, 2000 and could not resume until receiving word in December 2000 that an interagency panel had determined that an armed Predator was not a treaty violation. ${ }^{371}$ Once Predator manufacturer GA-ASI reopened after the holidays, Big Safari resumed work and conducted the first successful Hellfire shot from a laser-designator-equipped Predator in February 2001. ${ }^{372}$

The third additional obstacle was a disagreement between the CIA and the Pentagon over authorities and responsibilities. Neither was eager to take responsibility for authorizing Predator strikes or for actually killing a person from an RPA. The CIA feared that its involvement could be construed as a violation of a 1976 U.S. ban on assassinations. For its part, the Pentagon was worried about launching a weapon on an HVT outside of a combat zone. ${ }^{373}$ Money also was a problem, since neither the CIA nor the Pentagon wanted to pay for another deployment. ${ }^{374}$ The issues were hotly debated at a September 4, 2001 meeting of the National Security Council Principles Committee, but the issues were not resolved at the meeting. Instead, the committee decided to hold off on an armed Predator strike on bin Laden until these issues could be worked out. ${ }^{375}$

Finally, relatively minor technical issues of the sort that typically afflict weapons development programs also slowed down the armed Predator project. The CIA requested a Hellfire warhead designed to kill personnel rather than destroy tanks. ${ }^{376}$ It also requested the capability to conduct a revised version of split operations - known as "remote split operations" - that would move the Predator ground control stations out of Germany and back to the United States. (White House officials had become concerned about the political consequences of flying the Predator in a weaponized configuration from an allied country. ${ }^{377}$ ) It was not until September 10, 2001, the day before the 9/11

\footnotetext{
${ }^{369}$ Whittle, 2014, p. 177.

${ }^{370}$ Frisbee, 2004, p. 69.

${ }^{371}$ Jumper interview, July 31, 2013; Frisbee, 2004, p. 69.

${ }^{372}$ Frisbee, 2004, p. 76.

373. Campbell interview, April 3, 2014; National Commission on Terrorist Attacks upon the United States, 2004, pp. 211-212.

${ }^{374}$ National Commission on Terrorist Attacks upon the United States, 2004, p. 211.

${ }^{375}$ National Commission on Terrorist Attacks upon the United States, 2004, p. 214.

${ }^{376}$ National Commission on Terrorist Attacks upon the United States, 2004, p. 211.

${ }^{377}$ Campbell interview, April 3, 2014.
} 
terrorist attacks, that the USAF began its final tests of the remote split operations concept, signaling that the technical hurdles were finally all but surmounted. ${ }^{378}$

\section{Conclusion}

The USAF might have been able to weaponize the Predator prior to the September 11, 2001 attacks if it had framed and prioritized the effort as a solution to the national strategic problem of time-sensitive targeting of HVTs. By the late 1990s senior Air Force leaders had recognized the importance of Predator weaponization for solving the USAF's operational problem of time-sensitive targeting against conventional target sets. However, there was no obvious USAF mechanism to connect the operational problem of Predator weaponization to the strategic problem of tracking bin Laden. If such a mechanism had existed, it might have been possible to weaponize the Predator much sooner-perhaps as early as 1998, following the embassy bombings in Kenya and Tanzania. If nothing else, a more focused, strategic effort to overcome the problem of airborne HVT might have jumpstarted weaponization after the arrival of the WILD Predator in Kosovo in May 1999.

Absent a sense of urgency for solving a national strategic problem, Predator innovation was vulnerable to internal and external obstacles. ACC resisted the installation of the laser designator, declined the opportunity to run Afghan Eyes, and pushed back against the concept of Predator weaponization even after General Jumper arrived as ACC commander. There were also external political and technical challenges to weaponization. But if the USAF had framed and prioritized the problem sooner, it would have had more time to confront these challenges and to complete the process of Predator weaponization prior to Afghan Eyes in 2000 or at least before the September 11, 2001 attacks.

This case study has two important implications for the Air Force today. First, the USAF requires a mechanism for identifying and framing national strategic problems that it might have the internal capacity to solve through focused innovation. The USAF possessed the information and ability to address the HVT problem during the 1990s but lacked the means to formulate airborne HVT as a strategic problem and to operationalize a solution. It was only because General Jumper recognized the emerging operational problem of time-sensitive targeting that Predator weaponization gained traction with the USAF. But even then, external pressure was required to speed up the innovation process in response to a national need.

Second, the USAF may need to improve its capacity for innovation that brings together operators and prototype technologies for field exercises to solve a strategically

\footnotetext{
${ }^{378}$ Big Safari scientist interview, August 20, 2013.
} 
important operational problem quickly in peacetime. Big Safari provides part of this capacity. In fact, it did field-test the weaponized Predator over mud huts meant to resemble Tarnak Farms at the Naval Air Weapons Station China Lake in June 2001. ${ }^{379}$ But Big Safari is not responsible for identifying the strategically important problems, its acquisition procedures are unique within the $\mathrm{DoD}$, and it encounters resistance to its innovations from organizations focused on traditional acquisition. There is a need for a broader capability that integrates operators and technology developers to solve discrete problems.

${ }^{379}$ Whittle, 2014, pp. 201-204. 


\section{Findings and Implications}

Developing innovative means to go "over not through" national strategic challenges has always been central to the Air Force's contribution to American security and prosperity. ${ }^{380}$ The need for this contribution will become only more acute in the decades ahead, as the rise of new great powers and potent nonstate hybrid actors will increasingly challenge the stability of the international system at the same time that fiscal and demographic trends will put increasing pressure on U.S. defense resources. ${ }^{381}$ Innovation by the Air Force and its joint partners will be essential to bridging the looming gap between requirements and resources. It is therefore an appropriate moment for the Air Force to take a serious look at its capacity and propensity to innovate.

Senior Air Force leaders have initiated a wide-ranging conversation about whether the service is sufficiently innovative today and what can be done to make it more innovative in the future. This report aims to contribute to that conversation by assessing six historical cases of Air Force innovation, or apparent failure to innovate, in the context of the scholarly literature on military innovation.

\section{Cross-Case Findings}

\section{Air Force Innovation Begins with Strategy}

The case studies presented here show that Air Force innovation begins with strategy. While Air Force officers often think of innovation in purely technological terms, and while academics often discuss innovation in competitive economic or political terms, our research indicates that innovation in the Air Force usually begins with the identification of strategically significant operational problems to be solved. Where the Air Force has produced major innovation, such as strategic reconnaissance and post-Vietnam SEAD, it has been fueled and framed by the linkage of a concrete operational problem to a national strategic problem. Where the Air Force has failed to innovate, it is primarily because the

\footnotetext{
${ }^{380}$ Global Vigilance, Global Reach, Global Power for America, 2014.

${ }^{381}$ See discussion in Adam Grissom et al., The Air Force and the New American Grand Strategy, Santa Monica, Calif.: RAND Corporation, PR-1167-AF, 2014.
} 
service and its MAJCOMs have not perceived the linkage between a strategic and an operational problem and therefore have not seen it as worthy of added resources and attention. Pre-Vietnam SEAD, pre-Korea CAS, and airborne HVT in the 1990s are all examples of decisions to not innovate in the absence of a perceived strategic priority.

Notably, as depicted in Figure 8.1, many of our six successful and unsuccessful cases of innovation overlap in time. During the 1950s, the Air Force was at the same moment driving important innovations in strategic reconnaissance and nuclear survivability while failing to adapt its CAS capabilities for the jet age or to focus the TAF on defeating the Soviet IADS. During the 1990s, as the Air Force was perfecting precision strategic attack campaigns, it was also failing to pursue airborne HVT innovation. In the case of SEAD, a decade of innovation followed a decade of apparent failure to innovate. This suggests that there are limits to the utility of debating whether the Air Force "is" or "is not" innovative. At many points in its history, the USAF has simultaneously succeeded and failed to innovate. The central question at any point may therefore be where the Air Force is focusing its innovative energies rather than whether it is or is not innovative per se.

Figure 8.1. Innovation and Noninnovation Often Coincide

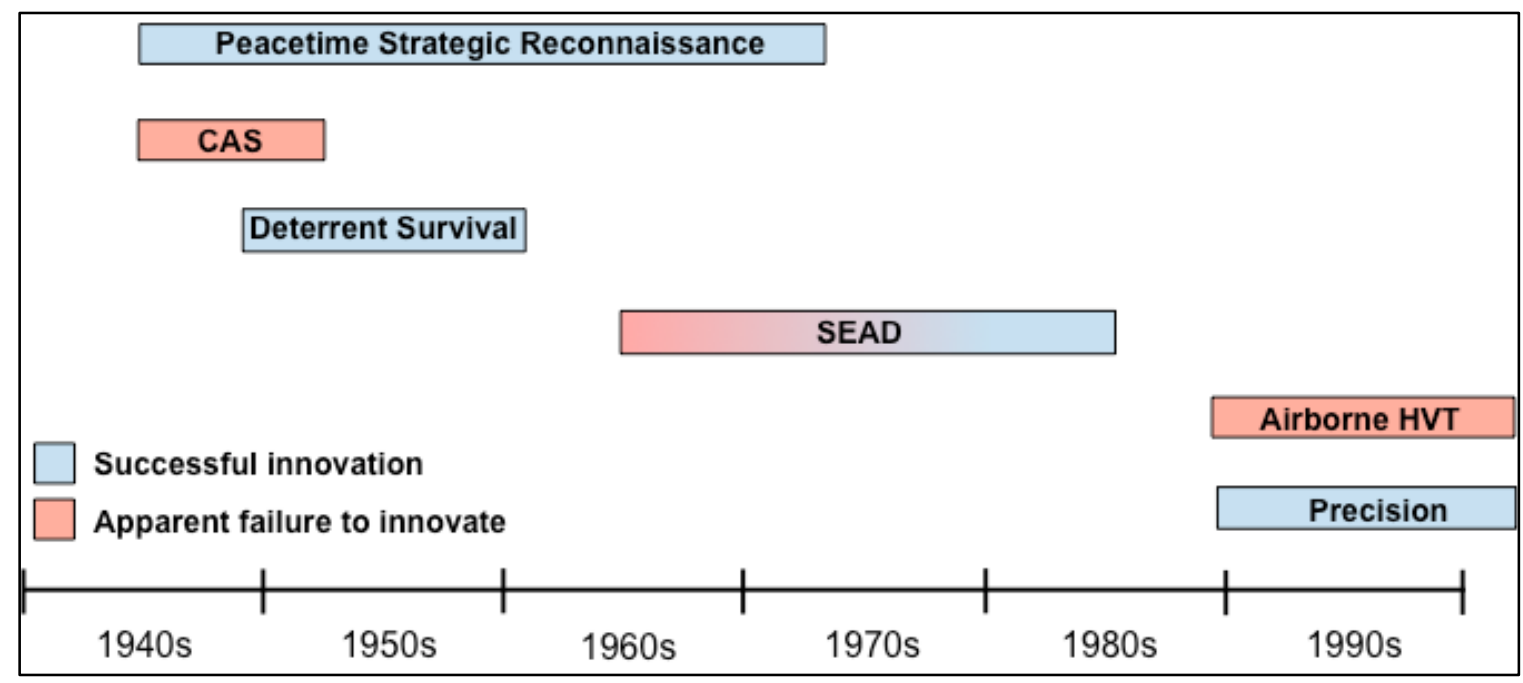

As Air Force leaders seek to make the service more innovative, it may therefore be useful to ask what strategically significant operational problems they have explicitly and implicitly framed for the service to solve.

\section{The Air Force Has a Distinct Heritage of Innovation}

The emerging conversation on Air Force innovation is motivated, at least in part, by concerns that the service may not be sufficiently innovative today. The case studies 
presented here cannot answer that question, but they do definitively demonstrate that the Air Force has accomplished remarkable innovations since its establishment. Indeed, it has a deep heritage of innovation and adaptation. The development of strategic reconnaissance capabilities, of a survivable nuclear retaliatory force, of SEAD capabilities, and of precision strategic attack capabilities were all important innovations that addressed pressing national strategic and operational problems.

Equally important, the Air Force heritage of innovation is not just distinguished but also distinct. The Air Force innovates differently than other military organizations. The academic literature on military innovation, which is built primarily on ground force experience, emphasizes doctrinal and organizational change as the typical indicators of innovation. When the U.S. Army innovates, for example, the key actors are most often the senior leaders in the Army Staff and in the Army's Training and Doctrine Command. The signifier of U.S. Army innovation is most often a revision of its capstone doctrinal manual and/or the creation of a new type of combat division or brigade associated with the innovation. ${ }^{382}$ In contrast, none of the major episodes of USAF innovation examined in this monograph resulted in a fundamental revision of formal USAF doctrine. Nor did the important cases of noninnovation, such as pre-Korea CAS and airborne HVT, trigger any significant doctrinal debate. Moreover, the SEAD and precision strike innovations did not even result in significant organizational restructuring.

Instead, the informal character of Air Force doctrine tends to conceal the scope and nature of the service's innovation. Generally speaking, the best way to determine if the USAF has innovated is to examine how operational units conduct operations in practice. Thus, contrary to the academic literature focusing on the doctrinal and organizational underpinnings of ground forces, the most reliable indicator of major strategic-level Air Force innovation is the de facto emergence of a new type of air campaign. The advent of nuclear retaliatory campaign plans in the 1950s, SEAD campaigns in the 1970s, and precision strategic attack campaigns in the 1990s are prime examples. Conversely, the mere existence of Air Force doctrine on CAS in the pre-Korea period and on SEAD in the pre-Vietnam period belied actual innovation in operational units.

Innovation in the Air Force also appears to be a more decentralized and diffuse phenomenon than in other services. Perhaps most intriguing is the unique set of roles played by key Air Force MAJCOMs. TAC was central to the pre-Korea CAS and postVietnam SEAD case studies. SAC was the locus of nuclear innovation. ACC was the key organization in the airborne HVT case. Judging from the military innovation literature, the USAF MAJCOMs have no obvious parallels in other U.S. military services.

\footnotetext{
382 "U.S. Army Innovation Orthodoxy," in Adam Grissom, To Digitize an Army: The U.S. Army Force XXI Initiative and the Digital Divide Controversy, 1994-2004, unpublished Ph.D. dissertation, King's College, London, 2009.
} 
Additionally, USAF innovation may be more permeable than in other services. The degree of outsider participation in the strategic reconnaissance, nuclear deterrent, and airborne HVT cases is remarkable, particularly given that much of the external intervention occurred laterally into the Air Force rather than top-down from civilian policymakers to the service leadership and thence down into the organization.

\section{Diversity of Air Force Innovation}

The different roles played by HAF, MAJCOMs, and operational units also produce a spectrum of different types of innovation across the Air Force. HAF-driven innovation has tended to be technologically focused and of extended duration. We term this phenomenon "long-cycle innovation" because it typically unfolds over multiple years or even Future Years Defense Plan (FYDP) periods. The strategic reconnaissance innovation is an archetypal case of long-cycle innovation, having focused on the creation of a completely new technological capability and having stretched over 25 years before the operational problem was conclusively solved. The nuclear deterrent survivability innovation also fits this model of a relatively long-term process resulting in a transition to the truly intercontinental combination of B-52s and KC-135s and, eventually, the ICBM. Pre-Korea CAS might be considered the obverse, as the Air Force's long-cycle choices about fighter design during the late 1940s led the service to miss the potential innovation of jet CAS until the mid-1960s.

On the other end of the temporal spectrum is immediate adaptation during active operations. Figure 8.2 depicts the difference between long-cycle innovation and immediate adaptation. The clearest example of immediate adaptation in our case studies is the attempt by the fighter wings based in Thailand to adapt to the evolving North Vietnamese IADS problem between 1965 and 1968. The experimental deployments of the Predator to the Balkans and Afghanistan also represent a type of immediate adaptation, driven by the air component and the CIA, respectively. 
Figure 8.2. Three Types of Air Force Innovation
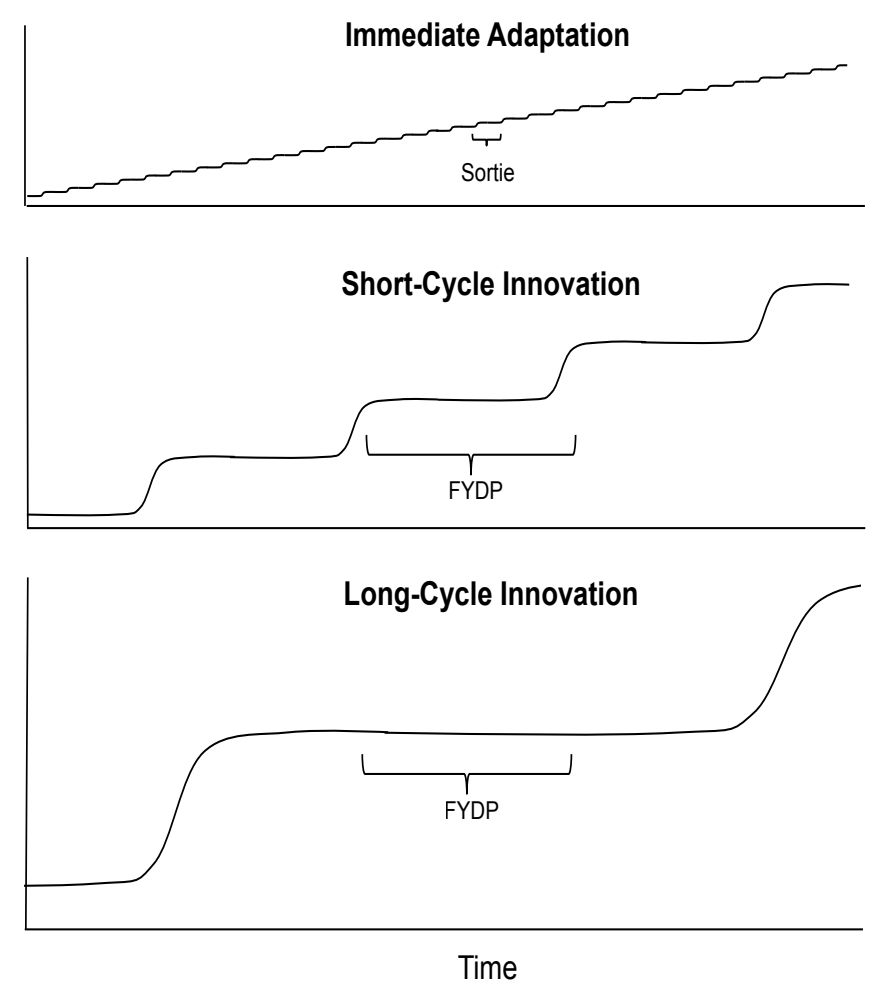

Between immediate adaptation and long-cycle innovation is a phenomenon we call short-cycle innovation. This type of innovation brings together operators and capability developers for a sustained series of field exercises and experiments to solve a strategically important operational problem on an accelerated basis in peacetime. The key cases of short-cycle innovation in this report are the post-Vietnam SEAD campaign and the precision strategic attack innovations, both during the 1970s and 1980s. Both innovations occurred at Nellis Air Force Base, where the Flag exercises provided the mechanism for the TAF to adapt to the evolving Soviet SEAD threat and to solve the strategic problem of coercing regional powers with precision airpower.

Interestingly, the temporal framework presented here, featuring long-cycle, shortcycle, and immediate changes to USAF capabilities, has no obvious parallel in the broader military innovation literature. This may be because the USAF's unique innovation structure - in which the HAF, MAJCOMs, and operational units all play important roles - is significantly different than that of other military organizations. On the other hand, it may be the case that other organizations also implement long-cycle, short-cycle, and immediate changes, but this has yet to be reflected in scholarship. 


\section{Implications for the Air Force}

The Air Force is a complex instrument of national power employed daily in an increasingly complex strategic environment. It is therefore necessary to exercise particular modesty in identifying the implications of this research for Air Force senior leaders. Nevertheless, we would venture to offer three such implications for senior leaders to consider.

\section{The Need for a Strategic Problem-Framing Mechanism}

Because fostering innovation in the Air Force is first and foremost about strategyparticularly the framing and prioritization of strategically significant operation problems to be solved - the emerging conversation on Air Force innovation should focus, to at least a degree, on whether the Air Force leadership possesses an appropriate mechanism for identifying and framing the key operational challenges that necessitate innovation.

Our discussions with Air Force leaders suggest it does not. There is no mechanism today, inside or outside of the strategic planning system, that will allow the senior leadership to identify and frame, let alone prioritize, the most pressing challenges in a deliberate fashion. Our conversations with senior leaders indicate that, in the absence of such a mechanism, the demands of running the service make it difficult to focus attention "outward" and "upward" on national strategic problems. This difficulty is exacerbated by a growing belief among USAF officers that, in the post-Goldwater-Nichols era, the Air Force is simply a force provider with no mandate to develop innovative solutions to the nation's strategic problems. Our analysis suggests this interpretation of the GoldwaterNichols Act reflects a misunderstanding of its intent, harms innovation, and squares poorly with the reality of a DoD system that still allocates the vast majority of innovative capacity to the services. To the extent that senior Air Force leaders are interested in making the service more innovative, their first step should be to devise a mechanism through which they can frame operational problems of national strategic significance, assign them to appropriate Air Force organizations and units to solve, and apportion suitable resources to enable those efforts.

\section{The Need for Short-Cycle Innovation}

The USAF should focus on preserving its capacity for short-cycle innovation. The Air Force's recent 30-year strategy emphasizes the need for rapid peacetime innovation in response to evolving strategic problems and threats. This fits our definition of shortcycle innovation, and the case of post-Vietnam SEAD innovation provides a canonical example. In that case, the capacity for innovation stemmed from the Nellis Flag exercises and schoolhouses, where operators, materiel developers, concept developers, and aggressors worked a problem together on a recurring basis. The physical and cognitive 
space provided by Nellis was essential to overcoming the rapidly evolving Soviet IADS problem during the 1970s and 1980s. However, the Air Force capacity for short-cycle innovation is extremely limited and could become much more so with budget reductions. The Air Force should examine whether its current field experimentation capacity is sufficient and, even more importantly, whether it remains well suited to innovating against priority national strategic problems.

\section{The Need for a Broader Conversation on Airpower Innovation}

Finally, our analysis indicates that there is a need for a great deal more conceptual and empirical work on airpower innovation. The military innovation literature, which is extraordinarily influential in DoD and on Capitol Hill, focuses almost exclusively on historical cases of ground forces. We found that the USAF (and perhaps air arms in general) innovates differently than ground and maritime services. Yet relatively little scholarship has been published on USAF innovation since $9 / 11$. This compares with dozens of books and articles published on ground force innovation in Iraq and Afghanistan. To the extent that the USAF wishes to bill itself as an innovative service and have a coherent conversation inside and outside the service on improving its innovativeness, this lack of scholarly support is a serious impediment. 


\section{References}

Abella, Alex, Soldiers of Reason: The RAND Corporation and the Rise of the American Empire, New York: Mariner Books, May 2009.

Adamsky, Dima, The Culture of Military Innovation: The Impact of Cultural Factors on the Revolution in Military Affairs in Russia, the US, and Israel, Stanford, Calif.: Stanford University Press, 2010.

Adamsky, Dima, and Kjell Inge Bjerga, Contemporary Military Innovation: Between Anticipation and Adaptation, New York: Routledge, 2012.

Air Force Space Command, Biography of Colonel Richard Sully Leghorn, USAF (Ret.), undated. As of September 11, 2015:

http://www.afspc.af.mil/library/biographies/bio.asp?id=9942

Air Tactics Against NVN Air/Ground Defenses, Honolulu, Hawaii: PACAF Tactical Evaluation Directorate, Project CHECO, February 27, 1967. Originally

SECRET/NOFORN, declassified by AF/HOH IAW E.O. 13526, November 26, 2010.

Allison, Fred H., "Black Sheep in Korea: A Reflection of Mission Transformation," in Jacob Neufeld and G. M. Watson, Jr., eds., Coalition Air Warfare in the Korean War, 1950-1953, Washington, D.C.: Air Force History and Museums Program, 2005.

Anderegg, C. R., Sierra Hotel: Flying Air Force Fighters in the Decade After Vietnam, Washington, D.C.: Air Force History and Museums Program, 2001.

Army Air Forces Scientific Advisory Group, "Science, the Key to Air Supremacy," Toward New Horizons, Washington, D.C.: Headquarters, Army Air Forces, 1945.

Benjamin, Daniel, and Steven Simon, The Age of Sacred Terror: Radical Islam's War Against America, New York: Random House, 2003.

Berkowitz, Bruce, The National Reconnaissance Office at 50 Years: A Brief History, Chantilly, Va.: National Reconnaissance Office (NRO), 2011.

Betts, Richard K., Nuclear Blackmail and Nuclear Balance, Washington, D.C.: Brookings Institution Press, 1987. 
Blair, Bruce G., Strategic Command and Control: Redefining the Nuclear Threat, Washington, D.C.: Brookings Institution Press, 1984.

Boose, D. W., "The Army View of Close Air Support in the Korean War," in Jacob Neufeld and G. M. Watson, Jr., eds., Coalition Air Warfare in the Korean War, 1950-1953, Washington, D.C.: Air Force History and Museums, 2005.

Boyd, Robert J., SAC's Fighter Planes and Their Operations, Office of the Historian, Strategic Air Command, August 1, 1988.

Boyle, Col. Ed, USAF (Ret.), author interview, February 11, 2015.

Brodie, Bernard, ed., The Absolute Weapon: Atomic Power and World Order, New York: Harcourt Brace, 1946, p. 76

— , "The Development of Nuclear Strategy," International Security, Vol. 2, No. 4, Spring 1978, pp. 65-83.

Butler, Amy, "Predator Will Rain Hellfire in Weaponization Demonstration," Inside the Air Force, August 11, 2000.

Byman, Daniel, "Why Drones Work: The Case for Washington's Weapon of Choice," Foreign Affairs, July/August, 2013.

C4ISR, November 1, 2004, p. 14.

Campbell, Lt. Gen. John, USAF (Ret.), author interview, April 3, 2014.

Carey, John, and Patricia Krantz, "Secrets of the Soviet H-Bomb," Business Week, October 27, 1996. As of September 11, 2015:

http://www.businessweek.com/stories/1996-10-27/secrets-of-the-soviet-h-bomb

Central Intelligence Agency,,National Intelligence Estimate 11-10-69, Trends and Prospects in Soviet Maritime Activities, June 12, 1969, declassified by CIA Historical Review Program, 1994.

—, National Intelligence Estimate 11-3-65, Soviet Strategic Air and Missile Defenses, November 18, 1965, Document C00278469, declassified by CIA Historical Review Program, 1965.

_- “A Look Back ... CORONA: The Nation's First Photoreconnaissance Satellite," fact sheet, 2010. As of September 11, 2015:

https://www.cia.gov/news-information/featured-story-archive/2010-featured-storyarchive/corona-the-nation2019s-first-photoreconnaissance-satellite.html

CIA—See Central Intelligence Agency. 
Clancy, Tom, and Chuck Horner, Every Man a Tiger: The Gulf War Air Campaign, New York: Berkley, 2000.

Clarke, Richard, Against All Enemies: Inside America's War on Terror, New York: Free Press, 2004.

Clauser, F. H., Preliminary Design of an Experimental World-Circling Spaceship, Santa Monica, Calif.: RAND Corporation, SM-11827, 1946. As of September 11, 2015: http://www.rand.org/pubs/special_memoranda/SM11827.html

Cockburn, Andrew, Kill Chain: The Rise of the High-Tech Assassins, New York: Henry Holt, 2015.

Coll, Steve, Ghost Wars: The Secret History of the CIA, Afghanistan, and Bin Laden, from the Soviet Invasion to September 10, 2001, New York: Penguin Books, 2004.

Cooter, Col. Mark, USAF (Ret.), author interview, May 22, 2014.

Cote, Owen R., Jr., The Politics of Innovative Military Doctrine: The U.S. Navy and Fleet Ballistic Missiles, Ph.D. dissertation, Massachusetts Institute of Technology, 1996.

Craven, Wesley Frank, and James Lea Cate, eds., The Army Air Forces in World War II, Europe, Volume Two: Torch to Point Blank, Washington, D.C.: Office of Air Force History, 1983, pp. 694-969.

Crickmore, Paul, Lockheed A-12: The CIA's Blackbird and Other Variants, New York: Osprey Publishing, 2014.

Cronin, Audrey Kurth, "Why Drones Fail: When Tactics Drive Strategy," Foreign Affairs, July/August, 2013.

Crumpton, Henry A., The Art of Intelligence: Lessons from a Life in the CIA's Clandestine Service, New York: Penguin Press, 2012.

Davies, Merton E., and William R. Harris, RAND's Role in the Evolution of Balloon and Satellite Observation Systems and Related U.S. Space Technology, Santa Monica, Calif.: RAND Corporation, R-3692-RC, 1988. As of September 11, 2015: http://www.rand.org/pubs/reports/R3692.html

Department of Defense Director of Operational Test and Evaluation, FY2001 Annual Report, 2002, pp. V-100-V-102.

Deptula, Lt. Gen. David, USAF (Ret.), author interview, February 2012.

Ehlers, Robert S., Jr., Targeting the Third Reich: Air Intelligence and the Allied Bombing Campaigns, Lawrence, Kan.: University Press of Kansas, 2009. 
Ehrhard, Thomas P., "Unmanned Aerial Vehicles in the United States Armed Services: A Comparative Study of Weapon System Innovation," Ph.D. dissertation, Johns Hopkins University, 2000.

Endicott, Judy G., The USAF in Korea: Campaigns, Units, and Stations, 1950-1953, Washington, D.C.: Air Force History and Museums Program, 2001, pp. 45-57.

Farquhar, John T., A Need to Know: The Role of Air Force Reconnaissance in War Planning, 1945-1953, Maxwell AFB, Ala.: Air University Press, 2004.

Farrell, Theo, "Improving in War: Military Adaptation and the British in Helmand Province, Afghanistan, 2006-2009," Journal of Strategic Studies, Vol. 33, No. 4, August 2010, pp. 567-594.

Foley, Robert, "A Case Study in Horizontal Military Innovation: The German Army, 1916-1918," Journal of Strategic Studies, Vol. 35, No. 6, December 2012, pp. 799 827.

Frankel, Matt, "The ABCs of HVT: Key Lessons from High Value Targeting Campaigns Against Insurgents and Terrorists," Studies in Conflict and Terrorism, Vol. 34, No. 1, 2011, pp. 17-30.

Franks, Tommy, American Soldier, New York: ReganBooks, 2004.

Freedman, Lawrence, The Evolution of Nuclear Strategy, $3^{\text {rd }}$ edition, London: Macmillan, 1983.

Frisbee, Sean, Weaponizing the Predator UAV: Toward a New Theory of Weapon System Innovation, Maxwell AFB, Ala.: Air University School of Advanced Air and Space Studies, 2004.

Frontline, Interview with General Charles Horner, Commander of the U.S. Ninth Air Force ("The Gulf War"), 1997.

Futrell, Robert Frank, Ideas, Concepts, Doctrine: Basic Thinking in the United States Air Force, 1907-1960, Vol. 1, Maxwell AFB, Ala.: Air University Press, 1989.

Global Vigilance, Global Reach, Global Power for America, Washington, D.C.: Headquarters, Air Force, 2014.

Gooderson, Ian, Air Power at the Battlefront: Allied Close Air Support in Europe, 19431945, London: Cass, 1998.

Gorn, Michael H., Harnessing the Genie: Science and Technology Forecasting for the Air Force, 1984-1986, Washington, D.C.: Office of Air Force History, 1988.

Grimes, Col. William, USAF (Ret.), author interview, November 4, 2013. 
—, The History of Big Safari, Richmond, B.C.: Archway, January 30, 2014.

Grissom, Adam, "The Future of Military Innovation Studies," Journal of Strategic

Studies, Vol. 29, No. 5, October 2006, pp. 905-934.

Grissom, Adam, Hal Brands, Lawrence Freedman, Jennifer Kavanagh, Patrick H. Mills, Stephan Seabrook, and Jerry M. Sollinger, The Air Force and the New American Grand Strategy, Santa Monica, Calif.: RAND Corporation, PR-1167-AF, 2014.

Gulf War Air Power Survey (5 vols.), Washington, D.C.: U.S Government Printing Office, 1993.

Gunston, Bill, The Encyclopedia of World Air Power, New York: Crescent, 1987.

Haave, Christopher, and Phil M. Haun, A-10s Over Kosovo, Maxwell AFB, Ala.: Air University Press, December 2003, p. 211.

Hafez, Mohammed, and Joseph M. Hatfield, "Do Targeted Assassinations Work? A Multivariate Analysis of Israel's Controversial Tactic During Al-Aqsa Uprising," Studies in Conflict and Terrorism, Vol. 29, No. 4, June 2006, pp. 359-382.

Hall, Cargill, "Sputnik, Eisenhower, and the Formation of the United States Space Program," Quest, Vol. 14, No. 4, 2007, p. 38.

Henriksen, Dag, NATO's Gamble: Combining Diplomacy and Airpower in the Kosovo Crisis, 1989-1999, Annapolis, Md.: Naval Institute Press, 2007.

Holley, I. B., Ideas and Weapons: Exploitation of the Aerial Weapon by the United States During World War I, New Haven, Conn: Yale University Press, 1953.

Honig, Or, "Explaining Israel's Misuse of Strategic Assassinations," Studies in Conflict and Terrorism, Vol. 30, No. 6, June 2007, pp. 563-577.

Hosmer, Stephen T., Operations Against Enemy Leaders, Santa Monica, Calif.: RAND Corporation, MR-1385-AF, 2001. As of September 13, 2015: http://www.rand.org/pubs/monograph_reports/MR1385.html

Hughes, Thomas A., Overlord: General Pete Quesada and the Triumph of Tactical Airpower in World War II, New York: Free Press, 1995.

International Security, International Security Data Site, "Drone Wars Pakistan:

Analysis," Washington, D.C.: New America, undated. As of September 13, 2015:

http://securitydata.newamerica.net/drones/pakistan-analysis.html

International Security, International Security Data Site, "Drone Wars Yemen: Analysis," Washington, D.C.: New America, undated. As of September 13, 2015: http://securitydata.newamerica.net/drones/yemen-analysis.html 
Jacobs, Will A., "The Battle for France, 1944," in Benjamin F. Cooling, ed., Case Studies in the Development of Close Air Support, Washington, D.C.: Office of Air Force History, 1990, pp. 237-294.

Johnson, David E., Fast Tanks and Heavy Bombers: Innovation in the U.S. Army, 19171945, Ithaca, N.Y.: Cornell University Press, 2003.

— Learning Large Lessons: The Evolving Roles of Ground Power and Air Power in the Post-Cold War Era, Santa Monica, Calif.: RAND Corporation, MG-405-1-AF, 2007. As of September 13, 2015:

http://www.rand.org/pubs/monographs/MG405-1.html

Johnson, Stephen B., The United States Air Force and the Culture of Innovation, Washington, D.C.: Air Force History and Museums Program, 2002.

Johnston, Patrick B., "Does Decapitation Work? Assessing the Effectiveness of Leadership Targeting in Counterinsurgency Campaigns," International Security, Vol. 36, No. 4, 2012, pp. 47-79.

Jordan, Jenna, "When Heads Roll: Assessing the Effectiveness of Leadership Decapitation,” Security Studies, Vol. 18, No. 4, December 2009, pp. 719-755.

Jumper, Gen. John, USAF (Ret.), author interview, July 31, 2013.

Kaplan, Fred, The Wizards of Armageddon, New York: Simon and Schuster, 1983.

Keaney, Thomas A., and Eliot A. Cohen, Revolution in Warfare? Air Power in the Persian Gulf, Annapolis, Md.: Naval Institute Press, 1995.

King, Neil, Jr., and David S. Cloud, "A Year Before September 11, U.S. Drones Spotted Bin Laden in his Camps but Couldn't Shoot," Wall Street Journal, November 23, 2001.

Knaack, Mercelle S., Encyclopedia of U.S. Air Force Aircraft and Missile Systems, Volume 1: Fighters, 1947-1975, Washington, D.C.: Office of Air Force History, 1978.

— , Post-World War II Bombers, 1945-1973, Washington, D.C.: Office of Air Force History, 1988.

Knemeyer, F., "Shrike's Forgotten Lessons," The China Laker: Newsletter of the China Lake Museum Foundation, Vol. 10, No. 4, Fall 2004.

Komons, Nick A., Science and the Air Force: A History of the Air Force Office of Scientific Research. Arlington, Va.: Office of Aerospace Research, 1966. 
Kopets, K. F., "The Close Air Support Controversy in Korea," in Jacob Neufeld and G. M. Watson, Jr., eds., Coalition Air Warfare in the Korean War, 1950-1953, Washington, D.C.: Air Force History and Museums Program, 2005, p. 122.

Kostelnik, Maj. Gen. Michael, USAF (Ret.), author interview, February 26, 2014.

Kreps, Sarah, and Micah Zenko, "The Next Drone Wars: Preparing for Proliferation," Foreign Affairs, March/April 2014.

Kuehl, D. T., The Radar Eye Blinded: The USAF and Electronic Warfare, 1945-1955, Ph.D. dissertation, Duke University, 1992.

Kuhl, Craig, interview with Colonel Richard Leghorn, The Cable Center Oral History Project, May 20, 2008. As of September 14, 2015 :

http://cablecenter.org/k-l-listings/richard-leghorn.html

Lambeth, Benjamin S., The Transformation of American Air Power, Ithaca, N.Y.: Cornell University Press, 2000.

—, NATO's Air War for Kosovo: A Strategic and Operational Assessment, Santa Monica, Calif:: RAND Corporation, MR-1365-AF, 2001. As of September 15, 2015: http://www.rand.org/pubs/monograph_reports/MR1365.html

- Air Power Against Terror: America's Conduct of Operation Enduring Freedom, Santa Monica, Calif.: RAND Corporation, MG-166-1-CENTAF, 2006. As of September 15, 2015: http://www.rand.org/pubs/monographs/MG166-1.html

Lavalle, A. J. C., ed., Airpower and the 1972 Spring Invasion, Washington, D.C.: Office of Air Force History, 1985, pp. 15-19.

Lippitz, M. J. and R. H. Van Atta, "Stealth Combat Aircraft," in R. H. Van Atta et al., Transformation and Transition: DARPA's Role in Fostering an Emerging Revolution in Military Affairs, Volume 2, Arlington, Va.: Institute for Defense Analyses, November 2003, Chapter I, pp. 1-9.

Mahnken, Thomas, Technology and the American Way of War Since 1945, New York: Columbia University Press, 2008.

Mark, E., Aerial Interdiction: Air Power and the Land Battle in Three American Wars, Washington, D.C.: Center for Air Force History, 1994, pp. 261-322.

May, Andrew D., The RAND Corporation and the Dynamics of American Strategic Thought, Ph.D. dissertation, Emory University, 1998.

Meilinger, Phillip S., Airwar: Theory and Practice, London: Frank Cass, 2003. 
Memorandum from Secretary of Defense Charles Hagel, "The Defense Innovation Initiative," Washington, D.C.: Department of Defense, November 15, 2014.

Mierzejewski, Alfred C., The Collapse of the German War Economy, 1944-1945, Chapel Hill, N.C.: University of North Carolina Press, 1988.

Miller, Greg, "CIA Flew Stealth Drones in to Pakistan to Monitor Bin Laden House," Washington Post, May 17, 2011.

Miller, Steven E., ed., Strategy and Nuclear Deterrence, Princeton, N.J.: Princeton University Press, 1984.

Moody, Walton S., Building a Strategic Air Force, Washington, D.C.: Air Force History and Museums Program, 1995.

Mortensen, D. R., A Pattern for Joint Operations: World War II Close Air SupportNorth Africa, Washington, D.C.: Army Center of Military History, 1987, pp. 17-28.

Mueller, Karl P., "Strategies of Coercion: Denial, Punishment, and the Future of Air Power," Security Studies, Vol. 7, No. 3, Spring 1998, pp. 182-228.

_ , "Strategic Airpower and Nuclear Strategy: New Theory for a Not-Quite-So-New Apocalypse," in Phillip S. Meilinger (ed.), The Paths of Heaven: The Evolution of Airpower Theory, Maxwell AFB, Ala.: Air University Press, 2000, pp. 279-320.

Mueller, Karl P., ed., Precision and Purpose: Airpower in the Libyan Civil War, Santa Monica, Calif.: RAND Corporation, RR-676-AF, 2015. As of September 15, 2015: http://www.rand.org/pubs/research_reports/RR676.html

Mueller, Karl P., Jasen J. Castillo, Forrest E. Morgan, Negeen Pegahi, and Brian Rosen, Striking First: Preemptive and Preventive Attack in U.S. National Security Policy, Santa Monica, Calif.: RAND Corporation, MG-403-AF, 2006. As of September 15, 2015:

http://www.rand.org/pubs/monographs/MG403.html

Muller, R. M., "Close Air Support: The German, British, and American Experiences, 1918-1941," in W. Murray and A. R. Millett, eds., Military Innovation in the Interwar Period, Cambridge, UK: Cambridge University Press, 1996, pp. 144-190.

Murphy, Richard and Afsheen John Radsan, "Due Process and Targeted Killing of Terrorists," Cardozo Law Review, Vol. 31, No. 2, 2010, pp. 405-450.

Murray, Williamson, "Korea, 1950-1953," in B. F. Cooling, ed., Case Studies in the Development of Close Air Support, Washington, D.C.: Office of Air Force History, 1990, pp. 361-363. 
National Commission on Terrorist Attacks upon the United States, The 9/11 Commission Report, New York: W. W. Norton and Company, 2004.

Neufeld, Jacob, The Development of Ballistic Missiles in the United States Air Force, 1946-1960, Washington, D.C.: Office of Air Force History, 1990.

Newman, Richard, “The Little Predator that Could," Air Force Magazine, March 2002.

Olsen, John Andreas, Strategic Airpower in Desert Storm, London: Routledge, 2003.

- John Warden and the Renaissance of American Air Power, Dulles, Va.: Potomac, 2007.

Orr, Andrew C., "Unmanned, Unprecedented, and Unresolved: The Status of American Drone Strikes in Pakistan under International Law," Cornell International Law Journal, Vol. 44, 2011, pp. 729-745.

Overy, Richard, The Bombing War: Europe, 1939-1945, London: Allen Lane, 2013.

Owen, Robert C., ed., Deliberate Force: A Case Study in Effective Air Campaigning, Maxwell AFB, Ala.: Air University Press, 2000.

PACAF_-See Pacific Air Forces.

Pacific Air Forces, USAF Tactics against Air and Ground Defenses in SEA: November 1968-May 1970, Honolulu, Hawaii: PACAF Tactical Evaluation Directorate, September 25, 1970. Originally classified SECRET, declassified by Air Force Declassification Office IAWE.O. 12958 on August 15, 2006.

Pape, Robert A., "The Strategic Logic of Suicide Terrorism," American Political Science Review, Vol. 97, No. 3, August 2003, pp. 1-19.

—, Bombing to Win: Air Power and Coercion in War, Ithaca, N.Y.: Cornell University Press, 1996.

Parkinson, Leonard F., and Logan H. Potter, "Closing the Missile Gap," in Joan Bird and John Bird, eds., Penetrating the Iron Curtain: Resolving the Missile Gap with Technology, 2011, pp. 17-40. As of September 17, 2015:

https://www.cia.gov/library/publications/cold-war/resolving-the-missile-gap-withtechnology/missile-gap.pdf

Pedlow, Gregory W., and Donald E. Welzenbach, The CIA and the U-2 Program, 19541974, Langley, Va.: Central Intelligence Agency, 1998, p. 1.

Peebles, Curtis, The Corona Project: America's First Spy Satellites, Annapolis, Md.: Naval Institute Press, 1997. 
Perry, Robert, Origins of the USAF Space Program: 1945-1956, Vol. V, WrightPatterson AFB, Ohio: Air Force Systems Command History Office, 1961.

Pocock, Chris, Dragon Lady: The History of the U-2 Spyplane, Shrewsbury, UK: Airlife Publishing, 1987.

Posen, Barry, The Sources of Military Doctrine: France, Britain, and Germany Between the World Wars, Ithaca, N.Y.: Cornell University Press, 1984.

Price, Bryan C., "Targeting Top Terrorists: How Leadership Decapitation Contributes to Counterterrorism," International Security, Vol. 4, No. 36, 2012, pp. 9-46.

Putney, Diane T., Airpower Advantage: Planning the Gulf Air Campaign, 1989-1991, Department of the Air Force, 2005.

Quinlivan, James T., Soviet Strategic Air Defense: A Long Past and an Uncertain Future, Santa Monica, Calif.: RAND Corporation, , P-7975, 1989.As of September 18, 2015: http://www.rand.org/pubs/papers/P7579.html

Raduenz, Lt. Col. Brian, USAF (Ret.), author interview, March 12, 2014.

Resende-Santos, Joao, Neorealism, States, and the Modern Mass Army, Cambridge, UK: Cambridge University Press, 2007.

Rosen, Stephen P., "New Ways of War: Understanding Military Innovation," International Security, Vol. 13, No. 1, Summer 1988, pp. 134-168.

- Winning the Next War: Innovation and the Modern Military, Ithaca, N.Y.: Cornell University Press, 1991.

Rosenau, William, Special Operations Forces and Elusive Enemy Ground Targets, Santa Monica, Calif.: RAND Corporation, MR-1408-AF, 2001. As of September 18, 2015: http://www.rand.org/pubs/monograph_reports/MR1408.html

Rosenwasser, Jon, Governance Structure and Weapon Innovation: The Case of Unmanned Aerial Vehicles, Tufts University, 2004.

Rothstein, Stephen M., Dead on Arrival? The Development of the Aerospace Concept: 1944-1958, Maxwell AFB, Ala.: Air University Press, November 2000.

Rowen, Henry S., "Policy Analysis as Heuristic Aid: The Design of Means, Ends, and Institutions," in Laurence Tribe, Corinne Schelling, and John Voss, eds., When Values Conflict: Essays on Environmental Analysis, Discourse, and Decision, Cambridge, Mass.: Ballinger, 1976, pp. 137-151.

Runkle, Benjamin, Wanted Dead or Alive: Manhunts from Geronimo to Bin Laden, New York: Palgrave MacMillan, 2011. 
Russell, James, Innovation, Transformation, and War: Counterinsurgency Operations in Anbar and Ninewa Provinces, Iraq, 2005-2007, Stanford, Calif.: Stanford University Press, 2011.

Ryan, Gen. Michael, USAF (Ret.), author interview, June 18, 2014.

Schriever, Bernard, "Military Space Activities: Recollections and Observations," in R. Cargill Hall and Jacob Neufeld, eds., The US Air Force in Space: 1945 to the TwentyFirst Century, Washington, D.C.: USAF History and Museums Program, 1998, pp. 11-12.

Sheehan, Neil, A Fiery Peace in a Cold War: Bernard Schriever and the Ultimate Weapon, New York: Random House, 2009.

Shiner, Linda, "Predator: First Watch," Air and Space Magazine, May 2001.

Sink, J. Taylor, Rethinking the Air Operations Center: Air Force Command and Control in Conventional War, master's thesis, School of Advanced Airpower Studies, June 1993.

Slife, J. C., Creech Blue: General Bill Creech and the Reformation of the Tactical Air Forces, 1978-1984, Maxwell AFB, Ala.: Air University Press, 2004, p. 26.

Spires, David, Beyond Horizons: A Half Century of Air Force Space Leadership, Colorado Springs, Colo.: Air Force Space Command, 1998.

- Airpower for Patton's Army: XIX Tactical Air Command in the Second World War, Washington, D.C.: Air Force History and Museums Program, 2002, pp. 56-62.

Staniland, Paul, "Defeating Transnational Insurgencies: The Best Offense is a Good Fence," Washington Quarterly, Vol. 29, No. 1, 2005, pp. 21-40.

Steiner, Barry H., Bernard Brodie and the Foundation of American Nuclear Strategy, Lawrence, Kan.: University Press of Kansas, 1991.

Streetly, M., Airborne Electronic Warfare: History, Techniques, and Tactics, London: Janes, 1988.

Sullivan, B. R., "The Downfall of the Regia Aeronautica," in R. Higham and S. J. Harris, eds., Why Air Forces Fail: The Anatomy of Defeat, Lexington, Ky.: University Press of Kentucky, 2006.

Syrett, D., “The Tunisian Campaign: 1942-1943," in B. F. Cooling, ed., Case Studies in the Development of Close Air Support, Washington, D.C.: Office of Air Force History, 1990, pp. 153-192.

Taubman, Philip, Secret Empire: Eisenhower, the CIA, and the Hidden Story of America's Espionage, New York: Simon and Schuster, 2003. 
Temple, L. Parker III, Shades of Gray: National Security and the Evolution of Space Reconnaissance, Reston, Va.; American Institute of Aeronautics and Astronautics, 2004.

Tenet, George, At the Center of the Storm: My Years at the CIA, New York: HarperCollins, 2007.

The SAC Alert Program, 1956-1959, Historical Study No. 79, Headquarters, Strategic Air Command, 1960.

Thies, Wallace J., When Governments Collide: Coercion and Diplomacy in the Vietnam Conflict, 1964-1968, Berkeley, Calif.: University of California Press, 1980.

Thompson, Wayne, To Hanoi and Back: The United States Air Force and North Vietnam, 1966-1973, Washington, D.C.: Air Force History and Museums Program, 2000, p. 243.

Thornborough, A. M., and F. B. Mormillo, Iron Hand: Smashing the Enemy's Air Defences, Somerset, UK: Patrick Stephens, Ltd., 2002.

Thornhill, Paula G., "Over Not Through": The Search for a Strong, Unified Culture for America's Airmen, Santa Monica, Calif.: RAND Corporation, OP-386-AF, 2012.

Tooze, Adam, The Wages of Destruction: The Making and Breaking of the Nazi Economy, New York: Viking, 2006.

"U.S. Army Innovation Orthodoxy," in Adam Grissom, To Digitize an Army: The U.S. Army Force XXI Initiative and the Digital Divide Controversy, 1994-2004, unpublished Ph.D. dissertation, King's College, London, 2009.

U.S. Department of Defense, News Transcript: DoD News Briefing with Secretary Gates and General Cartwright from the Pentagon, April 21, 2011. As of September 18, 2015:

http://archive.defense.gov/transcripts/transcript.aspx?transcriptid=4815

United States Strategic Bombing Survey (USBSS), Summary Report (European War), September 30, 1945.

United States Strategic Bombing Survey (USBSS), Summary Report (Pacific War), July 1, 1946.

Van Evera, S., Guide to Methods for Students of Political Science, Ithaca, N.Y.: Cornell University Press, 1997, pp. 67-71.

Van Staaveren, Jacob, Gradual Failure: The Air War Over North Vietnam, 1965-1966, Washington, D.C.: Air Force History and Museums Program, 2002.

Waltz, Kenneth, Theory of International Politics, New York: McGraw-Hill, 1979. 
Warden, John A., III, The Air Campaign: Planning for Combat, Washington, D.C.: Pergamon-Brassey's, 1989.

—_, "The Enemy as a System," Airpower Journal, Vol. 9, No. 1, Spring 1995.

Werrell, K. P., Archie to SAM: A Short Operational History of Ground-Based Air Defense, Montgomery, Ala.: Air University Press, 2005.

Whittle, Richard, "Predator's Big Safari," Air Force Association, Mitchell Institute for Airpower Studies, Mitchell Paper 7, August 2011.

- Predator: The Secret Origins of the Drone Revolution, New York: Henry Holt, 2014.

Withington, Thomas, Wild Weasel Fighter Attack: The Story of the Suppression of Enemy Air Defences, Yorkshire, UK: Pen and Sword Press, 2008, p. 62.

Y'blood, W. T., MiG Alley: The Fight for Air Superiority, Washington, D.C.: Air Force History and Museums Program, 2000.

- Down in the Weeds: Close Air Support in Korea, Washington, D.C.: Air Force History and Museums Program, 2002.

Zaloga, S. J., Defense of Japan: 1945, London: Osprey, 2010. 
RAND PROJECT AIR FORCE

www.rand.org

$\$ 32.00$

ISBN-10 0-8330-9184-0

ISBN-13 978-0-8330-9184-0

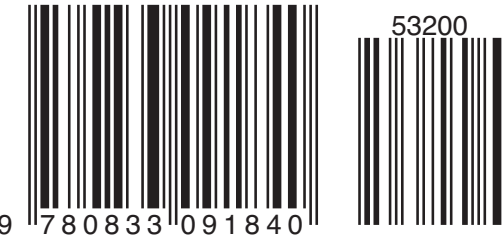

